\title{
Organic molecules, ions, and rare isotopologues in the remnant of the stellar-merger candidate, CK Vulpeculae (Nova 1670) ${ }^{\star}$
}

\author{
T. Kamiński ${ }^{1, \star \star}$, K. M. Menten ${ }^{2}$, R. Tylenda ${ }^{3}$, A. Karakas ${ }^{4}$, A. Belloche ${ }^{2}$, and N. A. Patel ${ }^{1}$ \\ 1 Harvard-Smithsonian Center for Astrophysics, 60 Garden Street, Cambridge, MA, USA \\ e-mail: tkaminsk@cfa.harvard.edu \\ 2 Max-Planck-Institut für Radioastronomie, Auf dem Hügel 69, 53121 Bonn, Germany \\ 3 Nicolaus Copernicus Astronomical Center, Polish Academy of Sciences, Rabiańska 8, 87-100 Toruń, Poland \\ ${ }^{4}$ Monash Centre for Astrophysics, School of Physics and Astronomy, Monash University, VIC 3800, Australia \\ Received 31 May 2017 / Accepted 7 August 2017
}

\begin{abstract}
Context. CK Vulpeculae (CK Vul) is an enigmatic star whose outburst was observed in 1670-72. A stellar-merger event was proposed to explain its ancient eruption.

Aims. We aim to investigate the composition of the molecular gas recently discovered in the remnant of CK Vul. Deriving the chemical, elemental, and isotopic composition is crucial for identifying the nature of the object and obtaining clues on its progenitor(s).

Methods. We observed millimeter and submillimeter-wave spectra of CK Vul using the IRAM $30 \mathrm{~m}$ and APEX telescopes. Radiativetransfer modeling of the observed molecular features was performed to yield isotopic ratios for various elements.

Results. The spectra of CK Vul reveal a very rich molecular environment of low excitation $\left(T_{\mathrm{ex}} \lesssim 12 \mathrm{~K}\right)$. Atomic carbon and twentyseven different molecules, including two ions, were identified. They range from simple diatomic to complex polyatomic species of up to seven atoms large. The chemical composition of the molecular gas is indicative of carbon and nitrogen-driven chemistry but oxides are also present. Additionally, the abundance of fluorine may be enhanced. The spectra are rich in isotopologues that are very rare in most known sources. All stable isotopes of $\mathrm{C}, \mathrm{N}, \mathrm{O}, \mathrm{Si}$, and $\mathrm{S}$ are observed and their isotopic ratios are derived.

Conclusions. The composition of the remnant's molecular gas is most peculiar and gives rise to a very unique millimeter and submillimeter spectrum. The observation of ions and complex molecules suggests the presence of a photoionizing source but its nature (a central star or shocks) remains unknown. The elemental and isotopic composition of the gas cannot be easily reconciled with standard stellar nucleosynthesis but processing in hot $\mathrm{CNO}$ cycles and partial helium burning can explain most of the chemical peculiarities. The isotopic ratios of CK Vul are remarkably close to those of presolar "nova grains" but the link of Nova 1670 to objects responsible for these grains is unclear. The accuracy of isotopic ratios can be improved by future observations at higher angular resolutions and with realistic models of the kinematical structure of the remnant.
\end{abstract}

Key words. atlases - stars: low-mass - stars: peculiar - submillimeter: stars - stars: individual: CK Vul - circumstellar matter

\section{Introduction}

CK Vul was observed in outburst in 1670-72 as a very bright object and is the oldest known nova-like variable with a well documented light curve (Hevelius 1671; Shara et al. 1985). Its maximum visual brightness was close to 2.6 mag. Light variations at a time scale of months were apparent to the naked eye and were followed by contemporary observers, including V. Anthelme, J. Hevelius, and G. Cassini. The object had not been recovered until 1981, when a remnant in the form of a bipolar optical nebula was found (Shara \& Moffat 1982; Shara et al. 1985; Hajduk et al. 2007). To date, no stellar object has been identified within the remnant, although a weak radio source is located at its center. The outburst of CK Vul was unusual: it lasted more than two years; the light curve displayed three peaks; and the object appeared reddish in color. Such observational characteristics do not resemble classical novae in outburst.

\footnotetext{
* The reduced spectra are only available at the CDS via anonymous ftp to cdsarc.u-strasbg. fr $(130.79 .128 .5)$ or via

http://cdsarc.u-strasbg.fr/viz-bin/qcat?]/A+A/607/A78

$\star \star$ Submillimeter Array fellow.
}

Several other scenarios have been proposed to explain the outburst of Nova 1670: a slow nova (Shara et al. 1985), a diffusioninduced nova (Miller Bertolami et al. 2011), a late thermal pulse (or a born-again object; Harrison 1996; Evans et al. 2002), and a stellar-merger event (Kato 2003; Tylenda et al. 2013). Although all of the proposed hypotheses have problems explaining observational constraints in hand (Evans et al. 2016; Hajduk et al. 2007), the merger event seems to be the most promising one and CK Vul is now considered to be a red nova. Red novae (or intermediate luminosity optical transients (ILOTs) or red transients) are a group of eruptive stars similar to V838 Mon (Tylenda 2005) which were demonstrated to erupt in stellarmerger events (Soker \& Tylenda 2003; Tylenda \& Soker 2006; Tylenda et al. 2011). A recent discovery of molecular gas of extraordinary chemical and elemental composition in CK Vul strongly supports the stellar-merger scenario for this ancient transient (Kamiński et al. 2015a). Here, we investigate deeper this highly unusual composition of the CK Vul remnant.

Since the re-discovery of CK Vul by Shara et al., the nature of the remnant has been extensively investigated in search for clues that would help explaining the ancient eruption. Identifying the 
central object and determining the chemical composition of the remnant are particularly important.

The nebula of CK Vul has a spectrum similar to HerbigHaro objects and in the optical it is dominated by atomic lines of HI, [N II], [O III], and [S II] (Shara \& Moffat 1982; Cohen 1985; Naylor et al. 1992). The (hydrogen) recombination timescale of the gas was estimated to be $\gtrsim 300 \mathrm{yr}$. This time seemed to be consistent with the gas originating in the 1670-72 events and no ionization source was necessary to explain the observations. Later observations of Hajduk et al. (2007) revealed that the nebula is much more extended $\left(71^{\prime \prime}\right)$ than the earlier observations had suggested and has an hourglass shape reminiscent of some planetary nebulae $(\mathrm{PNe})$ and pre-PNe. At a distance of $700 \pm 150 \mathrm{pc}$ (Hajduk et al. 2013), the large structure has a size of $0.24 \mathrm{pc}$. The brightest knots of the nebula are located closer (within $\lesssim 8^{\prime \prime}$ ) to the radio source which presumably is the location of the stellar remnant. Hajduk et al. proposed that the knots are excited directly by the stellar remnant. They calculated a recombination timescale for nitrogen of $75 \mathrm{yr}$, which is shorter than that of hydrogen derived by Shara et al. (1985) and which suggests an ionization mechanism that has been active after the ancient eruption. Subsequent observations indicated that the large-scale nebula is quickly fading, with a 20 30\% decrease between 1991 and 2009 (Hajduk et al. 2013). The tips of the large-scale nebula are moving with a de-projected velocity of $900 \mathrm{~km} \mathrm{~s}^{-1}$ (Hajduk et al. 2013) and the rest of the nebula expands at similar or smaller velocities. To explain the atomic emission in the inner optical nebula, an active ionization mechanism is necessary and Hajduk et al. (2007) proposed that shocks of velocities $>100 \mathrm{~km} \mathrm{~s}^{-1}$ can explain the observed intensity ratios of the recombination lines. The radio source discovered in the central part of the nebula is compact and its emission is thought to be produced by the free-free mechanism. According to Hajduk et al. (2007), the radio source requires a central photoionizing source with a luminosity of $\sim 1 L_{\odot}$. Additionally, Evans et al. (2016) observed in the mid-infrared (MIR) emission lines of $\mathrm{H}_{2}$ and of atoms at relatively high ionization degree, i.e. [Si II], [S III-IV], and [O IV], which they explain by postulating the presence of a photoionization stellar source of a temperature $>50000 \mathrm{~K}$. In summary, the optical and MIR observations suggest an ionizing source affecting the remnant's material at different spatial scales, but it is not clear if it is caused by an unidentified hot central source or by the fast shocks.

The first interpretations of the CK Vulpeculae (CK Vul) optical spectra suggested that the atomic gas is enhanced in nitrogen, with roughly three times higher nitrogen to oxygen ratio than in the standard cosmic composition (Shara \& Moffat 1982). In later observations, the radio continuum source was identified but no hydrogen recombination lines were observed at its location. This led Hajduk et al. (2007) to suggest that "the core" and some other nebular clumps are hydrogen poor. We note, however, that the central source is heavily obscured by circumstellar dust (Kamiński et al. 2015a) and optical photons arising in the central parts of the remnant may be completely trapped. In a subsequent paper presenting deeper images of the nebula, the claim of hydrogen-poor regions was retracted (Hajduk et al. 2013). The observed spatial differences in the intensity ratios of the $\mathrm{H} \alpha$ and $[\mathrm{N} \mathrm{II}]$ lines are not a consequence of varying elemental abundances but rather reflect differences in densities and recombination time scales. There is no conclusive observational evidence for $\mathrm{N}$ enhancement or $\mathrm{H}$ deficiency in CK Vul. More recent observations show however, that the gas in the remnant exhibits certain chemical anomalies. By studying spectra of two backgrounds stars, Hajduk et al. (2013) found that the outflow is rich in Li I.

Using the APEX telescope in 2014, Kamiński et al. (2015a) discovered bright and chemically complex molecular gas in emission surrounding the central parts of the remnant. Interferometric maps with the Submillimeter Array (SMA) showed that the emission arises from a bipolar nebula of $13^{\prime \prime}$ size located at the center of the larger hourglass-shaped optical nebula. The molecular lines have broad profiles with a full width of up to $\sim 400 \mathrm{~km} \mathrm{~s}^{-1}$. Observations within the millimeter $(\mathrm{mm})$ and submillimeter-wave (submm) range revealed a plethora of molecules: $\mathrm{CO}, \mathrm{CN}, \mathrm{HCN}, \mathrm{HNC}, \mathrm{H}_{2} \mathrm{CO}, \mathrm{HCO}^{+}, \mathrm{N}_{2} \mathrm{H}^{+}, \mathrm{CS}$, $\mathrm{CCH}, \mathrm{SiO}$, and SiS. Additionally, with the Effelsberg telescope, lines of $\mathrm{NH}_{3}$ were observed. The unusual inventory of observed molecules suggested that the gas is enriched in $\mathrm{N}$, while $\mathrm{O}$ and $\mathrm{C}$ seem to have similar relative abundances. However, a quantitative study of elemental abundances was not possible with these data and the $\mathrm{N}$ enhancement was only a tentative result. The molecular spectrum revealed an extraordinary isotopic composition of the molecular gas, with a very low ratios of ${ }^{12} \mathrm{C} /{ }^{13} \mathrm{C}=4 \pm 2$ (solar ratio is 89 ), ${ }^{16} \mathrm{O} /{ }^{18} \mathrm{O} \approx 26$ (solar 499 ), ${ }^{14} \mathrm{~N} /{ }^{15} \mathrm{~N} \approx 23$ (solar 441; terrestrial 272). The isotopic abundances rule out the possibility that the gas is a product of nuclear runaway in a classical nova. They cannot be explained by pure non-explosive CNO cycles, either. It was speculated, however, that the non-explosive $\mathrm{CNO}$ cycles with a subsequent incomplete He-burning and with an admixture of $\mathrm{H}$ might explain the isotopic ratios of CK Vul. A violent merger could be responsible for disrupting a star and dispersing the gas enriched in nuclear burning into the currently observed remnant.

In this paper, we present extensive $\mathrm{mm}$ and submm wavelength observations of the molecular gas of the CK Vul remnant. The spectral coverage of the observations is substantially wider than in Kamiński et al. (2015a) and the number of detected species is doubled. The observations are presented in Sect. 2 and analyzed in Sect. 3. The revised identification is described in Sect. 3.1. The kinematics and excitation of the molecular gas are analyzed in Sects. 3.2 and 3.3. In Sect. 4, we discuss the origin and implication of the chemical, elemental, and isotopic compositions of the molecular gas. The main conclusions are summarized in Sect. 5.

\section{Observations}

\subsection{APEX}

CK Vul was observed with the Atacama Pathfinder Experiment (APEX) 12-m telescope (Güsten et al. 2006) in May 2014, July 2014, June 2015, November 2015, April 2016, and 1819 July 2017. The frequency setups observed between 169 and $909 \mathrm{GHz}$ are listed in Table A.1. A fraction of the observations has been already reported in Kamiński et al. (2015a) and they are included here for completeness. For observations up to $200 \mathrm{GHz}$, we used the SEPIA Band-5 receiver (Billade et al. 2012) which produces separate spectra for each of the two sidebands. At higher frequencies up to $270 \mathrm{GHz}$, we used the SHeFI-1 receiver (Vassilev et al. 2008) which produces one single-sideband spectrum. For still higher frequencies, between 278 and $492 \mathrm{GHz}$, we used the $\mathrm{FLASH}^{+}$receiver (Klein et al. 2014) which operates simultaneously in the atmospheric windows at about 345 and $460 \mathrm{GHz}$. $\mathrm{FLASH}^{+}$separates the two heterodyne sidebands in each of the two 345/460 channels, giving four spectra simultaneously, each $4 \mathrm{GHz}$ wide. SEPIA, SHeFI-1, and $\mathrm{FLASH}^{+}$ are single-receptor receivers allowing for observations of one 
position on the sky at the time. Above $690 \mathrm{GHz}$, we used the $\mathrm{CHAMP}^{+}$receiver which consists of two arrays operating in the atmospheric windows at about 660 and $850 \mathrm{GHz}$. Each $\mathrm{CHAMP}^{+}$array has seven receptors whose spatial arrangement is given in Kasemann et al. (2006). Each of the fourteen receptors of the $\mathrm{CHAMP}^{+}$array produced a single-sideband spectrum. The image-band rejection factors for all the instruments used are all above $10 \mathrm{~dB}$ and at most frequencies the rejection is higher than $20 \mathrm{~dB}$. For SEPIA, SHeFi-1, and $\mathrm{FLASH}^{+}$, we found that the strongest spectral features indeed do not contaminate the image side band. In all the APEX observations, we used the eXtended Fast Fourier Transform Spectrometer (XFFTS; Klein et al. 2012) which typically provided us with resolutions better than $0.1 \mathrm{~km} \mathrm{~s}^{-1}$. For presentation purposes, we rebinned the spectra to a much lower resolution.

At the location of APEX, CK Vul can only be observed at low elevations of $25^{\circ}-40^{\circ}$. Most of our APEX observations were executed in excellent weather condition to compensate for high atmospheric opacity at these low elevations. The typical system temperatures $\left(T_{\text {sys }}\right)$ and rms noise levels reached are given in Table A.1. The full width at half maximum (FWHM) beam sizes and the main-beam efficiencies $\left(\eta_{\mathrm{mb}}\right)$ of the APEX antenna at each observed frequency are also listed in the table. We use both the antenna $\left(T_{\mathrm{A}}^{*}\right)$ and main-beam $\left(T_{\mathrm{mb}}\right)$ brightness temperature scales, as indicated accordingly in each instance. Velocities are expressed in the local standard of rest (LSR) frame.

First APEX observations of CK Vul were made with the band centered on the $\mathrm{CO}(2-1)$ line and using wobbler switching. In addition to a very broad emission feature $\left(F W H M=156 \mathrm{~km} \mathrm{~s}^{-1}\right)$ originating from the target itself, the spectra showed a considerable contamination from narrow $\left(F W H M=0.3-0.9 \mathrm{~km} \mathrm{~s}^{-1}\right)$ emission features present at the source position and at wobbler off-source positions. The emission features are at velocities between -0.4 and $9.0 \mathrm{~km} \mathrm{~s}^{-1}$ and in $16.8-25.9 \mathrm{~km} \mathrm{~s}^{-1}$. By obtaining a map which covered 3.0 $\times 2.5$ with sampling of $45^{\prime \prime}$, we found that this emission extends nearly across the entire field covered by the map. Taking the extent of the $\mathrm{CO}$ emission and the small widths of the lines, the emission is most likely interstellar in origin. Because we are interested here in the circumstellar material, we blanked all channels affected by these interstellar features before smoothing the spectra to a coarser resolution.

By examining continuum maps obtained with Herschel (cf. Kamiński et al. 2015a), which show patchy emission in a big field around CK Vul, we found a nearby position at an offset $\Delta \mathrm{RA}=-180^{\prime \prime}$ and $\Delta \mathrm{Dec}=-100^{\prime \prime}$ where the dust emission was weakest and which turned out to have none or very weak emission in $\mathrm{CO}$ transitions. For most of the spectra which cover the CO $J=2-1,3-2$, and 4-3 transitions and which were obtained later, we applied the total-power switching method using this position as a reference (OFF). Higher rotational transitions of $\mathrm{CO}$, all lines of ${ }^{13} \mathrm{CO}$, and all spectra that do not cover $\mathrm{CO}$ lines were observed with symmetric wobbler switching and with throws of $\pm 60, \pm 100$, or $\pm 120^{\prime \prime}$; they are not contaminated by the interstellar component.

The data processing included spectra averaging and baseline subtraction. Some APEX spectra contain spurious absorption features caused by telluric lines and the most obvious ones were blanked before final averaging.

By comparing overlapping spectra from different dates and different instrumental setups, we found that the relative calibration is better than $5 \%$. The absolute calibration uncertainty, including that of the beam efficiency, is of about $15 \%$ at frequencies up to $400 \mathrm{GHz}$ and worse at higher frequencies.

\subsection{IRAM $30 \mathrm{~m}$}

Observations with the IRAM $30 \mathrm{~m}$ telescope and the EMIR dualsideband receiver (Carter et al. 2012) were obtained in February, May, June, August 2015, and April and May 2016. Spectra of each linear polarization covered simultaneously the same range. The Fast Fourier Transform Spectrometer (FTS; Klein et al. 2012) and WILMA correlator ${ }^{1}$ were used in parallel as backends. The FTS was used as the primary spectrometer and covered $7.8 \mathrm{GHz}$ in each sideband at a resolution of $195 \mathrm{kHz}$ (typically $0.4 \mathrm{~km} \mathrm{~s}^{-1}$ ). WILMA, operating at a resolution of $2 \mathrm{MHz}$, covered a fraction of the available band and was used only to identify spurious instrumental effects in the FTS spectra, in particular in the regions where three different FTS units are stitched. Technical details of all the setups observed with IRAM/EMIR are given in Table A.2.

The spectra produced by the FTS required special processing in which a baseline of low order was subtracted individually from each of the spectrometer units. This removed the "platforming" effect. A few spikes introduced by the spectrometer were blanked before spectra were averaged and rebinned to a lower resolution. All IRAM observations were obtained using wobbler switching with OFF positions at $110^{\prime \prime}$ from the central position. Similarly to observations with APEX, some molecular transitions were affected by the extended interstellar emission, including the $J=1-0$ line of ${ }^{12} \mathrm{CO},{ }^{13} \mathrm{CO}$, and $\mathrm{HCN}$. Those features were blanked in the data reduction procedure.

The collected spectra are considerably affected by imperfect sideband rejection of EMIR. The E0 and E2 units of EMIR operating at the $90 \mathrm{GHz}$ and $230 \mathrm{GHz}$ atmospheric windows have image band rejection factors of over $10 \mathrm{~dB}$. At our signal-to-noise ratio $(\mathrm{S} / \mathrm{N})$ reaching 200 for some lines, these rejection factors are too low to block the signal from the image side band and strong lines sink into the symmetric side band. The rejection is even worse in the case of the E1 unit operating in the $150 \mathrm{GHz}$ window for which the rejection factors were of about $5 \mathrm{~dB}$ and changed strongly with frequency (Marka et al. 2015). In addition, ghost features were reported for E1 (Sievers et al. 2015). In order to distinguish real spectral features from those arising in the image side band and to be able to identify other instrumental artifacts, most spectral ranges were observed with at least two different local oscillator frequencies. In cases when a feature was undoubtedly identified as residual emission from the image side band, the feature was blanked before spectra averaging. However, not all spectral ranges were observed more than once and some of those spurious features remain in the spectra. We refer to them as OSB (other-sideband) or "instr." features.

Spectra obtained for orthogonal polarizations show differences of the order of $10 \%$ within the profiles of strongest lines (most pronounced in lines of $\mathrm{HCN}$ ). We attribute these differences primarily to the receiver performance. Observations of spectral features obtained on different dates and with different central frequencies (both polarizations averaged) are consistent within $15 \%$. The overall absolute calibration accuracy of the IRAM spectra is better than $20 \%$.

\subsection{Spatial characteristics of APEX and IRAM $30 \mathrm{~m}$ data}

Although we obtained extra APEX observations aiming to probe the extent of the molecular emission, we confine this paper to observations obtained toward the central source.

\footnotetext{
http://wWW.iram.fr/IRAMFR/TA/backend/veleta/wilma/ index.htm
} 


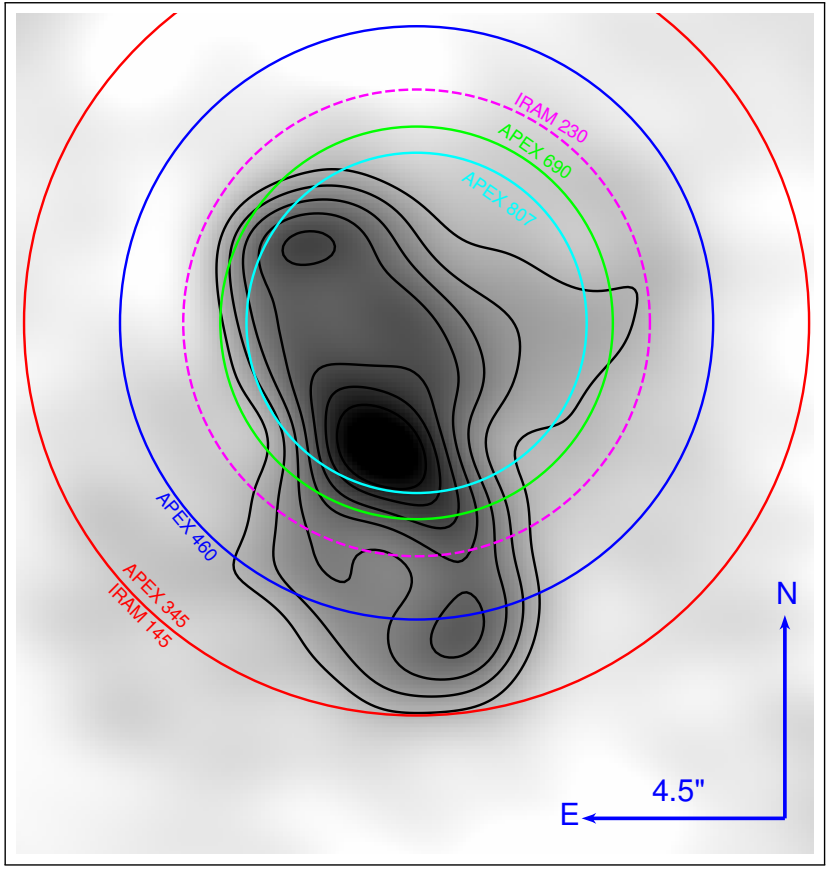

Fig. 1. Representative telescope beams overplotted on a map obtained with the SMA and APEX in CO(3-2) (Kamiński et al. 2015a). The diameters of the circles correspond to FWHMs of the beams. From largest to smallest the circles mark beams at: $345 \mathrm{GHz}$ of APEX and $145 \mathrm{GHz}$ of IRAM (red); $460 \mathrm{GHz}$ at APEX (blue); $230 \mathrm{GHz}$ at IRAM (magenta, dashed); $690 \mathrm{GHz}$ at APEX (green); and $810 \mathrm{GHz}$ at APEX (cyan). The beams corresponding to APEX observations below $300 \mathrm{GHz}$ and to IRAM observations below $100 \mathrm{GHz}$ are larger than the map and are not shown. The centering of the beams corresponds to perfect antenna pointing. In reality, the observations could have been performed with pointing errors leading to offsets of up to $3^{\prime \prime}$.

Most of our APEX and IRAM observations were obtained towards CK Vul's catalog position from SIMBAD ${ }^{2}$ (originally from Downes et al. 1997), i.e. at $\mathrm{RA}=19: 47: 38.0$, Dec $=+27: 18: 48.0$ (J2000). It is not the morphological center of the molecular emission (Kamiński et al. 2015a). It is 3".0 off from the radio continuum source observed with the Very Large Array (VLA; Hajduk et al. 2007). This offset is comparable to the pointing accuracy of both telescopes.

After the morphological details of the molecular emission were revealed by the interferometric maps obtained with the Submillimeter Array (SMA; Kamiński et al. 2015a), it was realized that the single-position APEX and IRAM observations probe slightly different emission regions at different frequencies, as is illustrated in Fig. 1. While the low-frequency APEX and IRAM observations encompass nearly the entire molecular region, the beams of APEX at frequencies above about $400 \mathrm{GHz}$ and these of IRAM above $230 \mathrm{GHz}$ were most sensitive to the central part and northern molecular lobe of the remnant. This spatial coupling is also responsible for systematic shifts in line velocities at different frequencies.

Interferometric observations of molecular gas in CK Vul were reported in Kamiński et al. (2015a). These observations were performed in July 2014 with the SMA in the 230 and $345 \mathrm{GHz}$ bands and with an angular resolution of 1".9 and 6".4. Since then, we have mapped the remnant using the NOEMA and ALMA interferometers at chosen frequency ranges between about 85 and $235 \mathrm{GHz}$ and at angular resolutions of 0 ".6-2'.8.

\footnotetext{
2 http://simbad.u-strasbg.fr/simbad/
}

Although the maps helped us to better understand the single-dish data and at instances we refer to them in this paper, these interferometric observations will be presented in a dedicated study.

\subsection{Spectral characteristics of APEX and IRAM $30 \mathrm{~m}$ data}

A graphical illustration of the spectral coverage and sensitivities reached is shown in Fig. 2. The rms values were measured in data combined from different settings and in ranges free of obvious emission lines. However, some spectral ranges appear confusion limited and the rms values may overestimate the noise levels. Our spectral coverage and sensitivities are a result of a search for particular molecular transitions making the spectral survey inhomogeneous and somewhat biased. We covered, however, a very big fraction of the submm and mm-wave spectrum within the available atmospheric windows and the resulting composite spectrum provides a good representation of CK Vul's emission spectrum. Also, the observed ranges give a good view on species that are most commonly observed in sources specific for submm and $\mathrm{mm}$ astronomy, such as interstellar medium (ISM), and envelopes of evolved and young stars.

The spectra acquired with APEX and IRAM overlap in 169.3-174.7 GHz and 230.5-232.5 GHz. In the former range, the telescope beams are much larger than the source size and the intensity of emission lines agrees very well in both spectra when they are compared in the $T_{\mathrm{mb}}$ scale corrected by the ratio of the respective beam solid angles. In the latter range, the IRAM beam is smaller than the source size while the APEX beam still encompasses the entire source. These differences in spatial coverage cause a mismatch in intensities of emission features even when spectra are corrected for the beam dilution. The full spectrum of CK Vul obtained with the two telescopes is shown in a form of an atlas in Figs. B.1 and B.2.

Single-dish observations of CK Vul were also obtained at selected radio frequencies between 1.6 and $25 \mathrm{GHz}$ using the Effelsberg telescope, including lines of ammonia, $\mathrm{OH}$, and $\mathrm{SiO}$, and they were described in Kamiński et al. (2015a). Here we focus only on the submm and mm spectra.

\section{Analysis}

\subsection{Line identification and inventory of species}

We detected over 320 unique features in the APEX and IRAM spectra. Molecular transitions could be assigned to most of these features. No likely candidate carrier was found for about forty features and they remain unidentified (U). One line is of atomic origin, i.e. of [CI]. All lines are listed in Tables C.1 and C.2. Some of the listed features are very weak and their presence or identification is uncertain. The identification procedure was based primarily on: line lists of Cologne Database for Molecular Spectroscopy (CDMS; Müller et al. 2001, 2005) and Jet Propulsion Laboratory (JPL; Pickett et al. 1998); original papers, e.g. Motiyenko et al. (2016) for ${ }^{13} \mathrm{CH}_{3} \mathrm{NH}_{2}$ and Pearson et al. (1976) for $\mathrm{H}^{15} \mathrm{~N}^{13} \mathrm{C}$; we also used CASSIS ${ }^{3}$ and Splatalogue ${ }^{4}$. For most molecules, we created in CASSIS a simulated spectrum over the full observed spectral range and under the assumption of local thermodynamic equilibrium (LTE; Sect. 3.3). The simulation helped us to identify blended lines.

Carbon is the only element observed in atomic form in the submillimeter spectra. All the molecular carriers are listed

\footnotetext{
3 http://cassis.irap.omp.eu

4 http://WWW.cv.nrao.edu/php/splat
} 


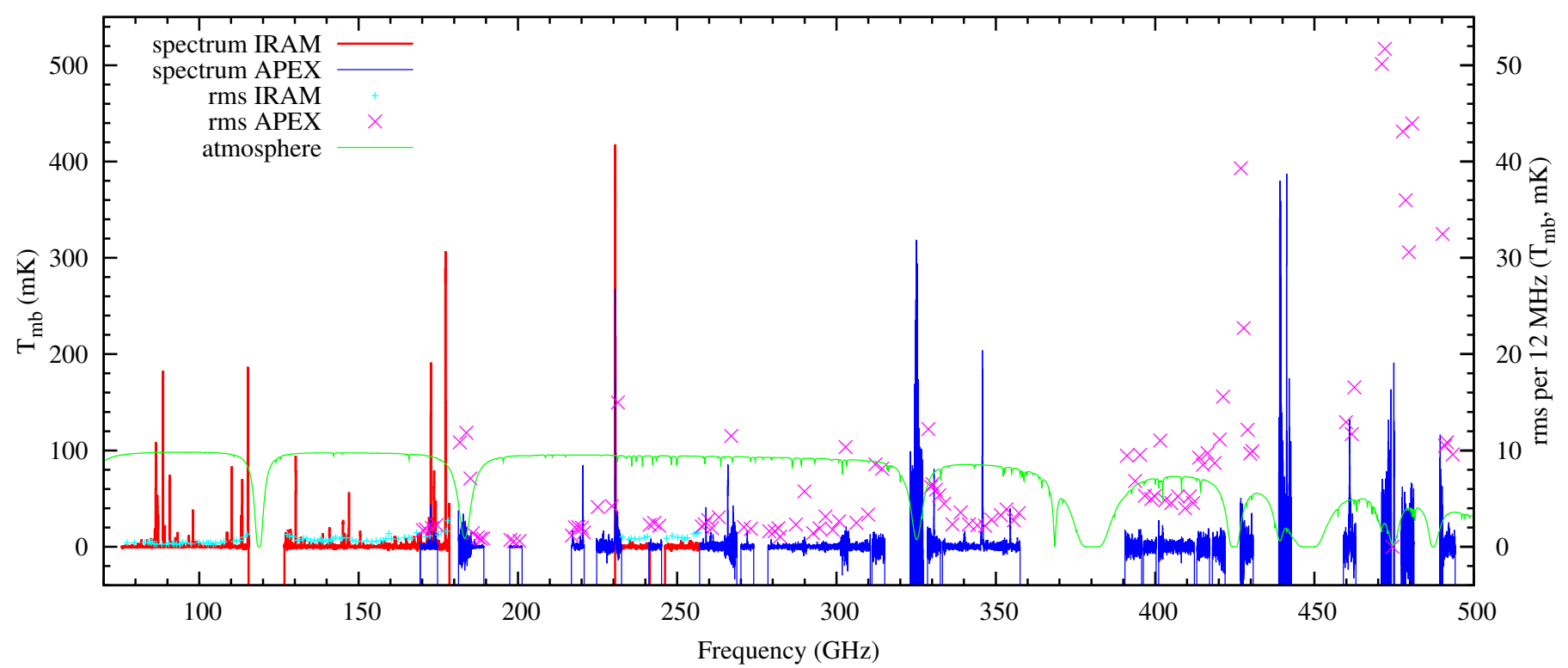

Fig. 2. Spectral coverage of the data collected with IRAM (red) and APEX (blue). Data up to $500 \mathrm{GHz}$ are shown but three more spectral ranges were covered at higher frequencies (Table A.1). Spectral binning is of $12 \mathrm{MHz}$. The spectra are in the $T_{\mathrm{mb}}$ scale shown in the left axis. The atmospheric transparency at the APEX site and at $1 \mathrm{~mm}$ of precipitable water vapour is shown (green) to illustrate the location of atmospheric windows (Pardo et al. 2001). Zero and full transparency (in \%) correspond to values of 0 and 100 on the left axis. Note that the width and depth of the telluric absorption bands depend on the actual weather conditions and some observations were performed within the telluric bands at excellent weather. Plus symbols show the rms levels reached by APEX (bigger, purple) and IRAM (smaller, cyan). They are displayed in the $T_{\mathrm{mb}}$ scale shown in the right axis.

Table 1. Identified molecules.

\begin{tabular}{|c|c|c|}
\hline 2 atoms & 3 atoms & 4 atoms \\
\hline $\begin{array}{l}\text { AlF } \\
\mathrm{CN}\left({ }^{13} \mathrm{CN}, \mathrm{C}^{15} \mathrm{~N},{ }^{13} \mathrm{C}^{15} \mathrm{~N}\right) \\
\mathrm{CO}\left({ }^{13} \mathrm{CO}, \mathrm{C}^{18} \mathrm{O},{ }^{13} \mathrm{C}^{18} \mathrm{O}, \mathrm{C}^{17} \mathrm{O} ?\right) \\
\mathrm{CS}\left({ }^{13} \mathrm{CS}, \mathrm{C}^{34} \mathrm{~S}, \mathrm{C}^{33} \mathrm{~S} ?\right) \\
\text { NO } \\
\text { NS } \\
\text { PN } \\
\text { SO ( }\left({ }^{34} \mathrm{SO}\right) \\
\mathrm{SiO}\left({ }^{29} \mathrm{SiO},{ }^{30} \mathrm{SiO}, \mathrm{Si}^{18} \mathrm{O}, \mathrm{Si}^{17} \mathrm{O} ?\right) \\
\mathrm{SiN} ?{ }^{c, d} \\
\mathrm{SiS}\end{array}$ & $\begin{array}{l}\mathrm{CCH}\left({ }^{13} \mathrm{CCH}, \mathrm{C}^{13} \mathrm{CH}\right) \\
\mathrm{H}_{2} \mathrm{~S}\left(\mathrm{H}_{2}^{34} \mathrm{~S} ?\right) \\
\mathrm{HCN}^{1}\left(\mathrm{H}^{13} \mathrm{CN}, \mathrm{HC}^{15} \mathrm{~N}, \mathrm{H}^{13} \mathrm{C}^{15} \mathrm{~N}\right) \\
\mathrm{HCO}^{+}\left(\mathrm{H}^{13} \mathrm{CO}^{+}, \mathrm{HC}^{18} \mathrm{O}^{+} ?\right) \\
\mathrm{HNC}^{+}\left(\mathrm{HN}^{13} \mathrm{C}, \mathrm{H}^{15} \mathrm{NC}, \mathrm{H}^{15} \mathrm{~N}^{13} \mathrm{C} ?\right) \\
\mathrm{N}_{2} \mathrm{H}^{+}\left({ }^{15} \mathrm{NNH}^{+}, \mathrm{N}^{15} \mathrm{NH}^{+} ?\right) \\
\mathrm{SO}_{2}\end{array}$ & $\begin{array}{l}\mathrm{NH}_{3}{ }^{a} \\
\mathrm{H}_{2} \mathrm{CO}\left(\mathrm{H}_{2}{ }^{13} \mathrm{CO}\right) \\
\mathrm{HNCO}^{b} \\
\mathrm{H}_{2} \mathrm{CS}\end{array}$ \\
\hline 5 atoms & 6 atoms & 7 atoms \\
\hline $\begin{array}{l}\mathrm{CH}_{2} \mathrm{NH}\left({ }^{13} \mathrm{CH}_{2} \mathrm{NH}\right) \\
\mathrm{HC}_{3} \mathrm{~N}\left(\mathrm{H}^{13} \mathrm{CCCN}, \mathrm{HC}^{13} \mathrm{CCN}, \mathrm{HCC}^{13} \mathrm{CN}\right)\end{array}$ & $\begin{array}{l}\mathrm{CH}_{3} \mathrm{CN}\left({ }^{13} \mathrm{CH}_{3} \mathrm{CN}\right) \\
\mathrm{CH}_{3} \mathrm{OH}\left({ }^{13} \mathrm{CH}_{3} \mathrm{OH}, \mathrm{CH}_{3}^{18} \mathrm{OH} ?\right)\end{array}$ & $\mathrm{CH}_{3} \mathrm{NH}_{2}\left({ }^{13} \mathrm{CH}_{3} \mathrm{NH}_{2} \text { ? }\right)^{d}$ \\
\hline
\end{tabular}

Notes. In parenthesis are rare isotopologues which were identified in addition to the main one. The presence of species followed by ? is questionable. ${ }^{(a)}$ Detected at radio wavelengths (Kamiński et al. 2015a). ${ }^{(b)}$ Most features of $\mathrm{HN}^{13} \mathrm{CO}$ and $\mathrm{HNCO}$ overlap and the presence of the former could not be verified. ${ }^{(c)}$ Only two features of SiN were detected. ${ }^{(d)}$ No spectroscopic data available for isotopologues containing ${ }^{15} \mathrm{~N}$.

in Table 1. The identified transitions belong to 27 different molecules, not counting their rare isotopologues. The list of detected molecules includes many simple diatomic and triatomic species, but more complex polyatomic compounds, including complex organic molecules, are also observed. The largest molecule identified is $\mathrm{CH}_{3} \mathrm{NH}_{2}$ (methylamine). The polyatomic molecules have a great number of transitions which however are usually weak (owing to the large partition functions) and, despite the omnipresence of their spectral features, their flux contribution to the observed spectrum is modest. Transitions of simpler molecules containing $\mathrm{H}$ and $\mathrm{CNO}$ elements dominate the spectrum in terms of intensity; these include lines of: $\mathrm{CO}, \mathrm{CN}$, $\mathrm{HCO}^{+}, \mathrm{HCN}, \mathrm{HNC}, \mathrm{H}_{2} \mathrm{CO}$, and $\mathrm{N}_{2} \mathrm{H}^{+}$. Lines of $\mathrm{CO}$ and $\mathrm{HCN}$ are by far the most intense ones. Molecules containing heavier elements are also abundant, including AlF, NS, PN, SO, SiO, $\mathrm{SiN}, \mathrm{SiS}, \mathrm{H}_{2} \mathrm{CS}$ and $\mathrm{SO}_{2}$. All of the molecules are built out of nine elements: $\mathrm{H}, \mathrm{C}, \mathrm{N}, \mathrm{O}, \mathrm{F}, \mathrm{Al}, \mathrm{Si}, \mathrm{P}$, and $\mathrm{S}$.

Perhaps the most striking spectral features are numerous lines of rare isotopologues, especially those of the CNO elements. Their presence makes the observed spectra very rich and indicates enhanced contribution of isotopes that are very rare in circumstellar envelopes and in the interstellar medium. 
Only two ionic species have been firmly identified, $\mathrm{HCO}^{+}$ and $\mathrm{N}_{2} \mathrm{H}^{+}$. Both give rise to very strong emission.

Assigning transitions to the complex polyatomic species has proven to be most challenging and it is possible that we misidentified a few of their lines. Our basic identification procedure relied on line positions and relative line intensities as predicted for isothermal gas in LTE (Sect. 3.3). Considering that both of these simplifying assumptions may be inadequate for the molecular gas in CK Vul, in a few cases we relaxed the requirement that the line ratios have to closely follow the LTE prediction. This applies mainly to $\mathrm{CH}_{3} \mathrm{CN}, \mathrm{CH}_{3} \mathrm{OH}, \mathrm{CH}_{2} \mathrm{NH}, \mathrm{CH}_{3} \mathrm{NH}_{2}$ and their isotopologues. We assigned transitions of these complex species to spectral features which are considerably stronger in the observed spectrum than in the LTE simulation but their velocity and line profiles match exactly other lines of the given species. These lines are marked with "??" in Tables C. 1 and C. 2 and in figures presented in the appendices.

As can be seen in Fig. 2 (and figures in the appendices), intense lines is observed mainly in the $\mathrm{mm}$ range, in particular at frequencies below about $180 \mathrm{GHz}$. In Sect. 3.3, we show that the gas excitation temperatures are very low, i.e. $\lesssim 12 \mathrm{~K}$. At these temperatures, the molecular gas radiates most effectively in the lowest rotational transitions which for a majority of molecules are located in the mm range. In Kamiński et al. (2015a), we reported and analyzed molecular inventory that was based primarily on submm spectra. That limitation introduced a bias to the earlier analysis. Some species with very weak emission, for instance these of the polyatomic compounds and sulfur oxides, although covered by some of the older submm spectra, were too weak to be detected or too few for unambiguous identification. With the much broader range of frequencies and energy levels covered by the combined data from the IRAM and APEX telescopes, the identifications proposed here are much more reliable. Still, the list of detected transitions is somewhat biased by our choices of observed spectral ranges and achieved sensitivities.

Many targeted transitions have not been detected despite the high sensitivity. These non-detections are significant for our understanding of CK Vul's chemistry. Among the most important searched but non-detected species are aluminum-bearing molecules, i.e. $\mathrm{AlO}, \mathrm{AlH}, \mathrm{AlH}^{+}, \mathrm{AlOH}, \mathrm{AlS}$, and oxides, i.e. $\mathrm{TiO}, \mathrm{TiO}_{2}, \mathrm{PO}, \mathrm{NO}_{2}, \mathrm{~N}_{2} \mathrm{O}, \mathrm{HNO}$, and $\mathrm{H}_{2} \mathrm{O}$. The latter was covered in two transitions, $3(1,3)-2(2,0)$ at $183.3 \mathrm{GHz}$ and $5(1,5)-$ $4(2,2)$ at $325.1 \mathrm{GHz}$, which however arise from relatively highlying energy levels of $E_{\mathrm{u}}=205 \mathrm{~K}$ and $470 \mathrm{~K}$ and should be weak at the anticipated excitation temperature of $<12 \mathrm{~K}$. Multiple strong transitions of the simplest cyclic hydrocarbon $c$ $\mathrm{C}_{3} \mathrm{H}_{2}$ and of one relatively well known ion $\mathrm{HCS}^{+}$are not seen in the spectra. Also, several hydrogen recombination lines were serendipitously covered by our most sensitive observations but are not detected. No deuterated species is detected, although numerous lines easily observable in the ISM were covered.

\subsection{Diversity of line profiles}

Figure 3 illustrates the variety of spectral profiles. Among the shown profiles are strong lines of $\mathrm{CO}$ which appear triangular, fairly symmetric, and have very broad wings that extend over a range of $\sim 500 \mathrm{~km} \mathrm{~s}^{-1}$. The profiles of CO features are rather unique in the spectrum of CK Vul. The majority of other species display narrower lines and those observed at a high $\mathrm{S} / \mathrm{N}$ have typically a FWHM of $\sim 190 \mathrm{~km} \mathrm{~s}^{-1}$ and a full width of about $300 \mathrm{~km} \mathrm{~s}^{-1}$. These widths are comparable to those of optical recombination lines of hydrogen and [N $\mathrm{II}]$ measured by Hajduk et al. (2007). The narrowest molecular profiles, with a
FWHM of $50 \mathrm{~km} \mathrm{~s}^{-1}$, are observed in all lines of $\mathrm{SO}_{2}$ and in $\mathrm{H}^{13} \mathrm{CO}^{+}(3-2)$. The ground-state lines of the two ions, $\mathrm{HCO}^{+}$ and $\mathrm{N}_{2} \mathrm{H}^{+}$, show double peaks in the central parts of their profiles, at about -30 and $22 \mathrm{~km} \mathrm{~s}^{-1}$. The biggest group of lines, e.g. of $\mathrm{HCN}, \mathrm{HNC}, \mathrm{HC}_{3} \mathrm{~N}, \mathrm{SiO}$ and their isotopologues, have an overall parabolic shape with multiple irregularities or overlapping discrete components. These discrete features are consistently present in lines of different species. This group of profiles shows also a small asymmetry - their blueshifted (negative velocity) part is slightly stronger.

The variety of profiles observed for different species reflects the differences in kinematical characteristics of the molecular gas. Some differences in profiles of different isotopologues can be partially explained by opacity effects. Most lines at lowest $E_{\mathrm{u}}$ are broad and rounded, suggesting saturation, while transitions from higher energy levels or the same transition of a rarer isotopologue appear narrower or sharper. Excitation conditions are responsible for the observed variations as well. It is not straightforward to distinguish the different effects, especially when one does not know a priori the exact isotopic ratios.

The strongest effect determining the line shape is the spatiokinematical distribution of gas. From our interferometric maps, to be reported in detail in a forthcoming paper, we can distinguish three basic types of morphologies of the molecular gas: some species are seen predominantly within a radius of $\sim 2^{\prime \prime}$ around the central source (e.g. AlF, $\mathrm{SO}, \mathrm{SO}_{2}, \mathrm{CS}, \mathrm{HCO}^{+}$, $\mathrm{CH}_{3} \mathrm{CN}$ ); other species are seen only in the molecular lobes (e.g. $\mathrm{CH}_{3} \mathrm{OH}$ ); and there are species whose emission is seen in the lobes and around the central source as in Fig. 1 (e.g. $\mathrm{H}_{2} \mathrm{CO}$, $\mathrm{HCN}, \mathrm{HNC}$, and $\mathrm{CO}$ ). However each of the spatial components is often characterized by multiple kinematical components indicating a very complex kinematical and chemical structure within the molecular nebula. There is no unique link between the appearance of the source-integrated single-dish spectral profiles presented here and the morphology of the molecular emission. The kinematics of the remnant will be studied in detail in an upcoming paper.

Based on the IRAM and APEX spectra, it is not straightforward to define one "central" velocity that would represent the entire remnant. Our modeling of molecular emission features with CASSIS allowed us to search for central velocity but the best fit results varied from -18 to $+8 \mathrm{~km} \mathrm{~s}^{-1}$ for different species. Emission of [C I] (1-0), the only atomic line observed, is centered at a unique velocity of $-50 \pm 13 \mathrm{~km} \mathrm{~s}^{-1}$. However, our spectra show systematic frequency-dependent differences related to how differently-sized beams couple to the source structure, as discussed in Sect. 2.3. We use the weighted-mean value of $-10 \mathrm{~km} \mathrm{~s}^{-1}$ as a rough representation of the LSR systemic velocity of CK Vul.

\subsection{Excitation of the molecular gas}

In order to improve our identification procedure and obtain first constraints on the excitation conditions in the molecular gas, we performed radiative-transfer simulations of the observed molecular spectra. The derived physical parameters are listed in Table D.1 and the final simulation of all species is compared to observations in Figs. E.1 and E.2.

All simulations have been performed using the LTE module of CASSIS (Vastel 2014). We used scripted routines ${ }^{5}$, in which observations of a given species are compared to a grid of models

\footnotetext{
http://cassis.irap.omp.eu/docs/CassisScriptingDoc/ las_index.html
} 

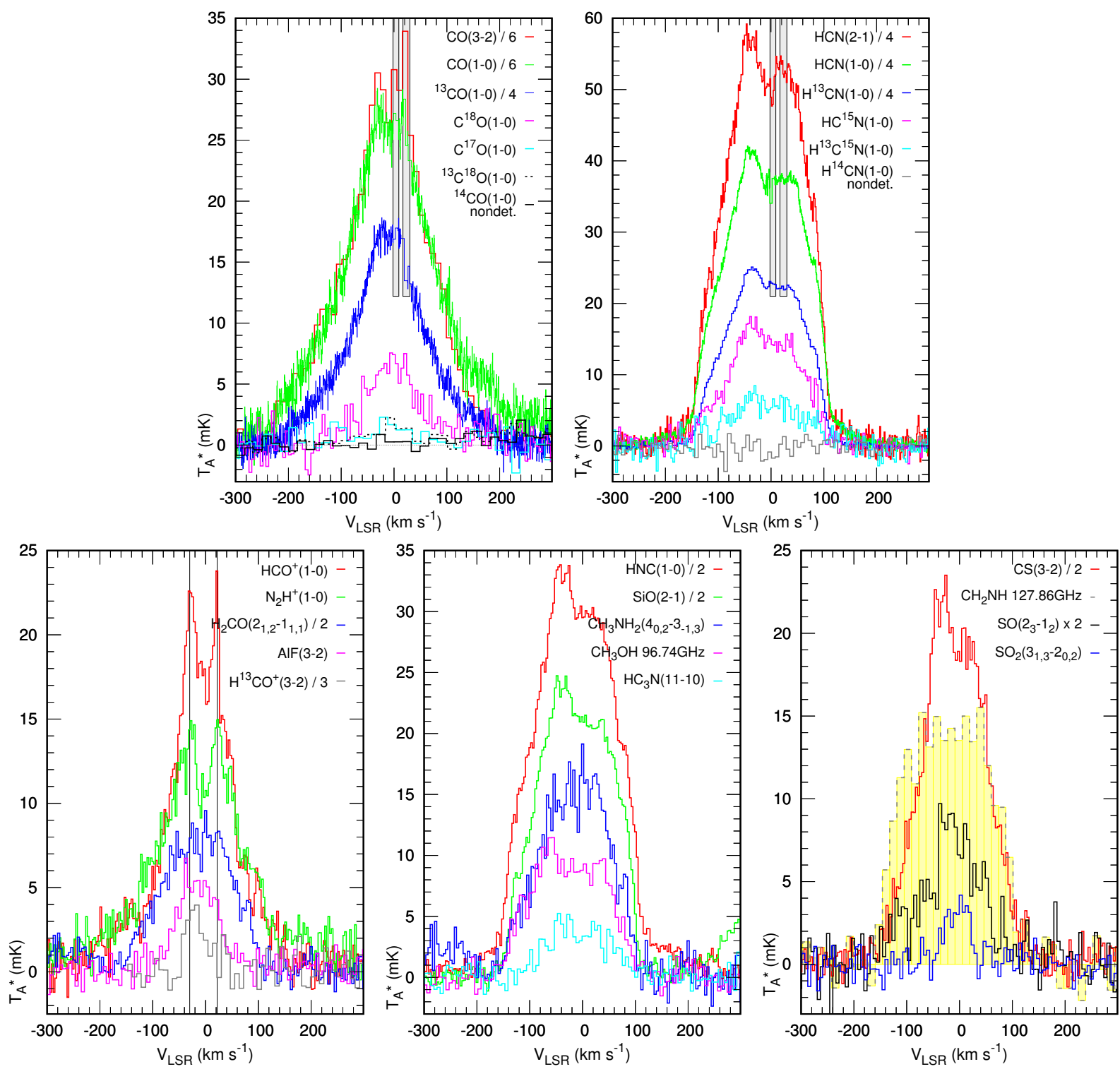

Fig. 3. Sample emission profiles. The species and transitions shown are indicated in the legends. For $\mathrm{CH}_{3} \mathrm{OH}$ and $\mathrm{CH}_{2} \mathrm{NH}$, the approximate frequencies are given instead of quantum numbers. We could not assign unique quantum numbers to these features because they are blends of components that arise from transitions of different energy levels or species of different symmetry (e.g. $E$ and $A$-type methanol). The shaded areas shown in the top panels mark the positions of interstellar features for which HCN and CO spectra were corrected. Some transitions have hyperfine splitting which, however, is insignificant compared to the total line width. For better presentation, some spectra were smoothed and scaled in intensity, as indicated in the legends.

and the best fit is determined by a $\chi^{2}$ minimization procedure. A single isothermal component with a Gaussian velocity profile was used to reproduce all observed transitions of a given molecule. The central velocity and the line width were first measured in the observed spectra and usually fixed in the models. In some cases, profile parameters were later iteratively optimized or set as free fit parameters to better reproduce the observations. Of course, the observed profiles are not Gaussian (Sect. 3.2) and the observed single-dish profiles result from a very complex kinematics. Our simplified treatment of line profiles in CASSIS leads to higher line saturation than if a true source structure were taken into account. Additionally, the gas is not isothermal and lines often appear narrower with increasing $E_{\mathrm{u}}$. The varying size of the beams at different frequencies (Sect. 2.3) affects the analysis of a few species, as well.
In the most basic procedure, the best model was searched in a dense grid of various excitation temperatures $\left(T_{\mathrm{ex}}\right)$ and column densities $(N)$, i.e. with two free parameters. The simulated spectra account for opacity effects and for beam dilution. Both effects are a function of the source size $\left(\theta_{\mathrm{S}}\right)$. For species for which we have obtained interferometric observations, the size was often fixed at a value that was measured directly in maps. For some of the species, however, the size is unknown and was another free parameter. The column density and source size are strongly coupled and their degeneracy led to unrealistically large source sizes for a few species. In such cases, we searched for models at smaller sizes which, although they did not correspond to the absolute $\chi^{2}$ minimum, still satisfactorily reproduced the observations. In a few cases, we had to use larger source sizes than those measured, in order to avoid complete saturation of 
the ground-state transitions. It is another limiting consequence of ignoring the real source structure in our model.

The excitation temperature is derived in the LTE models from relative line intensities corrected for the opacity effects. Therefore, $T_{\mathrm{ex}}$ can also depend on the source size and can be affected by the $N-\theta_{\mathrm{S}}$ degeneracy. Many species were detected in transitions from their lowest energy levels and in a very limited range of $E_{\mathrm{u}}$. This could result in underestimated $T_{\mathrm{ex}}$. To reduce this bias, we included in the analysis observations of transitions that were not detected. The final models are still far from satisfactory chiefly because some species may be excited in non-LTE conditions (Sect. 3.1) and for many molecules a single temperature is insufficient to explain the observations. Our radiativetransfer simulations included the cosmic background radiation of $2.73 \mathrm{~K}$.

CASSIS allows us to simultaneously analyze two versions of a given species and we used this mode to determine the columndensity ratio of different isotopologues. These simulations benefit from a better coverage of $E_{\mathrm{u}}$ and allow us for a more reliable opacity correction. Although simulations with combined isotopologue data introduce one extra free parameter, their results have proven to be more reliable than single-isotopologue results. The isotopic ratios are discussed in Sect. 4.5. The same CASSIS mode was used to yield the abundance ratio of the different spin or symmetry forms of a given molecule, such as the ortho and para versions of $\mathrm{H}_{2} \mathrm{CO}$, or $A$ and $E$ type $\mathrm{CH}_{3} \mathrm{OH}$. In these cases, we used the VASTEL database where the different-symmetry or spin species have separate line lists and partition functions. However, the ratio could be only determined for $\mathrm{H}_{2} \mathrm{CO}$ at ortho/para of $2.5 \pm 0.8$

The physical parameters derived here are more accurate than those reported in Kamiński et al. (2015a) owing to more transitions covered and the automated minimization procedure. However, they are still subject to many systematic uncertainties and should be treated with caution.

\section{Results and discussions}

\subsection{Why so cool?}

The derived excitation temperatures are very low, between 3 and $12.5 \mathrm{~K}$ (Table D.1). Because, in general, gas may be excited subthermally (see e.g. Goldsmith \& Langer 1999), these excitation temperatures do not necessarily indicate directly the gas kinetic temperatures. Observed transitions of $\mathrm{CO}$, which have lowest critical densities among all covered transitions, indicate the highest excitation temperature of 10-12 K, while many transitions of known high-density tracers, e.g. $\mathrm{H}_{2} \mathrm{CO}, \mathrm{HCO}^{+}, \mathrm{CCH}$, $\mathrm{HNC}$, yield temperatures of $3-3.5 \mathrm{~K}$. This would suggest subthermal excitation of the latter species but there are also highdensity tracers, e.g. transitions of $\mathrm{SiO}$ and $\mathrm{HCN}$, which yield higher temperatures of $8-12 \mathrm{~K}$. It is therefore unclear how low the kinetic temperatures are. The relatively large scatter in the derived excitation temperatures may be partially caused by physical variations of kinetic temperature within the remnant and we can conclude that the overall kinetic temperatures in the regions dominating the observed molecular emission are likely below $\sim 12 \mathrm{~K}$.

The 1670-72 eruption probably dispersed material of a relatively high temperature of a few $10^{3} \mathrm{~K}$ (as these are typical temperatures of material ejected by red novae in outburst) or even higher, i.e. $\gtrsim 10000 \mathrm{~K}$, since part of the hydrogen gas was ionized in the eruption (Sect. 1). We assume that the molecular remnant was created in the same event, i.e. after the gas recombined and formed molecules. Radiative cooling may be insufficient to cool down the hot plasma to these low gas temperatures in less than $350 \mathrm{yr}$. Adiabatic expansion into a pre-existing medium is another mechanism that can be responsible for efficient cooling of the gas (Bohigas 2017). Many pre-PNe of dynamical ages of a few hundred years contain molecular gas at similarly low excitation temperatures, e.g. 10-20 K in OH231.8 (Sánchez Contreras et al. 2015) and $10 \mathrm{~K}$ in Frosty Leo (Castro-Carrizo et al. 2005). This suggests that the cool gas in CK Vul indeed could have been dispersed only $350 \mathrm{yr}$ ago. Ultra-cool gas of extremely low excitation of $<3 \mathrm{~K}$, i.e. comparable to temperature estimates of some species in CK Vul, have been measured in the Boomerang Nebula and indicate very efficient adiabatic cooling in some parts of the outflow (Sahai \& Nyman 1997; Bohigas 2017). Similar processes could have taken place in CK Vul.

\subsection{Polyatomic and complex organic species}

Formaldehyde $\left(\mathrm{H}_{2} \mathrm{CO}\right)$, which was the only polyatomic species identified in CK Vul in our earlier work, is accompanied in the current inventory by six other large compounds: isocyanic acid $(\mathrm{HNCO})$, methaminine $\left(\mathrm{CH}_{3} \mathrm{NH}\right)$, cyanoacetylene $\left(\mathrm{HC}_{3} \mathrm{~N}\right)$, methanol $\left(\mathrm{CH}_{3} \mathrm{OH}\right)$, methyl cyanide $\left(\mathrm{CH}_{3} \mathrm{CN}\right)$, and methylamine $\left(\mathrm{CH}_{3} \mathrm{NH}_{2}\right)$. Note that only three of them contain oxygen and all, except methanol and formaldehyde, contain nitrogen. Future observations at better sensitivity or at lower frequencies may reveal even more complex species.

With the observed molecules, we trace the full hydrogenation sequence based on the cyanide radical: $\mathrm{CN}, \mathrm{HCN}, \mathrm{H}_{2} \mathrm{C}=\mathrm{NH}$, $\mathrm{H}_{3} \mathrm{C}=\mathrm{NH}_{2}$. A hydrogenation sequence is also apparent for $\mathrm{CO}$ based species: $\mathrm{CO},\left(\mathrm{HCO}^{+}\right), \mathrm{H}_{2} \mathrm{C}=\mathrm{O}$, and $\mathrm{H}_{3} \mathrm{C}=\mathrm{OH}$. The apparent hydrogenation sequences are likely to be the actual formation paths of the largest species observed in CK Vul. Long carbon chains are not detected in CK Vul at the current sensitivity but their building blocks, the simplest linear carbon chain $\mathrm{CCH}$ and the simplest cyanopolyyne $\mathrm{HC}_{3} \mathrm{~N}$ (and $\mathrm{HCN}$ ), are observed. Our $\mathrm{mm}$-wave spectra cover transitions of longer carbon chains but their $E_{\mathrm{u}}$ values are too high for the emission to be detected if their excitation temperature is $\lesssim 12 \mathrm{~K}$. Their presence should be verified by observations at lower radio frequencies.

In an attempt to understand the origin of polyatomic species in CK Vul, let us consider possible formation channels of $\mathrm{CH}_{3} \mathrm{OH}$ only. Much theoretical work has been devoted to understand the formation of methanol in different interstellar and circumstellar environments. These environments have initial elemental compositions that differ from these of CK Vul. Nevertheless, it is instructive to briefly review known chemical pathways that lead to methanol and consider if they are adequate for CK Vul.

- Efficient gas-phase production of methanol requires the presence of molecular ions. In the ISM, they are produced by cosmic rays (CRs) or ultraviolet (UV) radiation. Owing to low efficiency of these processes, the gas-phase production of $\mathrm{CH}_{3} \mathrm{OH}$ is often considered insignificant in the local ISM (Coutens et al. 2017). Note, however, that molecular ions are abundant in the remnant of CK Vul and ion chemistry may be a viable mechanism to produce the polyatomic species.

- Methanol can be produced in icy mantles through hydrogenation of CO (Watanabe \& Kouchi 2002). It is then released to the gas phase through desorption. Note that 
dust in CK Vul has a component of a temperature of $15 \mathrm{~K}$ (Kamiński et al. 2015a) or even lower (7.5 K; Tylenda et al., in prep.), at which the grains may contain icy mantles. Shocks in the fast molecular jets can naturally explain how methanol is liberated to the gas phase from ice (Hartquist et al. 1995). Additionally, in the central parts of the nebula, thermal desorption may be taking place and release hydrogenated polyatomic species from grains to gas. This is a viable scenario for CK Vul as there is also dust of a temperature of about $50 \mathrm{~K}$ at which many ices would be desorbed. If this is the case, methanol should be spatially collocated with the warmer dust. This can be verified by interferometric mapping.

- Methanol can also be produced in high-density neutral gas where three-body reactions are possible. It involves chemical reactions of a high order of endothermicity, i.e. of 6500 and $14700 \mathrm{~K}$ (Hartquist et al. 1995). This process requires the presence of $\mathrm{OH}$ and $\mathrm{H}_{2} \mathrm{O}$. Coutens et al. (2017) consider such a formation channel for $\mathrm{CH}_{3} \mathrm{OH}$ during grain explosions which have enough energy to break the reaction barrier. Grain explosions may occur in CK Vul, for instance after a passage of shocks. However, CK Vul does not appear to be abundant in O-bearing molecules other than $\mathrm{CO}$. In fact, the lack of $\mathrm{OH}$ features in the Effelsberg radio spectra (Kamiński et al. 2015a) may indicate that $\mathrm{OH}\left(\right.$ and $\mathrm{H}_{2} \mathrm{O}$ ) is currently frozen onto grain mantles. If water was liberated from the mantles to allow formation of methanol, we should be able to observe it in the gas phase in quantities comparable to these of methanol. This can be verified by a search for thermal emission of water (given the low temperature of the gas, this is however impossible from the ground).

Production of polyatomic species that involves icy mantles would require (i) quick formation of ice after the explosion of CK Vul or (ii) the presence of icy grains in older circumstellar or preexisting interstellar material. We cannot exclude the presence of dusty ISM surrounding the object before 1670 but icy grains are not expected there. In the direction of CK Vul, we observe only diffuse interstellar clouds (Sect.2) where icy mantles are not supposed to form or survive. Very quick formation of ice, i.e. on time scales shorter than $350 \mathrm{yr}$, is possible in CK Vul and would require substantial gas densities, i.e. $>10^{6} \mathrm{~cm}^{-3}$ at a kinetic temperature of $10 \mathrm{~K}$ (Spitzer 1978). This condition is not unrealistic.

With the current knowledge of CK Vul, we cannot distinguish between the different formation scenarios of the complex molecules. A detailed modeling of their origin is hampered by unknown physical parameters and the history of the remnant.

\subsection{Origin of ionic species}

Although $\mathrm{HCO}^{+}$and $\mathrm{N}_{2} \mathrm{H}^{+}$are often observed in the ISM and star-forming regions, they are very rare in circumstellar envelopes. The $\mathrm{HCO}^{+}$ion has been observed in a number of $\mathrm{O}$ - and $\mathrm{C}$-rich environments of evolved stars (Pulliam et al. 2011), mostly in pre-PNe (Bujarrabal et al. 1988; Sánchez Contreras et al. 2015) and PNe (Zhang et al. 2008; Zhang 2016). In O-rich media, the molecule is thought to be created in a reaction involving water, i.e. Mamon et al. (1987).

$\mathrm{C}^{+}+\mathrm{H}_{2} \mathrm{O} \rightarrow \mathrm{HCO}^{+}+\mathrm{H}$.

Carbon ions can be present in CK Vul as other atomic ions have been observed in its optical and IR spectra. However, gas-phase water does not appear to be abundant in CK Vul making the above formation channel questionable. An alternative channel occurs in the ISM and involves the protonated hydrogen molecule $\left(\mathrm{H}_{3}^{+}\right.$; Mamon et al. 1987),

$\mathrm{H}_{3}^{+}+\mathrm{CO} \rightarrow \mathrm{HCO}^{+}+\mathrm{H}_{2}$.

The $\mathrm{H}_{3}^{+}$ion can be produced from $\mathrm{H}_{2}$ (through $\mathrm{H}_{2}^{+}$) by ionization by $\mathrm{CRs}$ or by energetic far-UV radiation. A chemical impact of CRs should be negligible in CK Vul owing to the short life time of the remnant compared to CR ionization time scales. $\mathrm{HCO}^{+}$could rather be produced by an internal UV source. Sánchez Contreras et al. (2015) consider yet another formation channel, where $\mathrm{HCO}^{+}$is formed through proton exchange with $\mathrm{N}_{2} \mathrm{H}^{+}$. As we discuss below, however, the formation of $\mathrm{N}_{2} \mathrm{H}^{+}$ requires the presence of $\mathrm{H}_{3}^{+}$and, again, implies a photoionizing source.

Another ion seen in $\mathrm{CK} \mathrm{Vul}, \mathrm{N}_{2} \mathrm{H}^{+}$, has been observed in a PN, NGC 7027, whose ion chemistry is strongly influenced by radiation of the hot $(220000 \mathrm{~K})$ central star (Zhang et al. 2008), and in two well known pre-PNe: O-rich OH231.8 (Sánchez Contreras et al. 2015) and C-rich CRL 618 (Pardo et al. 2007). Efficient formation of $\mathrm{N}_{2} \mathrm{H}^{+}$requires the presence of $\mathrm{H}_{3}^{+}$(Mamon et al. 1987), i.e.

$\mathrm{H}_{3}^{+}+\mathrm{N}_{2} \rightarrow \mathrm{N}_{2} \mathrm{H}^{+}+\mathrm{H}_{2}$.

The relatively strong emission of $\mathrm{N}_{2} \mathrm{H}^{+}$in CK Vul would suggest a high formation rate of $\mathrm{H}_{3}^{+}\left(\right.$and $\mathrm{H}_{2}^{+}$), and this - in turn - would imply the presence of a UV emitter in the system. Sánchez Contreras et al. (2015) propose another formation channel of $\mathrm{N}_{2} \mathrm{H}^{+}$through a reaction of $\mathrm{H}_{2}$ with $\mathrm{N}_{2}^{+}$and propose $\mathrm{N}_{2}^{+}$is produced in proton exchange reaction of $\mathrm{N}_{2}$ with $\mathrm{He}^{+}$. The latter requires a direct ionization by UV photons. Therefore, both $\mathrm{HCO}^{+}$and $\mathrm{N}_{2} \mathrm{H}^{+}$, whatever their actual formation paths are, seem to imply the presence of a UV source in CK Vul.

In order to explain high abundances of the two molecular ions in OH231.8, Sánchez Contreras et al. (2015) proposed a major role of shocks in ion formation. As noted in Kamiński et al. (2015a), there are many similarities between $\mathrm{OH} 231.8$ and CK Vul. However, no physio-chemical models exist to verify this formation channel. If shocks indeed can explain the presence of the two ions, also in environments where oxygen is not an abundant element, one would not need to postulate the presence of a central UV source in CK Vul. Currently, we are not able to distinguish between the two alternatives.

\subsection{Chemistry and elemental abundances}

The elemental composition of the gas surrounding Nova 1670 is of primary interest as it may provide crucial information necessary to decode the nature of the object. As mentioned in Sect. 1, some hints on the gas elemental composition have been found from observations of the atomic component of the nebula. It is unknown if the molecular gas has the same elemental composition as the recombining plasma. To independently derive the elemental composition of the molecular remnant, it is first necessary to establish accurate molecular abundances and constrain the chemical history of the object. Considering how little is known about the structure and history of the remnant, this undertaking is currently impossible. However, the composition of CK Vul can be analyzed on phenomenological grounds, e.g. from comparisons with well-known objects characterized by different types of chemistry. Below, we discuss our results for the most interesting elements. 
Hydrogen. The high number of observed molecules containing hydrogen may suggest that the environment is not considerably depleted of hydrogen, against the claims in Hajduk et al. (2007). Unfortunately, we do not observe $\mathrm{mm}$ recombination lines and are unable to provide useful constraints on the amount of $\mathrm{H}$ in the recombining remnant. The detection of a MIR line of $\mathrm{H}_{2}$ (Evans et al. 2016) in combination with observations of other $\mathrm{H}_{2}$ lines might in future help determining the amount of molecular hydrogen in the remnant.

Carbon. From our inventory of molecules and the presence of the unidentified infrared emission bands (Evans et al. 2016), one could conclude that the chemistry of the remnant is dominated by carbon. Generally, this does not directly imply that the carbon abundance is higher than that of oxygen and nitrogen. We attempted a quantitative analysis of the relative abundances by comparing the number of $\mathrm{CNO}$ atoms observed in the molecular gas. For all molecular carriers of the given element, we summed the products of the column density and source solid angle derived in our LTE analysis (Table D.1). The numbers were corrected for the isotopic composition (Sect. 4.5) and the number of atoms building the molecule. This yielded the $\mathrm{C}: \mathrm{N}: \mathrm{O}$ ratios of 43:1:33 which suggest that carbon dominates over the two other metals, in particular over nitrogen. These ratios are highly influenced by a very high abundance of $\mathrm{CO}$. Because we do not observe all of the most abundant species - in particular observations of $\mathrm{C}_{2}, \mathrm{O}_{2}$, and $\mathrm{N}_{2}$ are missing - the ratios are only a suggestion of a dominance of carbon. In fact, the molecular inventory does not allow us to consider the environment as a typical "carbon-rich" one in the sense this term is used to classify AGB stars or pre-PNe. Additionally, there may be spatial variations of the relative elemental abundances across the remnant.

We observe the ${ }^{3} \mathrm{P}_{1}-{ }^{3} \mathrm{P}_{0}$ fine-structure line of neutral carbon, [C I], which is from an energy level at $E_{\mathrm{u}}=23.6 \mathrm{~K}$. The feature near $492.2 \mathrm{GHz}$ represents a tight blend of ${ }^{12} \mathrm{C}$ and ${ }^{13} \mathrm{C}$ transitions (Figs. B.2 and E.2). The spatial distribution of the atomic gas and its excitation temperature are currently unknown. In the ISM, neutral carbon is found to trace the same intermediatedensity material as that seen in low to moderate opacity low$J{ }^{13} \mathrm{CO}$ lines (e.g. Plume et al. 1999). Assuming thus that the $[\mathrm{C} \mathrm{I}]$ emission originates from the same region as $\mathrm{CO}$ and the ${ }^{12} \mathrm{C}$ to ${ }^{13} \mathrm{C}$ ratio is of 3.8 (Sect. 4.5 ), the measured line intensity of $3.7 \mathrm{~K} \mathrm{~km} \mathrm{~s}^{-1}\left(T_{\mathrm{A}}^{*}\right)$ implies $\mathrm{C}$ I column densities of the order of $10^{17} \mathrm{~cm}^{-2}$, i.e. similar to that of $\mathrm{CO}$, for excitation temperatures of $6-13 \mathrm{~K}$ that are typical for most molecular species in Table D.1. At lower excitation temperatures, the ${ }^{12} \mathrm{C}$ I column densities would have to be considerably higher, e.g. of $5 \times 10^{19} \mathrm{~cm}^{-2}$ at $3.5 \mathrm{~K}$, and atomic gas would then be the dominant C-bearing component of the remnant. We therefore conclude that $\mathrm{C}$ is a major element in the remnant but there is currently no direct observational evidence that it is the dominant CNO element.

Oxygen. The lack of oxides typically omnipresent in spectra of O-rich envelopes of AGB stars and red supergiants (e.g. Kamiński et al. 2013b; Tenenbaum et al. 2010) strongly suggests that the circumstellar gas of $\mathrm{CK} \mathrm{Vul} \mathrm{is} \mathrm{not} \mathrm{dominated}$ by oxygen. We observe strong lines of $\mathrm{SiO}$, but this molecule is also observed in envelopes of carbon stars (Schöier et al. 2006). Some other O-bearing molecules we observe $-\mathrm{HCO}^{+}$, $\mathrm{H}_{2} \mathrm{CO}$, and $\mathrm{CO}-$ are present in a broad range of chemically diverse objects and their presence does not constrain the dominant chemistry type. On the other hand, $\mathrm{SO}, \mathrm{SO}_{2}, \mathrm{NO}, \mathrm{HNCO}$, and $\mathrm{CH}_{3} \mathrm{OH}$ are never observed in $\mathrm{C}$-rich media. Their presence can be explained by non-equilibrium chemistry taking place in shocks, analogously to how O-bearing molecules are produced in C-rich stars (Cherchneff 2006). These molecules form mainly after dissociation of $\mathrm{CO}$ which liberates oxygen for chemical reactions with other metals.

Nitrogen. A striking feature of the $\mathrm{mm}$ and submm spectra of CK Vul is the rich variety of N-bearing species. In addition, radio observations revealed relatively strong emission of $\mathrm{NH}_{3}$ (Kamiński et al. 2015a). From all the N-bearing species predicted to be abundant in thermal-equilibrium (for gas dominated by $\mathrm{N}$ or $\mathrm{O}$ over $\mathrm{C}$ ), i.e. $\mathrm{N}_{2}, \mathrm{NO}, \mathrm{HCN}, \mathrm{HNC}$, and $\mathrm{NH}_{3}$ (Quintana-Lacaci et al. 2013), only $\mathrm{N}_{2}$ remains undetected in CK Vul. In addition to these abundant species, we also observe $\mathrm{PN}, \mathrm{NS}, \mathrm{N}_{2} \mathrm{H}^{+}, \mathrm{SiN}$ and several polyatomic organic species that contain N. Note that although we do not observe species like CP and $\mathrm{SiC}$, we do observe their N-bearing analogs, $\mathrm{PN}$ and $\mathrm{SiN}$. Does the enhanced abundance of N-bearing species indicate an enhanced abundance of elemental nitrogen in CK Vul? As discussed in Sánchez Contreras et al. (2015) for OH231.8, shockinduced chemistry can produce $\mathrm{N}$-bearing species in environments where the abundance of $\mathrm{N}$ is not enhanced. Based only on observations of molecules, the evidence for an overabundance of elemental $\mathrm{N}$ is currently circumstantial, at best.

Fluorine. The presence of the bright emission of AlF in the spectrum of CK Vul is remarkable. Although we are not able to provide any quantitative evidence at this time, we believe this emission can be an indication of an overabundance of ${ }^{19} \mathrm{~F}$ relative to solar composition. Fluorine-bearing species are not easily traceable in circumstellar envelopes of cool stars at mm wavelengths. The only two other sources where rotational lines of $\mathrm{AlF}$ have been detected are the prototypical C-rich AGB star IRC+10216 (Cernicharo et al. 2000; Ziurys et al. 1994) and a young PPN CRL 2688 (Highberger et al. 2001). The AlF emission in IRC+10216 indicates a substantial overabundance of fluorine which, most likely, was produced in He-burning thermal pulses (Jorissen et al. 1992; Highberger et al. 2001).

The inventory of species in Table 1 shows that CK Vul has molecules typical for all known chemical types of circumstellar envelopes and does not relate directly to any known object. The abundance of elemental carbon seems to exceed these of oxygen or nitrogen but complex chemistry stands in the way of us making definitive conclusions about the elemental composition of the molecular gas.

\subsection{Extraordinary isotopic composition}

We are able to characterize the isotopic composition of the molecular gas much better than the elemental composition. Table 2 lists the isotopic ratios derived in the LTE analysis with CASSIS (Sect. 3.3). The values in the third column of the table specify the $3 \sigma$ range of the $\chi^{2}$ distribution. The $\chi^{2}$ distribution is often asymmetric around the minimum. Also, in a few cases the minimum is found but the $3 \sigma$ range for the upper limit is indeterminate. For a majority of species, we also calculated line ratios which are given in the last column of the table. These are flux ratios corrected for the spectroscopic line strength $\left(S \mu^{2}\right)$ and frequency but not for opacity. If several transitions are observed with a consistent ratio, a weighted mean is given in the table. 
T. Kamiński et al.: Molecules in CK Vul

Table 2. Isotopic ratios resulting from our LTE analysis with CASSIS and directly from line ratios.

\begin{tabular}{|c|c|c|c|}
\hline Isotopologues & $\begin{array}{l}\text { Column-density } \\
\text { ratio }\end{array}$ & $\begin{array}{l}3 \sigma \text { ratio } \\
\text { range }\end{array}$ & $\begin{array}{l}\text { Line ratio } \\
\text { and } 3 \sigma \text { errol }\end{array}$ \\
\hline \multicolumn{4}{|c|}{${ }^{12} \mathbf{C} /{ }^{13} \mathbf{C}=3.8 \pm 1.0[89.3]_{\odot}$} \\
\hline $\mathrm{HC}_{3} \mathrm{~N}, \mathrm{H}^{13} \mathrm{CCCN}, \mathrm{HC}^{13} \mathrm{CCN}+\mathrm{HCC}^{13} \mathrm{CN}$ & 4.3 & $3.3-5.6$ & $4.1 \pm 1.1$ \\
\hline $\mathrm{CCH},{ }^{13} \mathrm{CCH}, \mathrm{C}^{13} \mathrm{CH}$ & 3.0 & $2.2-3.4$ & \\
\hline $\mathrm{CN},{ }^{13} \mathrm{CN}^{a}$ & 2.3 & $2.1-2.6$ & \\
\hline $\mathrm{CS},{ }^{13} \mathrm{CS}$ & 4.6 & $3.1-7.0$ & $3.4 \pm 0.2$ \\
\hline $\mathrm{HCO}^{+}, \mathrm{H}^{13} \mathrm{CO}^{+}$ & 2.5 & $1.8-4.2$ & $2.1 \pm 0.1$ \\
\hline $\mathrm{HCN}, \mathrm{H}^{13} \mathrm{CN}$ & 2.0 & $1.6-2.6$ & $1.7-2.7^{b}$ \\
\hline $\mathrm{CO},{ }^{13} \mathrm{CO}$ & 4.0 & $3.0-5.3$ & \\
\hline $\mathrm{CH}_{3} \mathrm{OH},{ }^{13} \mathrm{CH}_{3} \mathrm{OH}^{c}$ & 3.8 & $2.9-4.9$ & $3.8 \pm 0.6$ \\
\hline $\mathrm{CH}_{3} \mathrm{CN},{ }^{13} \mathrm{CH}_{3} \mathrm{CN}^{a, c}$ & 1.5 & $1.2-2.8$ & $4.3 \pm 0.1$ \\
\hline $\mathrm{H}_{2} \mathrm{CO}, \mathrm{H}_{2}^{13} \mathrm{CO}^{d}$ & 6.5 & $4.4-9.7$ & $4.0 \pm 0.2$ \\
\hline $\mathrm{HNC}, \mathrm{HN}^{13} \mathrm{C}$ & 6.2 & $4.3-8.5$ & $2.1 \pm 0.1$ \\
\hline $\mathrm{C}^{18} \mathrm{O},{ }^{13} \mathrm{C}^{18} \mathrm{O}$ & 5.0 & $2.5-16.6$ & \\
\hline \multicolumn{4}{|c|}{${ }^{13} \mathbf{C} /{ }^{14} \mathbf{C}>141$} \\
\hline $\mathrm{H}^{13} \mathrm{CN}, \mathrm{H}^{14} \mathrm{CN}$ & & & $>142$ \\
\hline${ }^{13} \mathrm{CO},{ }^{14} \mathrm{CO}$ & & & $>72$ \\
\hline \multicolumn{4}{|c|}{${ }^{14} \mathbf{N} /{ }^{15} \mathbf{N}=20 \pm 10[441]_{\odot}{ }^{e}$} \\
\hline $\mathrm{CN}, \mathrm{C}^{15} \mathrm{~N}^{b}$ & 44.8 & $24.0-190.0$ & \\
\hline $\mathrm{N}_{2} \mathrm{H}^{+},{ }^{15} \mathrm{NNH}^{+}, \mathrm{N}^{15} \mathrm{NH}^{+}$ & 14.6 & $>5.3$ & $16.2 \pm 9.5$ \\
\hline $\mathrm{HCN}, \mathrm{HC}^{15} \mathrm{~N}$ & 12.8 & $10.1-17.0$ & $11.1 \pm 0.3$ \\
\hline $\mathrm{HNC}, \mathrm{H}^{15} \mathrm{NC}$ & 30.8 & $15.2-67.0$ & $15.9 \pm 1.7$ \\
\hline $\mathrm{NS},{ }^{15} \mathrm{NS}$ & & $>17.4$ & \\
\hline $\mathrm{HC}_{3} \mathrm{~N}, \mathrm{HC}_{3}{ }^{15} \mathrm{~N}$ & & $>7.6$ & \\
\hline${ }^{13} \mathrm{CN},{ }^{13} \mathrm{C}^{15} \mathrm{~N}$ & & $>37.0$ & \\
\hline $\mathrm{H}^{13} \mathrm{CN}, \mathrm{H}^{13} \mathrm{C}^{15} \mathrm{~N}$ & 18.4 & $13.8-27.5$ & $16.3 \pm 1.4$ \\
\hline $\mathrm{HN}^{13} \mathrm{C}, \mathrm{H}^{15} \mathrm{~N}^{13} \mathrm{C}$ & & & $13.9 \pm 6.2$ \\
\hline $\mathrm{HC}_{3} \mathrm{~N}, \mathrm{HC}_{3}^{15} \mathrm{~N}$ & & $>7.6$ & \\
\hline${ }^{13} \mathrm{CN} \times 3.8^{f}, \mathrm{C}^{15} \mathrm{~N}$ & 69.1 & $49.0-106.0$ & \\
\hline $\mathrm{H}^{13} \mathrm{CN} \times 3.8^{f}, \mathrm{HC}^{15} \mathrm{~N}$ & 23.6 & $19.0-30.8$ & $24.4 \pm 1.1$ \\
\hline $\mathrm{HN}^{13} \mathrm{C} \times 3.8^{f},{ }^{15} \mathrm{HNC}$ & 55.1 & $30.4-84.4$ & $26.2 \pm 2.3$ \\
\hline \multicolumn{4}{|c|}{${ }^{16} \mathbf{O} /{ }^{18} \mathbf{O}=36 \pm 14[498.8]_{\odot}$} \\
\hline $\mathrm{CO}, \mathrm{C}^{18} \mathrm{O}$ & 36.7 & $26.2-60.0$ & $24.5 \pm 2.7$ \\
\hline $\mathrm{SiO}, \mathrm{Si}^{18} \mathrm{O}$ & 12.1 & $9.3-16.7$ & $11.5 \pm 2.3$ \\
\hline $\mathrm{HCO}^{+}, \mathrm{HC}^{18} \mathrm{O}^{+}$ & 53.1 & $>25.0$ & $15.3 \pm 8.1$ \\
\hline $\mathrm{SO}, \mathrm{S}^{18} \mathrm{O}$ & & $>16.5$ & \\
\hline $\mathrm{H}_{2} \mathrm{CO}, \mathrm{H}_{2} \mathrm{C}^{18} \mathrm{O}^{d}$ & & $>71.6$ & \\
\hline${ }^{13} \mathrm{CO},{ }^{13} \mathrm{C}^{18} \mathrm{O}$ & 69.2 & $>32.0$ & $40.2 \pm 19.7$ \\
\hline${ }^{13} \mathrm{CO} \times 3.8^{f}, \mathrm{C}^{18} \mathrm{O}$ & 52.1 & $35.3-76.0$ & $37.4 \pm 6.2$ \\
\hline $\mathrm{H}^{13} \mathrm{CO}^{+} \times 3.8^{f}, \mathrm{HC}^{18} \mathrm{O}^{+}$ & 86.5 & $39.9-534.7$ & $35.4 \pm 18.8$ \\
\hline \multicolumn{4}{|c|}{${ }^{18} \mathbf{O} /{ }^{17} \mathbf{O} \gtrsim 5[5.4]_{\odot}$} \\
\hline $\mathrm{Si}^{18} \mathrm{O}, \mathrm{Si}^{17} \mathrm{O}$ & $>7.7$ & & $2.8 \pm 2.3$ \\
\hline $\mathrm{C}^{18} \mathrm{O}, \mathrm{C}^{17} \mathrm{O}$ & 5.5 & 4.9-8.3 & $4.7 \pm 4.1$ \\
\hline \multicolumn{4}{|c|}{${ }^{28} \mathrm{Si},{ }^{29} \mathrm{Si},{ }^{30} \mathrm{Si}:{ }^{28} \mathrm{Si} /{ }^{29} \mathrm{Si}=6.7 \pm 0.4[19.7]_{\odot} ;{ }^{29} \mathrm{Si} /{ }^{30} \mathrm{Si}=1.0 \pm 0.1[0.7]_{\odot}$} \\
\hline $\mathrm{SiO},{ }^{29} \mathrm{SiO}$ & 7.3 & $5.7-9.4$ & $6.6 \pm 0.5$ \\
\hline $\mathrm{SiS},{ }^{29} \mathrm{SiS}$ & 7.7 & $>2.3$ & \\
\hline $\mathrm{SiO},{ }^{30} \mathrm{SiO}$ & 8.9 & $6.7-11.8$ & $6.7 \pm 0.7$ \\
\hline${ }^{29} \mathrm{SiO},{ }^{30} \mathrm{SiO}$ & 1.2 & $1.0-1.5$ & $1.0 \pm 0.1$ \\
\hline \multicolumn{4}{|c|}{$\left.{ }^{32} \mathbf{S},{ }^{33} \mathbf{S},{ }^{34} \mathbf{S}:{ }^{32} \mathbf{S} /{ }^{34} \mathbf{S}=14 \pm 3[22.5]\right]_{\odot} ;{ }^{32} \mathbf{S} /{ }^{33} \mathbf{S}>34[126.6]_{\odot}$} \\
\hline $\mathrm{CS}, \mathrm{C}^{33} \mathrm{~S}$ & $>34.0$ & & \\
\hline $\mathrm{CS}, \mathrm{C}^{34} \mathrm{~S}$ & 23.5 & & $13.9 \pm 3.3$ \\
\hline $\mathrm{SO},{ }^{34} \mathrm{SO}$ & 14.1 & $>5.5$ & \\
\hline $\mathrm{NS}, \mathrm{N}^{34} \mathrm{~S}$ & 35.3 & $>15.0$ & \\
\hline${ }^{13} \mathrm{CS} \times 3.8^{f}, \mathrm{C}^{34} \mathrm{~S}$ & 19.0 & $11.8-37.2$ & $14.1 \pm 7.2$ \\
\hline
\end{tabular}

Notes. The headlines with isotopic ratios in boldface indicate the most likely values of the ratios in CK Vul, as discussed in the text. The values given in square brackets correspond to solar system isotopic ratios from Lodders (2003). ${ }^{(a)}$ Very poor fit. ${ }^{(b)}$ We obtain different ratios for different transition pairs and therefore the values were not averaged. ${ }^{(c)}$ Analysis performed at the fixed $A$ to $E$ ratio of $1 .{ }^{(d)}$ Only ortho transitions were analyzed. ${ }^{(e)}$ Marty et al. (2011) measured a ${ }^{14} \mathrm{~N} /{ }^{15} \mathrm{~N}$ ratio of 441 for the solar wind. The value of 272.3 in Lodders (2003) corresponds to terrestrial ratio. ${ }^{(f)}$ As explained in the text, the ratios were transformed with the average ${ }^{12} \mathrm{C} /{ }^{13} \mathrm{C}$ ratio. 
For the species which we observed in multiple isotopic versions, the emission in the main isotopologue is typically very strong. It is often saturated, in particular in transitions to the ground state. Our CASSIS models apply a simple correction for opacity but the oversimplified treatment of the source structure makes this correction insufficient in some cases. Additionally, CASSIS simulations reproduce only very crudely the profile shapes, in particular for molecules that show complex kinematics (e.g. CO and HCN). Other shortcomings of our models mentioned in Sect. 3.3 also influence the isotopic ratios. Below, we critically discuss the results for all relevant isotopic pairs.

\subsection{1. ${ }^{12} \mathrm{C}$ to ${ }^{13} \mathrm{C}$ ratio}

The values in Table 2 typically yield ${ }^{12} \mathrm{C} /{ }^{13} \mathrm{C}$ between 2 and 4 and have a weighted mean of $2.9 \pm 0.1(3 \sigma)$. However, the results are not free from the saturation effect which leads to underestimated values of the ratio. Strong emission features, e.g. of $\mathrm{HCN}, \mathrm{HNC}$, and $\mathrm{HCO}^{+}$, imply values that are systematically lower ( 2) than the much weaker emission of $\mathrm{CS}$ and $\mathrm{HC}_{3} \mathrm{~N}$ (with the ratio of $>4$ ). We believe that the weaker lines are optically thin, as they all have the same ratios, while for species with saturated emission, the line ratio is small (1.7-2.7) and systematically increases with $E_{\mathrm{u}}$. However, we cannot entirely exclude that the differences in ${ }^{12} \mathrm{C} /{ }^{13} \mathrm{C}$ for different species in Table 2 arise due to isotopic fractionation (Sect. 4.6). Ignoring these systematic uncertainties, we consider the median of all measurements of $3.8 \pm 1.0$ as the best value on ${ }^{12} \mathrm{C} /{ }^{13} \mathrm{C}$ (the uncertainty is one median absolute deviation).

\subsection{2. ${ }^{14} \mathrm{~N}$ to ${ }^{15} \mathrm{~N}$}

The line ratios in Table 2 yield a median ${ }^{14} \mathrm{~N} /{ }^{15} \mathrm{~N}$ ratio of $16 \pm$ $6(3 \sigma)$. The corresponding CASSIS models lead to values with a large scatter but are generally consistent with the ratios derived from integrated line fluxes. The LTE analysis of CN and $\mathrm{C}^{15} \mathrm{~N}$ suggests a much higher ratio, i.e. of 24-190. Since CN is likely a photo-dissociation product of $\mathrm{HCN}$, some fractionation enhancing $\mathrm{CN}$ over $\mathrm{C}^{15} \mathrm{~N}$ is possible. Also, the LTE models for $\mathrm{CN}$ species are among the worst and the results should be treated with more caution. The analysis of HNC also leads to a somewhat higher ratio, most likely owing to an imperfect fit constrained by only one firm detection of $\mathrm{H}^{15} \mathrm{NC}$.

Strong constraints on the ${ }^{14} \mathrm{~N} /{ }^{15} \mathrm{~N}$ ratio are set the by line ratio and CASSIS models of HCN which combined give a value of $\approx 12$. The models however overpredict the intensity of the cores of the $\mathrm{HC}^{15} \mathrm{~N}$ transitions indicating saturation in the lines of the main species. The actual isotopic ratios may be higher than derived for $\mathrm{HCN}$ isotopologues, possibly above the formal uncertainty calculated for the line ratios.

In an attempt to reduce the saturation problem for $\mathrm{CN}, \mathrm{HCN}$, and $\mathrm{HNC}$, we also compared the pairs of rare isotopologues substituted by ${ }^{15} \mathrm{~N}$ and ${ }^{13} \mathrm{C}$, for instance $\mathrm{H}^{13} \mathrm{CN}$ and $\mathrm{HC}^{15} \mathrm{~N}$. Ignoring the CASSIS simulations for $\mathrm{CN}$ and $\mathrm{HNC}$, which unsatisfactorily reproduce the observations, we find $a{ }^{13} \mathrm{C} /{ }^{15} \mathrm{~N}$ ratio of 6.2 and the corresponding $3 \sigma$ range of $5.0-8.1$. With the ${ }^{12} \mathrm{C} /{ }^{13} \mathrm{C}$ ratio of 3.8 derived above, we obtain ${ }^{14} \mathrm{~N} /{ }^{15} \mathrm{~N}$ of $23.6(19.0-$ 30.8). This value is close to ratios derived directly from line ratios of $\mathrm{H}^{13} \mathrm{CN}$ and $\mathrm{HC}^{15} \mathrm{~N}$, and of $\mathrm{HN}^{13} \mathrm{C}$ and $\mathrm{H}^{15} \mathrm{NC}$. The weighted mean of these three measurements of $24 \pm 1(3 \sigma)$ is slightly higher than the value 12 and 16 deduced in the previous paragraphs but is affected by an extra uncertainty in the adopted ${ }^{12} \mathrm{C} /{ }^{13} \mathrm{C}$ ratio.
We conclude that the elemental ${ }^{14} \mathrm{~N} /{ }^{15} \mathrm{~N}$ ratio is most likely in the range of about $12-24$ and we arbitrarily adopt $20 \pm 10$ as its most representative value.

\subsection{3. ${ }^{16} \mathrm{O}$ to ${ }^{18} \mathrm{O}$ and ${ }^{18} \mathrm{O}$ to ${ }^{17} \mathrm{O}$}

We use the median of all measurements and the median absolute deviation, $36 \pm 14$, as the representative values for the ${ }^{16} \mathrm{O} /{ }^{18} \mathrm{O}$ ratio and its uncertainty. Direct comparisons of emission fluxes of the main species with these where ${ }^{16} \mathrm{O}$ is substituted by ${ }^{18} \mathrm{O}$ give systematically lower values, but the saturation effect for these pairs must be most severe. We trust more the results obtained for isotopologue pairs involving the ${ }^{13} \mathrm{C}$ isotope which give values of 32-40, close to the overall median.

The $\mathrm{C}^{17} \mathrm{O}$ and $\mathrm{Si}^{17} \mathrm{O}$ isotopologues are only tentatively detected and yield upper limits on the elemental abundance of ${ }^{17} \mathrm{O}$. Because line intensities of ${ }^{17} \mathrm{O}$-bearing isotopologues are comparable in intensity to these of ${ }^{18} \mathrm{O}$, the ${ }^{18} \mathrm{O}$ vs. ${ }^{17} \mathrm{O}$ pairs permit a more accurate determination of the isotopic ratio than ${ }^{16} \mathrm{O}$ vs. ${ }^{17} \mathrm{O}$. Our estimates yield the ${ }^{18} \mathrm{O} /{ }^{17} \mathrm{O}$ ratio of $\gtrsim 5$. Subsequently, ${ }^{16} \mathrm{O} /{ }^{17} \mathrm{O}>110$, using the lowest value of ${ }^{16} \mathrm{O} /{ }^{18} \mathrm{O}$ of 22 within the uncertainties quoted above.

\subsubsection{Other isotopes}

We are able to constrain the relative abundance of the unstable isotope of carbon, ${ }^{14} \mathrm{C}$, with a half-life time of $t_{1 / 2}=5730 \mathrm{yr}$. The upper limit on the emission of ${ }^{14} \mathrm{CO}(1-0)$ yields ${ }^{13} \mathrm{C} /{ }^{14} \mathrm{C}>72$. An analysis of the $\mathrm{H}^{14} \mathrm{CN}(1-0)$ line provides an even more stringent $3 \sigma$ limit of ${ }^{13} \mathrm{C} /{ }^{14} \mathrm{C}>141$ or ${ }^{12} \mathrm{C} /{ }^{14} \mathrm{C}>530$. The line frequencies were taken from Rodriguez Kuiper et al. (1977).

Our LTE models and line ratios provide a very accurate ratio of ${ }^{29} \mathrm{SiO}$ to ${ }^{30} \mathrm{SiO}$ of $1.0 \pm 0.1(3 \sigma)$. The ratios of the two $\mathrm{Si}$ isotopes with respect to the main one are affected by saturation in the lines of the main isotopologue and are less certain. Nevertheless, our analysis of the ${ }^{28} \mathrm{Si} /{ }^{29} \mathrm{Si}$ and ${ }^{28} \mathrm{Si} /{ }^{30} \mathrm{Si}$ ratios implies a weighted mean of $6.7 \pm 0.4$. Additionally, from an upper limit on the $J=2-1$ line of ${ }^{32} \mathrm{SiO}$ - i.e. the isotopologue containing the radioactive nuclide of ${ }^{32} \mathrm{Si}\left(t_{1 / 2}=153 \mathrm{yr}\right)$ - we derive a lower limit on the ${ }^{30} \mathrm{Si} /{ }^{32} \mathrm{Si}$ ratio of 12 , which converted to the ${ }^{28} \mathrm{Si} /{ }^{32} \mathrm{Si}$ ratio gives a lower limit of about 80 .

The heaviest isotope seen in our data is ${ }^{34} \mathrm{~S}$ and it is $\sim 14$ times less abundant than the main isotope of sulfur. We compared both $\mathrm{CS}$ and ${ }^{13} \mathrm{CS}$ to $\mathrm{C}^{34} \mathrm{~S}$ and expect all lines to be optically thin. The isotope of ${ }^{33} \mathrm{~S}$ is even less abundant with a lower limit of ${ }^{32} \mathrm{~S} /{ }^{33} \mathrm{~S}>34$.

\subsection{Interpretation of the isotopic composition}

Fractionation. In the above, we interpreted the molecular ratios as the elemental isotopic ratios and ignored isotopic fractionation processes that can alter the observational signatures of the isotopes and lead to biased isotopic ratios. We mentioned that photodissociation can cause fractionation that could enhance the abundance of the rare isotopologues relative to these of the main ones, but this effect seems to be only likely in the case of the $\mathrm{CN}$ isotopologues. However, fractionation can be also caused by a thermodynamic effect and isotope-exchange reactions. Terzieva \& Herbst (2000) and Roueff et al. (2015) explored these fractionation effects on $\mathrm{N}$ - and ${ }^{15} \mathrm{~N}$-bearing species in physical conditions typical for dense interstellar clouds. Temperatures in these clouds are similarly low $(\sim 10 \mathrm{~K})$ as in CK Vul's remnant. The studies included reactions with 
molecular ions but their chemical networks are not directly applicable to CK Vul. For most species, the expected fractionation is at a negligible level of a few \%. Terzieva \& Herbst (2000) found higher values of up to $39 \%$ (typically 20\%) for $\mathrm{CN}, \mathrm{HCN}$ and HNC but Roueff et al. (2015) questioned some of these results and nitrogen fractionation is likely to be negligible. Roueff et al. showed, however, that carbon fractionation is important in nitriles and can considerably enhance (in the case of $\mathrm{CN}$ ) or deplete (mainly in the case of $\mathrm{HCN}$ and $\mathrm{HNC}$ ) ${ }^{13} \mathrm{C}$ in molecules. The thermodynamic fractionation may be therefore non-negligible in CK Vul and may introduce extra uncertainties of a few tens of $\%$ in our derived elemental isotopic ratios. A detailed reaction network explaining the formation of all species would be necessary to correct our results for this effect. This task is beyond our current possibilities.

The isotopic ratios derived here are more accurate than in our earlier study and the list of isotopic pairs is much longer. Below, we attempt to identify the origin of the isotopic ratios.

Hydrostatic CNO burning. The enhanced abundance of the rare $\mathrm{CNO}$ isotopes in CK Vul suggests that the gas of the remnant was processed by hydrogen-burning in the CNO cycles. Let us consider first whether hydrostatic $\mathrm{H}$ burning via the $\mathrm{CNO}$ cycles can explain the observed isotopic ratios. Non-explosive $\mathrm{CNO}$ burning very quickly converts all the CNO nuclides available into ${ }^{14} \mathrm{~N}$. The processed gas should be dominated by this isotope and nitrogen should be most abundant among the three CNO elements. Optical and our mm-wave data for CK Vul suggest that nitrogen may indeed be enhanced but quantitative estimates are missing. Predictions for the relative abundances of the other $\mathrm{CNO}$ elements depend on the burning temperature (mass of the star) and duration of the CNO burning (Arnould et al. 1999). In most conditions, the ${ }^{12} \mathrm{C} /{ }^{13} \mathrm{C}$ ratio quickly reaches its equilibrium value of about 4.0 (Iliadis 2007). This ratio is in excellent agreement with what we found for CK Vul (3.8 \pm 1.0$)$. Taken at face value, it could indicate that all the carbon we observe was processed by the $\mathrm{CNO}$ cycles. If that were the case, however, in a wide range of burning conditions ${ }^{16} \mathrm{O}$ should be over $10^{4}$ times more abundant than ${ }^{18} \mathrm{O}$, while the CK Vul ratio is much lower, i.e. of $\sim 36$. The $\mathrm{CNO}$ cycles enhance the ${ }^{17} \mathrm{O}$ abundance so that it can be even four orders of magnitude more abundant than ${ }^{18} \mathrm{O}$. The CK Vul's ${ }^{18} \mathrm{O} /{ }^{17} \mathrm{O}$ ratio of $\gtrsim 5$ is far from predictions for the CNO burning. In fact, ${ }^{18} \mathrm{O}$ and similarly ${ }^{19} \mathrm{~F}$ are typically destroyed in hydrostatic $\mathrm{CNO}$ burning at temperatures less than 100 million K. Even more importantly, ${ }^{15} \mathrm{~N}$ should be $\sim 10^{4}$ times less abundant than ${ }^{14} \mathrm{~N}$ as a result of hydrostatic burning while the observations indicate a low ratio of about 20 in CK Vul. We conclude that it is impossible to explain the observed isotopes with pure products of hydrostatic $\mathrm{H}$ burning in $\mathrm{CNO}$ cycles.

Nova nucleosynthesis. Hot (explosive) CNO cycles, taking place in classical novae, can proceed along many different scenarios (different chemical compositions of the accretor and donor stars, extent of the convective mixing, mass of the white dwarf, etc.) and it is impossible to define any standard isotopic yields. State of the art models of runaway nucleosynthesis show, however, that classical novae are the main Galactic producers of ${ }^{13} \mathrm{C},{ }^{15} \mathrm{~N},{ }^{17} \mathrm{O}$ and synthesize other important isotopes, e.g. ${ }^{7} \mathrm{Li},{ }^{19} \mathrm{~F}$, and ${ }^{26} \mathrm{Al}$ (José 2002). Most of these isotopes are enhanced in CK Vul. In particular, hot CNO nucleosynthesis at temperatures above 100 million $\mathrm{K}$ appears to be the only mechanism able to explain the low ${ }^{14} \mathrm{~N} /{ }^{15} \mathrm{~N}$ ratio measured in $\mathrm{CK}$ Vul. For instance, some CO nova models of José et al. (2004) predict the right ${ }^{14} \mathrm{~N} /{ }^{15} \mathrm{~N}$ ratio of about 20 but at the same time produce too much ${ }^{13} \mathrm{C}$ and ${ }^{17} \mathrm{O}$ (by factors of $\sim 13$ and 34) and not enough ${ }^{18} \mathrm{O}$ (by a factor of $\sim 5$ ) compared to CK Vul. José et al. (2004) consider also novae with a $\mathrm{NeO}$ white dwarf that produce ${ }^{12} \mathrm{C} /{ }^{13} \mathrm{C}$ ratios close to the value measured in CK Vul but then other isotopic ratios are inconsistent with observations, most importantly the model yields too much ${ }^{15} \mathrm{~N}$ and ${ }^{17} \mathrm{O}$ (by factors of $\sim 50$, and $>78$, respectively). No nova model can explain consistently all isotopic ratios measured in CK Vul; in particular, most nova models do not produce enough ${ }^{18} \mathrm{O}$. It is worth noting that the detection of $\mathrm{Li}$ in the remnant (Hajduk et al. 2013) would be consistent with nova-type nucleosynthesis as ${ }^{7} \mathrm{Li}$ is abundantly produced in nova runaway explosions (Tajitsu et al. 2015). However, the measured $\mathrm{CNO}$ isotopic ratios strongly suggest that the molecular material does not originate from pure nova runaway nucleosynthesis. This adds to a large body of evidence that Nova 1670 was not a classical nova (Kamiński et al. 2015a; Evans et al. 2016).

He burning. We next discuss whether the gas of CK Vul was enriched in products of He burning. Partial He burning of material already processed in $\mathrm{CNO}$ cycles can add ${ }^{12} \mathrm{C}$ and reduce ${ }^{14} \mathrm{~N}$, possibly inverting the $\mathrm{C} / \mathrm{N}$ ratio to values $>1$. It can also lower the ${ }^{16} \mathrm{O} /{ }^{18} \mathrm{O}$ ratio as ${ }^{14} \mathrm{~N}$ is converted to ${ }^{18} \mathrm{O}$ (Iliadis 2007) and increase the abundance of ${ }^{19} \mathrm{~F}$ (Jorissen et al. 1992). Such partial He burning taking place in a merger event between a He- and a $\mathrm{CO}$-white dwarf was introduced to explain very low ${ }^{16} \mathrm{O} /{ }^{18} \mathrm{O}$ ratios, i.e. 1-20, observed in R Coronae Borealis (RCB) stars (Clayton et al. 2007; Jeffery et al. 2011; Menon et al. 2013). Although this ratio is also very low in CK Vul $(34 \pm 14)$, other chemical signatures of $\mathrm{CK}$ Vul appear to be very different from RCB stars, e.g. RCB stars are $\mathrm{H}$ deficient and typically have relatively high ${ }^{12} \mathrm{C} /{ }^{13} \mathrm{C}$ ratios of $40-100$ (Hema et al. 2012; there are exceptions with ${ }^{12} \mathrm{C} /{ }^{13} \mathrm{C} \approx 3-4$; Rao \& Lambert 2008). Partial He burning is an attractive scenario for CK Vul because it could explain the high abundance of elemental carbon, the presence of fluorine, and the low ratio of ${ }^{16} \mathrm{O} /{ }^{18} \mathrm{O}$. It would have to be activated, however, in astrophysical circumstances different than these proposed for progenitor systems of RCB stars.

CNO ashes as impurities. We next consider if the observed composition can be explained by a mixture of processed and unprocessed material of solar composition. Given the high isotopic ratios of ${ }^{12} \mathrm{C} /{ }^{13} \mathrm{C},{ }^{14} \mathrm{~N} /{ }^{15} \mathrm{~N}$, and ${ }^{16} \mathrm{O} /{ }^{17,}{ }^{18} \mathrm{O}$ in solar composition (Table 2), a dilution of nuclear ashes in unprocessed gas is equivalent to adding mainly ${ }^{16} \mathrm{O},{ }^{14} \mathrm{~N}$, and ${ }^{12} \mathrm{C}$ to the mixture. For both hydrostatic and explosive CNO burning, such an addition would help explain the observed nitrogen and oxygen isotopic ratios but the added unprocessed mass would have to be orders of magnitude higher than the mass of the nuclear products. Also, ${ }^{12} \mathrm{C} /{ }^{13} \mathrm{C}$ would then become much higher (hydrostatic burning) or much lower (explosive burning) than the observed ratio. However, we discuss below nova runaway models whose yields mixed into material of a solar composition give isotopic ratios that are close to these in CK Vul.

Given that only hot CNO cycles can explain the measured ${ }^{14} \mathrm{~N} /{ }^{15} \mathrm{~N}$ ratio and that partial He burning seems to be the only mechanism able to produce a ${ }^{16} \mathrm{O} /{ }^{18} \mathrm{O}$ ratio close to the observed one, we consider a mixture of products of these different nucleosynthesis processes. Such a mixture would be in agreement with the high abundance of elemental carbon and fluorine - originating mainly from He burning - and nitrogen, originating from hot CNO burning (although, the elemental composition of 
CK Vul needs to be verified by observations). Most of ${ }^{17} \mathrm{O}$ would come from the hot $\mathrm{CNO}$ cycles. The observed ratio of carbon isotopes $\left({ }^{12} \mathrm{C} /{ }^{13} \mathrm{C} \approx 3.8\right)$ can be explained if carbon produced in $\mathrm{CNO}$ cycles with ${ }^{12} \mathrm{C} /{ }^{13} \mathrm{C}$ of 0.53 (Eq. (5.86) in Iliadis 2007) ${ }^{6}$ is mixed with ${ }^{12} \mathrm{C}$ from He-burning products that contain no extra ${ }^{13} \mathrm{C}$ (which is destroyed by $\alpha$-capture reactions). Helium burning would have to yield 1.7 times more ${ }^{12} \mathrm{C}$ than $\mathrm{H}$ burning (if no extra admixture of solar-composition material is considered). We therefore conclude that hot $\mathrm{H}$ and partial He burning are very likely to explain the isotopic composition of CK Vul. Identifying the astrophysical scenario in which they were activated is beyond the scope of this paper.

Presolar grains. There is a rare type of $\mathrm{SiC}$ presolar dust grains known as "nova grains" but of unclear origin (e.g. Liu et al. 2016; Nittler \& Hoppe 2005). Their measured isotopic ratios for $\mathrm{C}, \mathrm{N}$, and $\mathrm{Si}$ are remarkably close to these of CK Vul (oxygen is not present in these grains). The best explanation of nova grains seem to be nova runaway events involving hot nucleosynthesis on a massive $\left(>1.2 M_{\odot}\right)$ ONe white dwarf (e.g. Amari et al. 2001; José \& Hernanz 2007). Pure nova ashes give isotopic ratios that are less extreme than those in nova grains but a very good match is achieved by diluting the theoretical nucleosynthesis products with unprocessed material of solar composition. The mixture has to be dominated by the unprocessed material so that only a few percent of the total mass originates from runaway products (e.g. Amari et al. 2001). These models have several problems, though: (i) there is no optimal mixture that can simultaneously reproduce well all of the isotopes; (ii) it is unclear what would be the origin of the unprocessed material and how it would be mixed with the runaway products; and (iii) the mixture would be dominated by O-rich material that should not produce $\mathrm{SiC}$ dust. The very close match between isotopic ratios of nova grains with those of CK Vul is however striking and may provide clues on the true nature of Nova 1670. It appears that the models attempting to explain nova grains in many respects match better the characteristics of CK Vul, which also does not have SiC dust (Evans et al. 2016). The link of CK Vul to nova grains is very intriguing.

Nuclear burning during a merger. From the above discussion, it is clear that the remnant of CK Vul is enhanced in products of helium and CNO hydrogen burning that occurred under unusual, as yet unknown, conditions. Since the observational characteristics of the 1670-73 eruption and its remnant are consistent with a "red nova" (Kato 2003; Tylenda et al. 2013; Kamiński et al. 2015a), we now consider how this thermonuclear burning can be accommodated with the stellar-merger scenario for CK Vul (cf. Sect. 1). The outbursts of red novae are thought to be powered mainly by the gravitational energy of the merging binary (Tylenda \& Soker 2006). However, this does not exclude the possibility that during the collision some nuclear burning takes place. Because stellar mergers involve objects with active nuclear-burning regions, the nuclear reactions can be affected by the coalescence, particularly when the cores of the stars finally merge into one. Admittedly, it is not clear how products of such altered burning could be dispersed into circumstellar environment. What is the contribution of such nuclear burning to the overall energy of red novae eruptions and to the observational appearance of red novae transients are other intriguing and

\footnotetext{
6 The value of 0.53 should be treated here as an example only. Other
} values of the ratio are possible. important problems that need to be addressed in future observational and theoretical studies. However, this would not change the general conclusion that red novae are powered by mergers.

The chemical composition of CK Vul derived here is extraordinary, even among other red novae. Remnants of other red novae, as observed years to decades after their respective eruptions, are all oxygen-rich (i.e. $\mathrm{O} / \mathrm{C}>1$ ), have only minor chemical peculiarities (e.g. V838 Mon has a lithium excess, Kamiński et al. 2009; and V4332 Sgr and V1309 Sco have exceptionally strong bands of CrO, Kamiński et al. 2010, 2015b), and their overall chemical compositions appear close to solar (e.g. Kipper et al. 2004). Their isotopic compositions remain largely unknown but based on the spectra available thus far, they are unlikely to be as extreme as in CK Vul (e.g. Rushton et al. 2005, derived ${ }^{12} \mathrm{C} /{ }^{13} \mathrm{C}>16$ for $\mathrm{V} 838 \mathrm{Mon}$ ), if at all are non-standard. The distinctive chemical composition of the CK Vul's remnant does not necessarily indicate a very different, i.e. other than a merger, origin of this ancient transient. Stellar mergers are expected to occur in many different binary configurations and all across the Hertzsprung-Russell diagram. For instance, V838 Mon was a young (<25 Myr; Afşar \& Bond 2007; Kamiński et al. 2011) triple system (Tylenda et al. 2005) whereas V1309 Sco was an evolved contact binary with both components probably having evolved off the main sequence (Stępień 2011; Tylenda et al. 2011). If CK Vul is a product of a merger, it could have involved stars in yet another configuration and evolutionary phases. Future studies exploring the merger scenario may be able to identify the progenitor system of CK Vul from the extraordinary chemical composition of the remnant.

\section{Summary and main conclusions}

The extraordinary molecular spectrum of CK Vul acquired with single antennas reveals the cool molecular nebula which was most likely dispersed in the 1670-72 eruption. The observations lead to the following conclusions:

- With 27 identified molecules and their associated isotopologues, the molecular remnant of CK Vul is one of the most chemically rich stellar-like objects known to mm-wave astronomy. Only a handful of envelopes of AGB and postAGB stars have higher or comparable number of identified molecules. It is certainly the most chemically-rich environment associated with an eruptive object, although some other red novae are also surrounded by molecular gas of high complexity (Kamiński et al. 2009, 2010, 2015b).

- The kinematics of the remnant traced in single-antenna line profiles is very complex and requires interferometric imaging for a full disclosure of its multiple components. Different molecules are associated with different kinematical components indicating that the chemical composition of the gas may vary across the remnant.

- The excitation temperatures of the molecular gas are of 3$12 \mathrm{~K}$ and may imply a kinetic temperature of about $12 \mathrm{~K}$ for the remnant regions that give rise to the most intense molecular emission. Radiative losses and adiabatic expansion can be responsible for effective cooling of the molecular remnant since the 1670-72 eruption.

- The chemical and elemental compositions of the remnant are very peculiar. The molecular inventory includes a myriad of C-bearing species typical for carbon stars, a great abundance of N-bearing species, and several oxides which are never observed in carbon stars. CK Vul's chemistry cannot be categorized with the known classifications. It appears that carbon 
is the most abundant among the CNO elements but this finding requires further study. Nitrogen and fluorine appear enhanced, but the evidence is only circumstancial.

- The remnant contains various polyatomic organic molecules whose emission lines are particularly apparent in the $\mathrm{mm}$ wave spectra and were not seen in the submm-wave spectra analyzed in Kamiński et al. (2015a). The origin of these complex species in CK Vul is not understood but their formation requires ion chemistry or reactions on icy grain mantles.

- The two observed ions, $\mathrm{HCO}^{+}$and $\mathrm{N}_{2} \mathrm{H}^{+}$, indicate the presence of a photo-ionization source in the remnant. With the current data, we are unable to distinguish whether the ionization is caused by the central stellar source or strong shocks.

- We derive isotopic ratios for five elements at a higher accuracy than in Kamiński et al. (2015a). No standard stellar-nucleosynthesis scenario can explain these ratios but the observed material was very likely processed in hot CNO cycles and partial and rapid He burning. Further studies are necessary to investigate the relation of these nucleosynthesis signatures to the outburst of CK Vul, including the stellarmerger scenario.

- The isotopic ratios of CK Vul are very unusual and are close to these measured in presolar nova grains. Deeper investigation of the link may explain the nature of Nova 1670 or origin of nova grains.

Prospects. The current study determines the direction of future more detailed modeling and observational efforts. Decoding the remnant's chemistry and deriving better isotopic ratios is possible if detailed interferometric mapping is performed and a 3-dimensional radiative-transfer code is used to take into account the complex structure of CK Vul. Such efforts are pending and include observations from the NOEMA and ALMA arrays. They will allow us to look for spatial variations of the isotopic ratios and investigate the role of fractionation on the isotopic abundances. In parallel, the spatio-kinematical structure of the ionized and molecular regions should be investigated to understand better the dynamics of the remnant and establish dynamical ages of its components. This will shed light on the history of the remnant and its chemical composition, bringing us closer to solving the CK Vul puzzle.

Acknowledgements. We thank Alexander Breier for providing us with a line lis of ${ }^{32} \mathrm{SiO}$ and Jan-Martin Winters for reading and commenting on the manuscript. Based on observations made with IRAM $30 \mathrm{~m}$ and APEX telescopes. IRAM observations were carried out under project numbers 183-14, 161-15, and D07-14 with the IRAM $30 \mathrm{~m}$ Telescope. IRAM is supported by INSU/CNRS (France), MPG (Germany) and IGN (Spain). The IRAM observations were supported by funding from the European Commission Seventh Framework Programme (FP/2007-2013) under grant agreement No. 283393 (RadioNet3). Part of APEX data were collected under the programs 095.F-9543(A) and 296.D-5009(A). APEX is a collaboration between the Max-Planck-Institut für Radioastronomie, the European Southern Observatory, and the Onsala Space Observatory. Analysis was partly carried out with the CASSIS software. CASSIS has been developed by IRAP-UPS/CNRS.

\section{References}

Afșar, M., \& Bond, H. E. 2007, AJ, 133, 387

Amari, S., Gao, X., Nittler, L. R., et al. 2001, ApJ, 551, 1065

Arnould, M., Goriely, S., \& Jorissen, A. 1999, A\&A, 347, 572

Billade, B., Nystrom, O., Meledin, D., et al. 2012, IEEE Trans. Terahertz Sci. Techn., 2, 208

Bohigas, J. 2017, MNRAS, 466, 1412

Bujarrabal, V., Gomez-Gonzalez, J., Bachiller, R., \& Martin-Pintado, J. 1988 A\&A, 204, 242

Carter, M., Lazareff, B., Maier, D., et al. 2012, A\&A, 538, A89
Castro-Carrizo, A., Bujarrabal, V., Sánchez Contreras, C., Sahai, R., \& Alcolea, J. 2005, A\&A, 431, 979

Cernicharo, J., Guélin, M., \& Kahane, C. 2000, A\&AS, 142, 181

Cherchneff, I. 2006, A\&A, 456, 1001

Clayton, G. C., Geballe, T. R., Herwig, F., Fryer, C., \& Asplund, M. 2007, ApJ, 662,1220

Cohen, J. G. 1985, ApJ, 292, 90

Coutens, A., Rawlings, J. M. C., Viti, S., \& Williams, D. A. 2017, MNRAS, 467, 737

Downes, R., Webbink, R. F., \& Shara, M. M. 1997, PASP, 109, 345

Evans, A., van Loon, J. T., Zijlstra, A. A., et al. 2002, MNRAS, 332, L35

Evans, A., Gehrz, R. D., Woodward, C. E., et al. 2016, MNRAS, 457, 2871

Goldsmith, P. F., \& Langer, W. D. 1999, ApJ, 517, 209

Güsten, R., Nyman, L. A., Schilke, P., et al. 2006, A\&A, 454, L13

Hajduk, M., Zijlstra, A. A., van Hoof, P. A. M., et al. 2007, MNRAS, 378, 1298

Hajduk, M., van Hoof, P. A. M., \& Zijlstra, A. A. 2013, MNRAS, 432, 167

Harrison, T. E. 1996, PASP, 108, 1112

Hartquist, T. W., Menten, K. M., Lepp, S., \& Dalgarno, A. 1995, MNRAS, 272, 184

Hema, B. P., Pandey, G., \& Lambert, D. L. 2012, ApJ, 747, 102

Hevelius, J. 1671, Philos. Trans. R. Soc. London, Ser. I, 6, 2197

Highberger, J. L., Savage, C., Bieging, J. H., \& Ziurys, L. M. 2001, ApJ, 562, 790

Iliadis, C. 2007, Nuclear Physics of Stars (Wenheim, Germany: Wiley-VCH Verlag)

Jeffery, C. S., Karakas, A. I., \& Saio, H. 2011, MNRAS, 414, 3599

José, J. 2002, Classical Nova Explosions, 637, 104

José, J., \& Hernanz, M. 2007, Meteor. Planet. Sci., 42, 1135

José, J., Hernanz, M., Amari, S., Lodders, K., \& Zinner, E. 2004, ApJ, 612, 414

Jorissen, A., Smith, V. V., \& Lambert, D. L. 1992, A\&A, 261, 164

Kamiński, T., Schmidt, M., Tylenda, R., Konacki, M., \& Gromadzki, M. 2009, ApJS, 182, 33

Kamiński, T., Schmidt, M., \& Tylenda, R. 2010, A\&A, 522, A75

Kamiński, T., Tylenda, R., \& Deguchi, S. 2011, A\&A, 529, A48

Kamiński, T., Gottlieb, C. A., Young, K. H., Menten, K. M., \& Patel, N. A. 2013, ApJS, 209, 38

Kamiński, T., Menten, K. M., Tylenda, R., et al. 2015a, Nature, 520, 322

Kamiński, T., Mason, E., Tylenda, R., \& Schmidt, M. R. 2015b, A\&A, 580, A34

Kasemann, C., Güsten, R., Heyminck, S., et al. 2006, Proc. SPIE, 6275

Kato, T. 2003, A\&A, 399, 695

Kipper, T., Klochkova, V. G., Annuk, K., et al. 2004, A\&A, 416, 1107

Klein, B., Hochgürtel, S., Krämer, I., et al. 2012, A\&A, 542, L3

Klein, T., Ciechanowicz, T., Leinz, Ch. M., et al. 2014, IEEE Trans. Terahertz Sci. Technol., 4, 588

Liu, N., Nittler, L. R., O’D. Alexander, C. M., et al. 2016, ApJ, 820, 140

Lodders, K. 2003, ApJ, 591, 1220

Menon, A., Herwig, F., Denissenkov, P. A., et al. 2013, ApJ, 772, 59

Mamon, G. A., Glassgold, A. E., \& Omont, A. 1987, ApJ, 323, 306

Marka, C., Kramer, C., Navarro, S., \& John, D. 2015, Report on E150 image band rejections V3.0, http://www.iram.es/IRAMES/mainWiki/ EmirforAstronomers\#Reports_and_publications

Marty, B., Chaussidon, M., Wiens, R. C., Jurewicz, A. J. G., \& Burnett, D. S. 2011, Science, 332, 1533

Miller Bertolami, M. M., Althaus, L. G., Olano, C., \& Jiménez, N. 2011, MNRAS, 415, 1396

Motiyenko, R. A., Margulès, L., Ilyushin, V. V., et al. 2016, A\&A, 587, A152

Müller, H. S. P., Thorwirth, S., Roth, D. A., \& Winnewisser, G. 2001, A\&A, 370, L49

Müller, H. S. P., Schlöder, F., Stutzki, J., \& Winnewisser, G. 2005, J. Mol. Struct., 742,215

Naylor, T., Charles, P. A., Mukai, K., \& Evans, A. 1992, MNRAS, 258, 449

Nittler, L. R., \& Hoppe, P. 2005, ApJ, 631, L89

Pardo, J. R., Cernicharo, J., \& Serabyn, E. 2001, IEEE Trans. Antennas Propag., 49, 1683

Pardo, J. R., Cernicharo, J., Goicoechea, J. R., Guélin, M., \& Asensio Ramos, A. 2007, ApJ, 661, 250

Pearson, E. F., Creswell, R. A., Winnewisser, M., \& Winnewisser, G. 1976, Z. Natur. Teil A, 31, 1394

Pickett, H. M., Poynter, R. L., Cohen, E. A., et al. 1998, J. Quant. Spectr. Rad. Transf., 60, 883

Plume, R., Jaffe, D. T., Tatematsu, K., Evans, N. J., II, \& Keene, J. 1999, ApJ, 512, 768

Pulliam, R. L., Edwards, J. L., \& Ziurys, L. M. 2011, ApJ, 743, 36

Rao, N. K., \& Lambert, D. L. 2008, MNRAS, 384, 477

Quintana-Lacaci, G., Agúndez, M., Cernicharo, J., et al. 2013, A\&A, 560, L2

Rodriguez Kuiper, E. N., Kuiper, T. B. H., Kakar, R. K., \& Zuckerman, B. 1977, ApJ, 214, 394

Roueff, E., Loison, J. C., \& Hickson, K. M. 2015, A\&A, 576, A99 
Rushton, M. T., Geballe, T. R., Filippenko, A. V., et al. 2005, MNRAS, 360, 1281

Sahai, R., \& Nyman, L.-Å. 1997, ApJ, 487, L155

Sánchez Contreras, C., Velilla Prieto, L., Agúndez, M., et al. 2015, A\&A, 577, A52

Schöier, F. L., Olofsson, H., \& Lundgren, A. A. 2006, A\&A, 454, 247

Shara, M. M., \& Moffat, A. F. J. 1982, ApJ, 258, L41

Shara, M. M., Moffat, A. F. J., \& Webbink, R. F. 1985, ApJ, 294, 271

Sievers, A., John, D., Navarro, S., \& Kramer, C. 2015, Report on suppression of E150 ghost lines after installation of an LO filter, V1.2, http://www.iram.es/IRAMES/mainWiki/EmirforAstronomers\# Reports_and_publications

Soker, N., \& Tylenda, R. 2003, ApJ, 582, L105

Spitzer, L. 1978, in Physical Processes in the Interstellar (New York: Wiley-Interscience)

Stępień, K. 2011, A\&A, 531, A18
Tajitsu, A., Sadakane, K., Naito, H., Arai, A., \& Aoki, W. 2015, Nature, 518, 381 Tenenbaum, E. D., Dodd, J. L., Milam, S. N., Woolf, N. J., \& Ziurys, L. M. 2010 ApJS, 190, 348

Terzieva, R., \& Herbst, E. 2000, MNRAS, 317, 563

Tylenda, R. 2005, A\&A, 436, 1009

Tylenda, R., \& Soker, N. 2006, A\&A, 451, 223

Tylenda, R., Soker, N., \& Szczerba, R. 2005, A\&A, 441, 1099

Tylenda, R., Hajduk, M., Kamiński, T., et al. 2011, A\&A, 528, A114

Tylenda, R., Kamiński, T., Udalski, A., et al. 2013, A\&A, 555, A16

Vassilev, V., Meledin, D., Lapkin, I., et al. 2008, A\&A, 490, 1157

Vastel, C., 2014, Formalism for the CASSIS Software, http: //cassis.irap. omp.eu/docs/RadiativeTransfer.pdf

Watanabe, N., \& Kouchi, A. 2002, ApJ, 571, L173

Zhang, Y. 2016, arXiv e-prints [arXiv: 1611.03593]

Zhang, Y., Kwok, S., \& Dinh-V-Trung 2008, ApJ, 678, 328

Ziurys, L. M., Apponi, A. J., \& Phillips, T. G. 1994, ApJ, 433, 729 


\section{Appendix A: Observation logs}

Table A.1. Details of APEX observations of CK Vul.

\begin{tabular}{|c|c|c|c|c|c|c|c|}
\hline $\begin{array}{c}\text { Central } \\
\text { Freq. } \\
\text { (MHz) }\end{array}$ & $\begin{array}{l}T_{\text {sys }} \\
(\mathrm{K}) \\
\end{array}$ & $\begin{array}{c}\text { Time on } \\
\text { source } \\
(\min )\end{array}$ & $\begin{array}{c}\text { Bandwidth } \\
(\mathrm{GHz})\end{array}$ & $\begin{array}{c}\mathrm{rms}^{a} \\
T_{\mathrm{A}}^{*} \\
(\mathrm{mK}) \\
\end{array}$ & $\eta_{\mathrm{mb}}$ & $\begin{array}{c}\text { Beam } \\
F W H M \\
\left({ }^{\prime \prime}\right)\end{array}$ & $\begin{array}{c}\text { Observation } \\
\text { dates }\end{array}$ \\
\hline $171311.9^{b}$ & 141 & 23.8 & 4.0 & 1.2 & 0.78 & 36.4 & 6-Jun.-2015 \\
\hline 172811.8 & 142 & 20.8 & 4.0 & 1.2 & 0.78 & 36.1 & 6-Jun.-2015 \\
\hline $183310.1^{b}$ & 915 & 23.8 & 4.0 & 7.7 & 0.77 & 34.0 & 6-Jun.-2015 \\
\hline $184810.0^{b}$ & 540 & 20.8 & 4.0 & 6.9 & 0.77 & 33.8 & 6-Jun.-2015 \\
\hline 187400.3 & 293 & 415.8 & 4.0 & 0.6 & 0.77 & 33.3 & 4, 5, 6, 7-Nov.-2015, 9, 10, 11-Apr.-2016 \\
\hline 199400.0 & 162 & 415.8 & 4.0 & 0.3 & 0.76 & 31.3 & 4, 5, 6, 7-Nov.-2015, 9, 10, 11-Apr.-2016 \\
\hline 218800.0 & 151 & 39.7 & 4.0 & 1.0 & 0.75 & 28.5 & 9-May-2014 \\
\hline $226739.6^{b, c}$ & 183 & 15.1 & 4.0 & 3.7 & 0.75 & 27.5 & 5-May-2014 \\
\hline 230538.0 & 183 & 12.8 & 4.0 & 3.5 & 0.75 & 27.1 & 4, 5-Маy-2014 \\
\hline 243100.0 & 177 & 41.6 & 4.0 & 19.8 & 0.74 & 25.7 & 9-Jun.-2015 \\
\hline $259011.8^{b}$ & 258 & 93.5 & 4.0 & 1.0 & 0.73 & 24.1 & 5, 9, 10-Мay-2014 \\
\hline $262900.0^{b}$ & 293 & 58.0 & 4.0 & 27.4 & 0.73 & 23.7 & 4-Jun.-2015 \\
\hline 266721.9 & 268 & 5.5 & 4.0 & 3.9 & 0.73 & 23.4 & 5-Маy-2014 \\
\hline 271981.0 & 225 & 97.1 & 4.0 & 0.9 & 0.73 & 22.9 & 18, 19-Jul.-2017 \\
\hline $280500.0^{b}$ & 156 & 53.4 & 4.0 & 0.7 & 0.72 & 22.2 & 8-May-2014, 9-Jul.-2014 \\
\hline $283979.7^{b}$ & 217 & 97.1 & 4.0 & 0.8 & 0.72 & 22.0 & 18, 19-Jul.-2017 \\
\hline 287364.0 & 162 & 26.1 & 4.0 & 1.1 & 0.72 & 21.7 & 19-Мау-2014 \\
\hline $292498.5^{b}$ & 155 & 53.4 & 4.0 & 0.7 & 0.72 & 21.3 & 8-May-2014, 9-Jul.-2014 \\
\hline $293701.8^{b}$ & 201 & 26.8 & 4.0 & 34.9 & 0.72 & 21.2 & 5-Jun.-2015 \\
\hline $293801.8^{b}$ & 193 & 11.9 & 4.0 & 52.4 & 0.72 & 21.2 & 5-Jun.-2015 \\
\hline $296601.8^{b}$ & 197 & 23.9 & 4.0 & 36.4 & 0.72 & 21.0 & 5-Jun.-2015 \\
\hline $299362.5^{b}$ & 154 & 26.1 & 4.0 & 0.9 & 0.72 & 20.8 & 19-May-2014 \\
\hline 305700.0 & 202 & 26.8 & 4.0 & 38.0 & 0.71 & 20.4 & 5-Jun.-2015 \\
\hline $305800.0^{b}$ & 193 & 11.9 & 4.0 & 52.9 & 0.71 & 20.4 & 5-Jun.-2015 \\
\hline $308600.0^{b}$ & 204 & 23.9 & 4.0 & 40.1 & 0.71 & 20.2 & 5-Jun.-2015 \\
\hline $330588.0^{b}$ & 393 & 21.9 & 4.0 & 2.6 & 0.70 & 18.9 & 8-May-2014 \\
\hline $333797.5^{b}$ & 240 & 14.0 & 4.0 & 2.3 & 0.70 & 18.7 & 6-May-2014 \\
\hline $336301.5^{b}$ & 186 & 40.0 & 4.0 & 0.9 & 0.70 & 18.6 & 6, 8, 14-Мау-2014 \\
\hline 340247.8 & 192 & 22.4 & 4.0 & 1.5 & 0.70 & 18.3 & 6-May-2014, 9-Jul.-2014 \\
\hline $342586.4^{b}$ & 266 & 21.9 & 4.0 & 1.9 & 0.69 & 18.2 & 8-May-2014 \\
\hline $343601.5^{b}$ & 196 & 44.1 & 4.0 & 1.4 & 0.69 & 18.2 & 6, 14, 15-Мау-2014 \\
\hline $345796.0^{b}$ & 228 & 14.0 & 4.0 & 2.6 & 0.69 & 18.0 & 6-Мay-2014 \\
\hline $348300.0^{b}$ & 196 & 40.0 & 4.0 & 1.0 & 0.69 & 17.9 & 6, 8, 14-Мay-2014 \\
\hline $352246.3^{b}$ & 237 & 22.4 & 4.0 & 1.4 & 0.69 & 17.7 & 6, 9-Jul.-2014 \\
\hline 355600.0 & 228 & 44.1 & 4.0 & 1.3 & 0.69 & 17.5 & $6,14,15-$ Мay-2014 \\
\hline $392500.0^{b}$ & 870 & 64.1 & 4.0 & 74.6 & 0.67 & 15.9 & 5-Jun.-2015 \\
\hline 393749.9 & 545 & 28.4 & 4.0 & 2.4 & 0.67 & 15.8 & 9-Jul.-2014 \\
\hline 398306.3 & 484 & 56.4 & 4.0 & 1.4 & 0.67 & 15.7 & 14, 15-Мау-2014 \\
\hline $403086.0^{b}$ & 452 & 14.2 & 4.0 & 3.1 & 0.67 & 15.5 & 9-Jul.-2014 \\
\hline $404498.2^{b}$ & 575 & 64.1 & 4.0 & 42.6 & 0.66 & 15.4 & 5-Jun.-2015 \\
\hline $405748.8^{b}$ & 416 & 28.4 & 4.0 & 1.9 & 0.66 & 15.4 & 9-Jul.-2014 \\
\hline $407963.5^{b}$ & 442 & 26.1 & 4.0 & 2.6 & 0.66 & 15.3 & 19-May-2014 \\
\hline 410304.8 & 449 & 56.4 & 4.0 & 1.5 & 0.66 & 15.2 & 14, 15-Мау-2014 \\
\hline 415085.0 & 449 & 14.2 & 4.0 & 2.7 & 0.66 & 15.0 & 9-Jul.-2014 \\
\hline 419962.0 & 610 & 26.1 & 4.0 & 3.5 & 0.66 & 14.9 & 19-Мау-2014 \\
\hline 428766.7 & 1165 & 40.4 & 4.0 & 8.1 & 0.65 & 14.6 & 6, 8-Маy-2014 \\
\hline 440765.2 & 5137 & 40.4 & 4.0 & 29.7 & 0.65 & 14.2 & 6, 8-Мау-2014 \\
\hline 461040.8 & 1085 & 48.0 & 4.0 & 4.8 & 0.64 & 13.5 & 6, 8-Мау-2014 \\
\hline 473039.2 & 4949 & 48.0 & 4.0 & 36.9 & 0.63 & 13.2 & 6, 8-Мау-2014 \\
\hline 479201.5 & 1186 & 7.9 & 4.0 & 10.8 & 0.63 & 13.0 & 6-May-2014 \\
\hline $491200.0^{b}$ & 1659 & 7.9 & 4.0 & 17.3 & 0.62 & 12.7 & 6-May-2014 \\
\hline 492160.0 & 992 & 97.1 & 4.0 & 2.8 & 0.62 & 12.7 & 18, 19-Jul.-2017 \\
\hline 691473.1 & 2728 & 88.3 & 2.9 & 4.9 & 0.53 & 9.0 & 17-May-2014 \\
\hline 806651.8 & 6236 & 8.2 & 2.9 & 36.2 & 0.47 & 7.7 & 17-May-2014 \\
\hline 909158.8 & 17593 & 80.1 & 2.9 & 42.9 & 0.42 & 6.9 & 17-May-2014 \\
\hline
\end{tabular}

Notes. Only observations longer than 5 min are listed. ${ }^{(a)}$ The rms noise level per $40 \mathrm{~km} \mathrm{~s}^{-1}$ bin. ${ }^{(b)}$ Spectral range overlaps with the next setup in the table. ${ }^{(c)}$ The higher-frequency half of the spectrum was severely affected by bad performance of the receiver. 
Table A.2. Same as Table A.1 but for IRAM $30 \mathrm{~m}$ observations.

\begin{tabular}{|c|c|c|c|c|c|c|c|}
\hline $\begin{array}{l}\text { Central } \\
\text { Freq. } \\
\text { (MHz) }\end{array}$ & $\begin{array}{l}T_{\text {sys }} \\
(\mathrm{K})\end{array}$ & $\begin{array}{c}\text { Time on } \\
\text { source } \\
\text { (min) }\end{array}$ & $\begin{array}{c}\text { Bandwidth } \\
\text { (GHz) }\end{array}$ & $\begin{array}{c}\mathrm{rms}^{a} \\
T_{\mathrm{A}}^{*} \\
(\mathrm{mK})\end{array}$ & $\eta_{\mathrm{mb}}$ & $\begin{array}{c}\text { Beam } \\
F W H M \\
{ }^{\left({ }^{\prime \prime}\right)}\end{array}$ & $\begin{array}{c}\text { Observation } \\
\text { dates }\end{array}$ \\
\hline $79587.0^{b}$ & 99 & 184.6 & 7.8 & 0.5 & 0.88 & 30.8 & 18-May-2016 \\
\hline $85888.0^{b}$ & 112 & 26.6 & 7.8 & 1.3 & 0.87 & 28.5 & 11-Aug.-2015 \\
\hline $86036.7^{b}$ & 143 & 86.1 & 7.8 & 0.9 & 0.87 & 28.4 & 11-Aug.-2015 \\
\hline $86886.9^{b}$ & 75 & 98.9 & 7.8 & 0.4 & 0.87 & 28.1 & 8-Мay-2015 \\
\hline $89288.8^{b}$ & 72 & 134.0 & 7.8 & 0.4 & 0.86 & 27.4 & 22-Feb.-2015 \\
\hline $95267.0^{b}$ & 108 & 184.6 & 7.8 & 0.5 & 0.85 & 24.8 & 18-May-2016 \\
\hline $95911.8^{b}$ & 76 & 119.3 & 7.8 & 0.4 & 0.85 & 24.6 & 22-Feb.-2015 \\
\hline $101563.3^{b}$ & 130 & 26.6 & 7.8 & 1.4 & 0.84 & 23.3 & 11-Aug.-2015 \\
\hline $101714.5^{b}$ & 172 & 86.1 & 7.8 & 1.2 & 0.84 & 23.2 & 11-Aug.-2015 \\
\hline $102565.6^{b}$ & 82 & 98.9 & 7.8 & 0.4 & 0.84 & 23.0 & 8-May-2015 \\
\hline $104961.8^{b}$ & 83 & 134.0 & 7.8 & 0.3 & 0.83 & 22.5 & 22-Feb.-2015 \\
\hline 111582.8 & 112 & 119.3 & 7.8 & 0.5 & 0.83 & 21.8 & 22-Feb.-2015 \\
\hline $130589.4^{b}$ & 100 & 62.6 & 7.8 & 0.6 & 0.80 & 18.6 & 7-May-2015 \\
\hline $138419.3^{b}$ & 78 & 70.3 & 7.8 & 0.4 & 0.79 & 17.5 & 8-May-2015 \\
\hline $146260.5^{b}$ & 107 & 62.6 & 7.8 & 0.6 & 0.77 & 16.2 & 7-May-2015 \\
\hline $151180.2^{b}$ & 101 & 65.8 & 7.8 & 0.5 & 0.77 & 16.0 & 7-May-2015 \\
\hline $154099.7^{b}$ & 88 & 70.3 & 7.8 & 0.5 & 0.76 & 15.4 & 8-May-2015 \\
\hline $158405.7^{b}$ & 98 & 16.7 & 7.8 & 1.2 & 0.75 & 15.0 & 6-May-2015 \\
\hline 158904.3 & 104 & 85.9 & 7.8 & 0.5 & 0.75 & 15.0 & 6-May-2015 \\
\hline $166850.3^{b}$ & 133 & 65.8 & 7.8 & 0.6 & 0.74 & 14.2 & 7-May-2015 \\
\hline $174089.6^{b}$ & 158 & 16.7 & 7.8 & 2.0 & 0.73 & 13.9 & 6-May-2015 \\
\hline 174578.3 & 168 & 85.9 & 7.8 & 0.8 & 0.73 & 13.9 & 6-May-2015 \\
\hline $234405.8^{b}$ & 179 & 158.9 & 7.8 & 0.5 & 0.64 & 10.3 & 12-Jun.-2015, 1-Apr.-2016 \\
\hline $234504.1^{b}$ & 192 & 132.3 & 7.8 & 0.6 & 0.64 & 10.3 & 12-Jun.-2015, 1-Apr.-2016 \\
\hline $236910.9^{b}$ & 252 & 13.2 & 7.8 & 2.1 & 0.63 & 10.2 & 2-Apr.-2016 \\
\hline $237009.3^{b}$ & 275 & 6.6 & 7.8 & 3.1 & 0.63 & 10.2 & 2-Apr.-2016 \\
\hline $237402.7^{b}$ & 293 & 147.9 & 7.8 & 0.6 & 0.63 & 10.2 & 2-Apr.-2016, 19-May-2016 \\
\hline 237501.0 & 212 & 102.9 & 7.8 & 0.8 & 0.63 & 10.2 & 19-May-2016 \\
\hline $250086.8^{b}$ & 196 & 158.9 & 7.8 & 0.7 & 0.61 & 9.5 & 1-Apr.-2016 \\
\hline $250185.3^{b}$ & 210 & 132.3 & 7.8 & 0.6 & 0.61 & 9.5 & 1-Apr.-2016 \\
\hline $252581.7^{b}$ & 280 & 13.2 & 7.8 & 2.7 & 0.60 & 9.4 & 2-Apr.-2016 \\
\hline $252680.2^{b}$ & 303 & 6.6 & 7.8 & 4.0 & 0.60 & 9.4 & 2-Apr.-2016 \\
\hline $253091.0^{b}$ & 328 & 147.9 & 7.8 & 0.7 & 0.60 & 9.4 & 2-Apr.-2016, 19-May-2016 \\
\hline 253189.5 & 229 & 102.9 & 7.8 & 0.6 & 0.60 & 9.4 & 19-May-2016 \\
\hline
\end{tabular}

Notes. ${ }^{(a)}$ The rms noise level per $40 \mathrm{~km} \mathrm{~s}^{-1}$ bin. ${ }^{(b)}$ Spectral range overlaps with the next setup in the table. 


\section{Appendix B: An atlas of IRAM and APEX spectra}
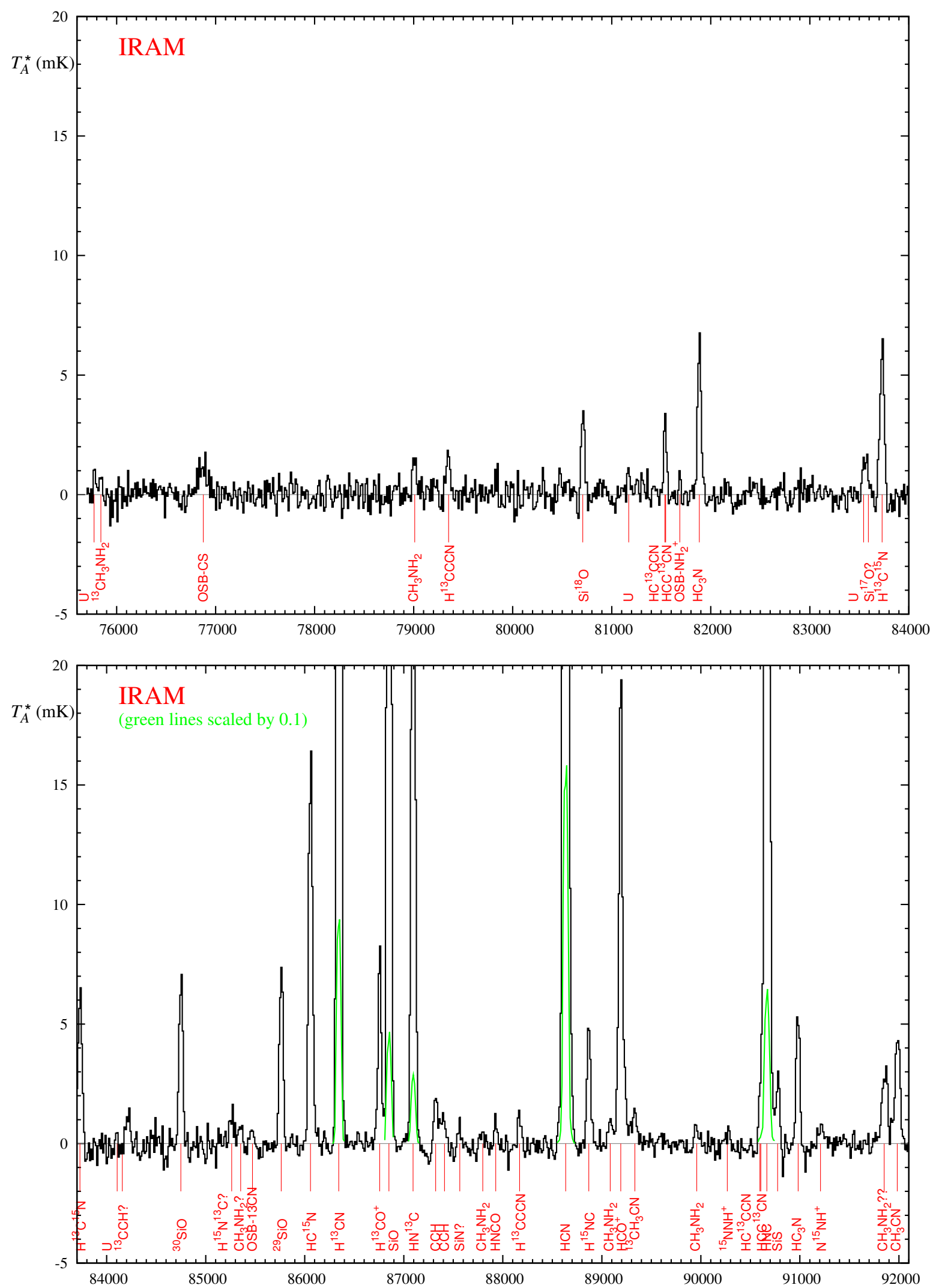

Fig. B.1. IRAM spectra (black) and assigned spectral features. Shown with green line are profiles of bright lines scaled by 0.1 . The spectra are displayed in rest frequency (i.e. are corrected for $V_{\mathrm{LSR}}=-10 \mathrm{~km} \mathrm{~s}^{-1}$ ) in $\mathrm{MHz}$ and in the antenna-temperature scale in $\mathrm{mK}$. 

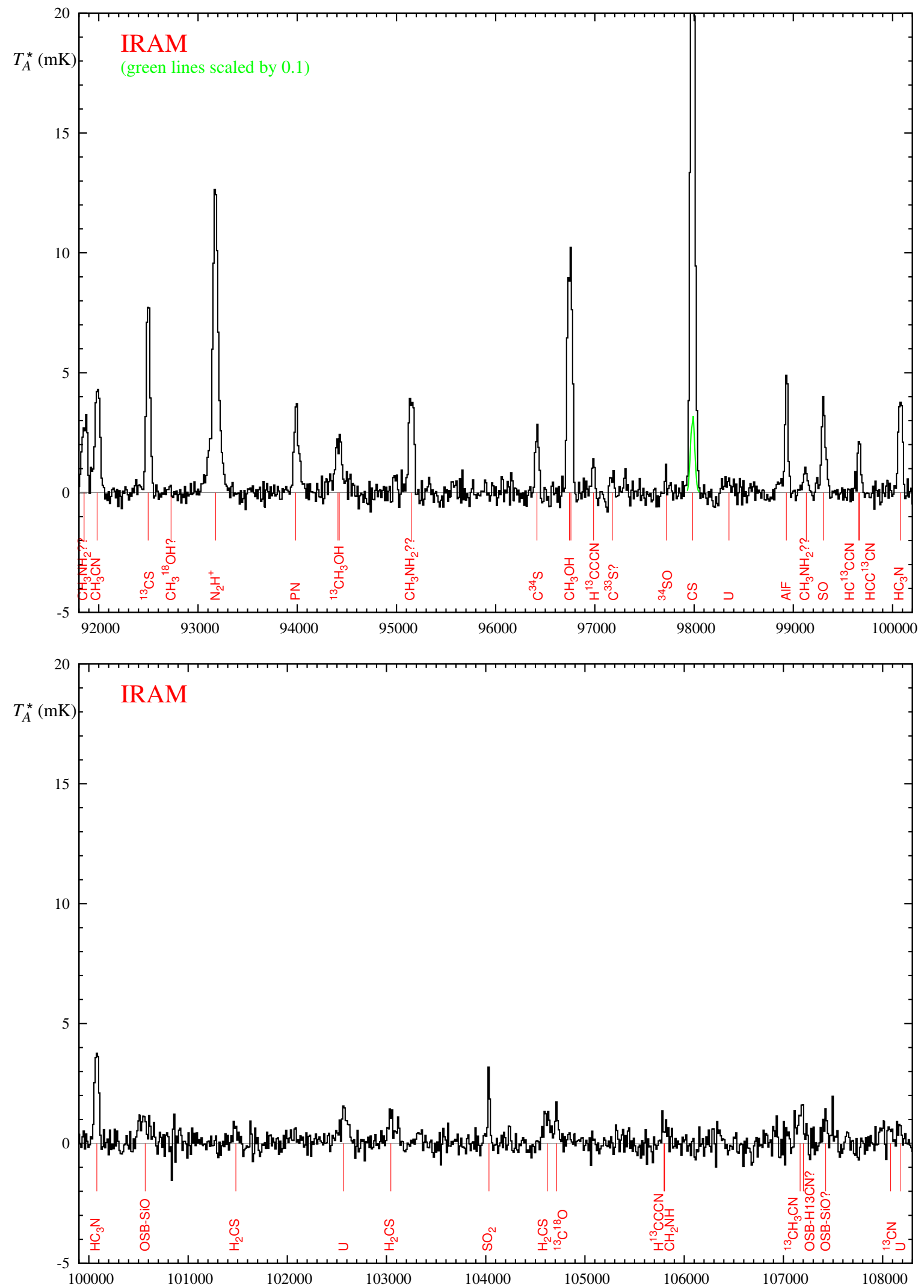

Fig. B.1. continued. 
T. Kamiński et al.: Molecules in CK Vul
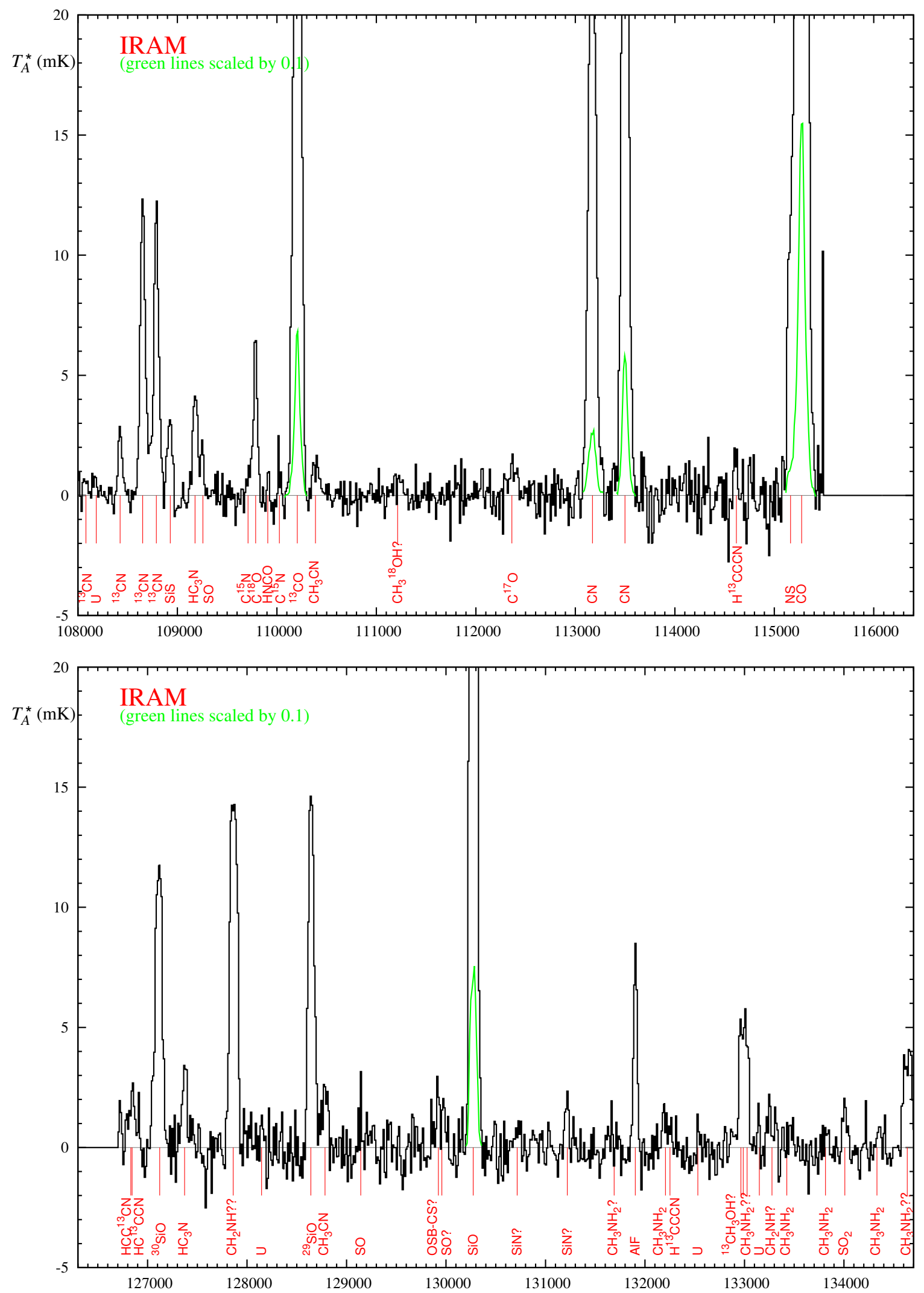

Fig. B.1. continued. 

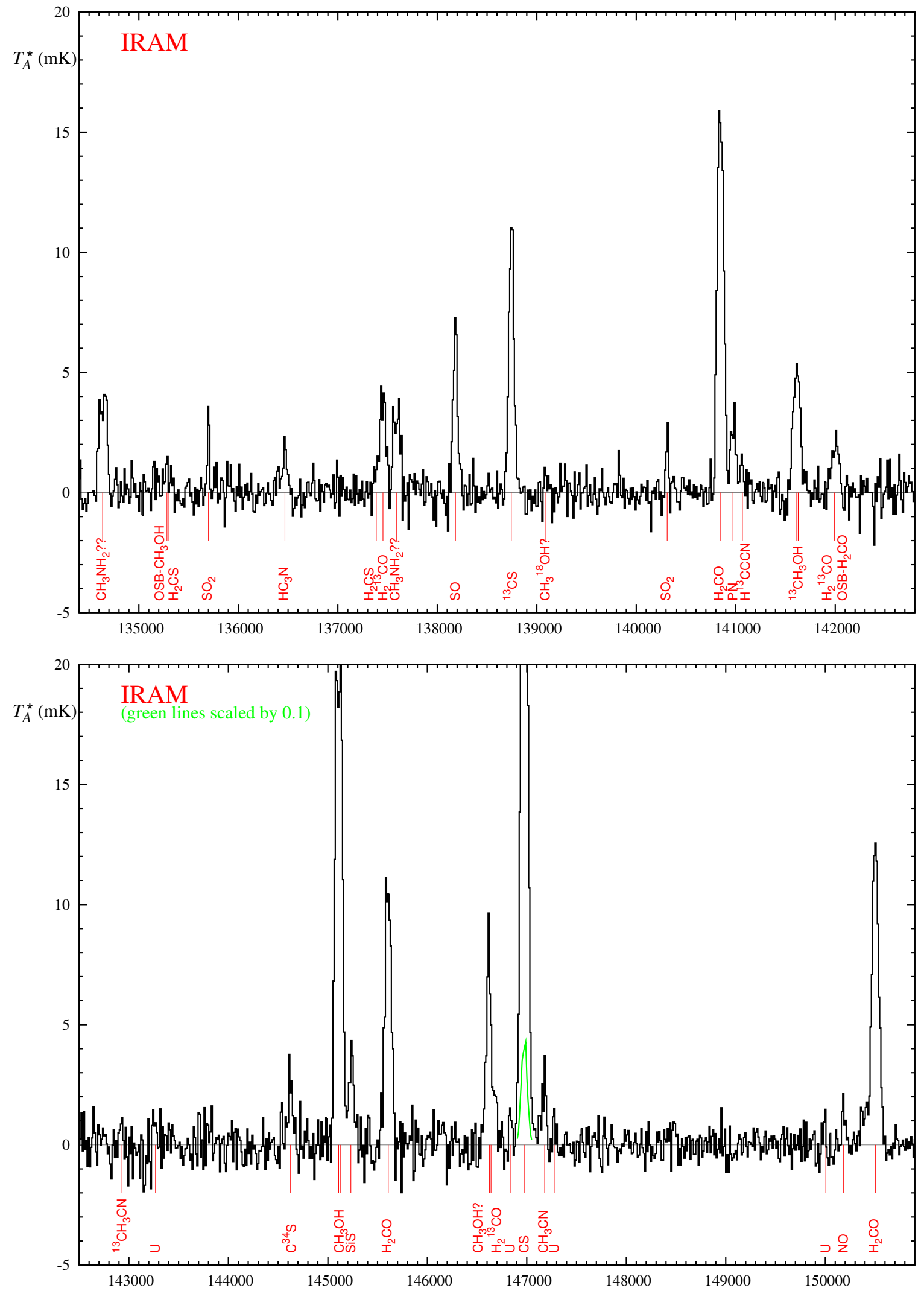

Fig. B.1. continued. 

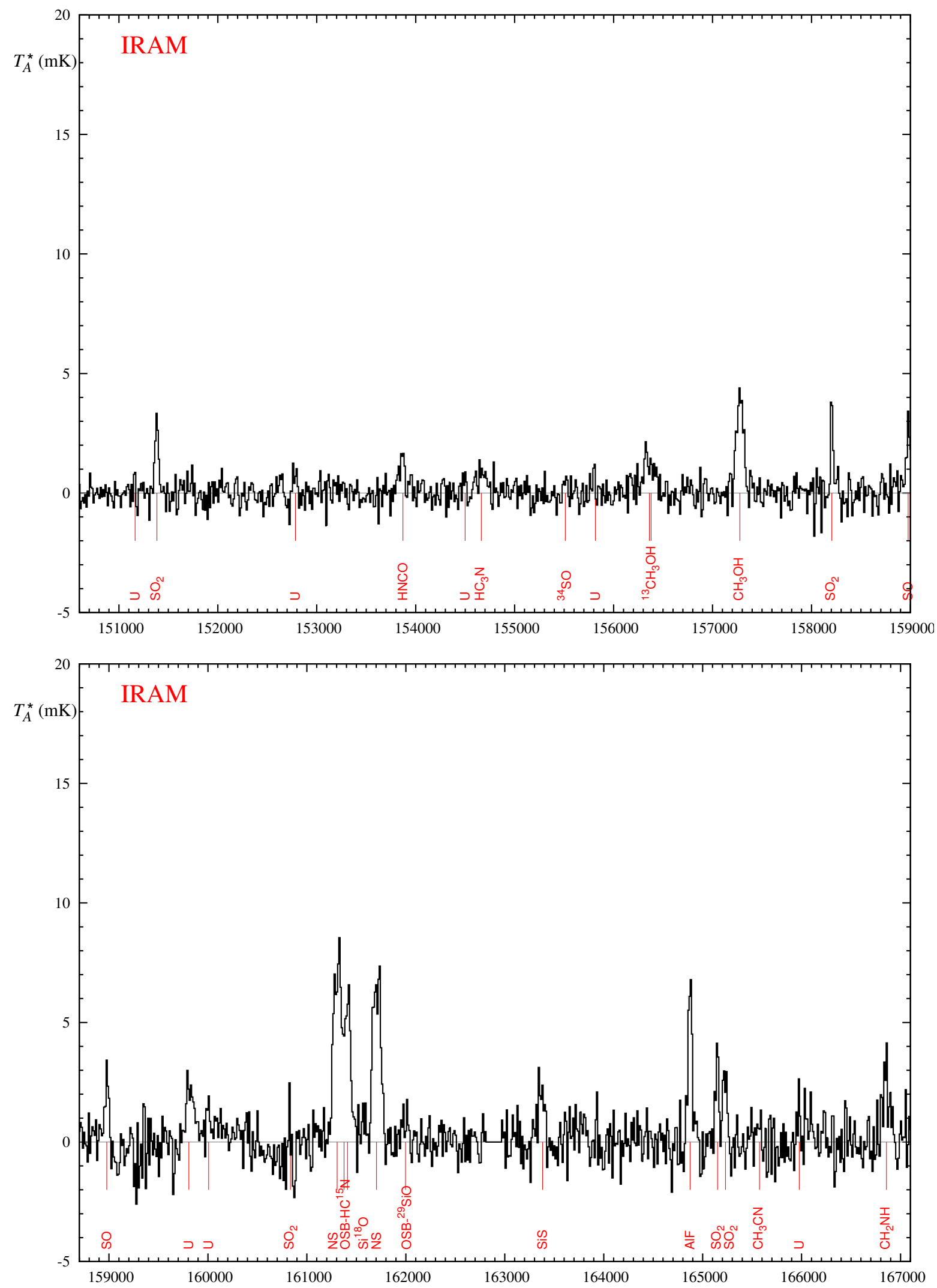

Fig. B.1. continued. 

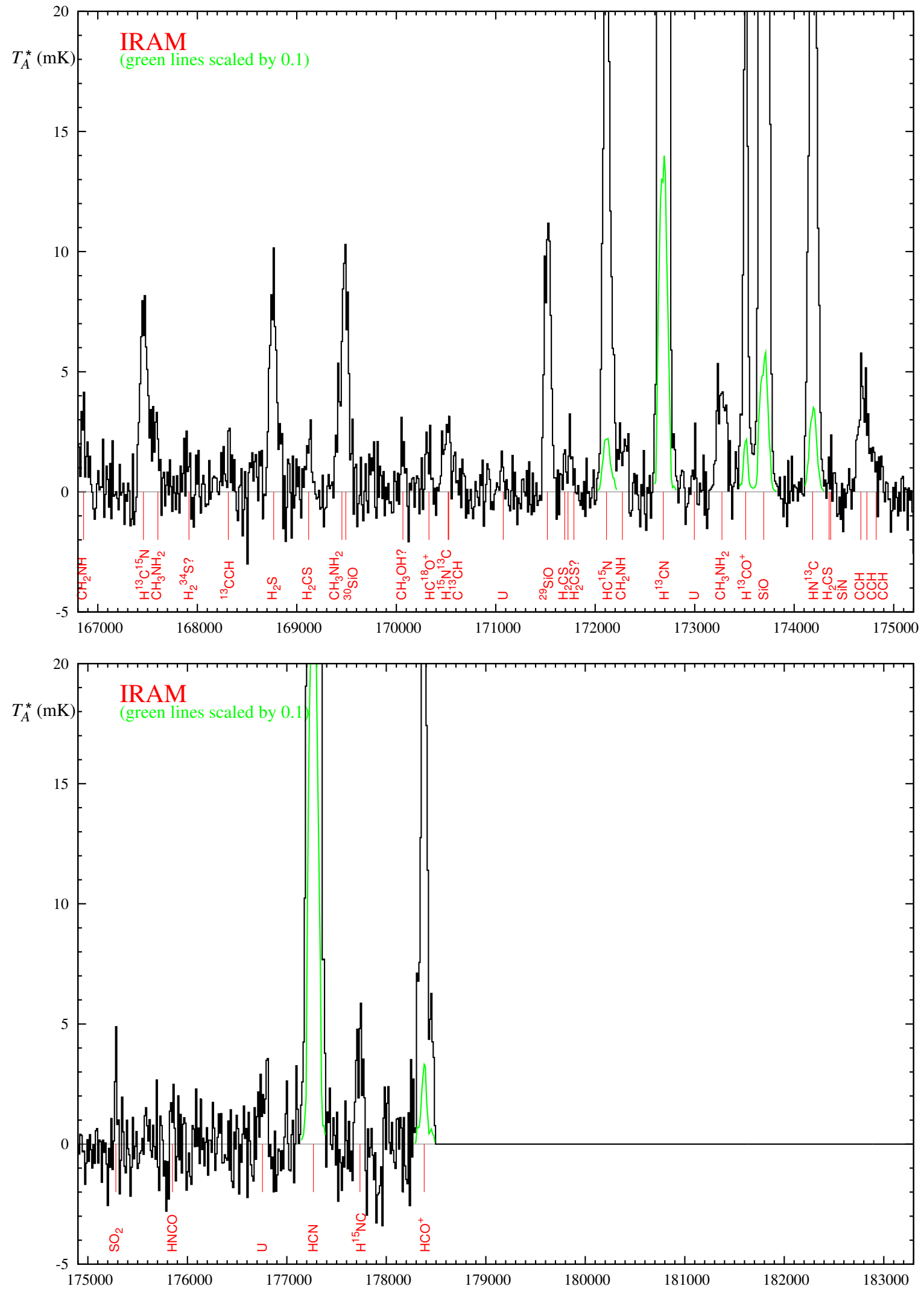

Fig. B.1. continued. 

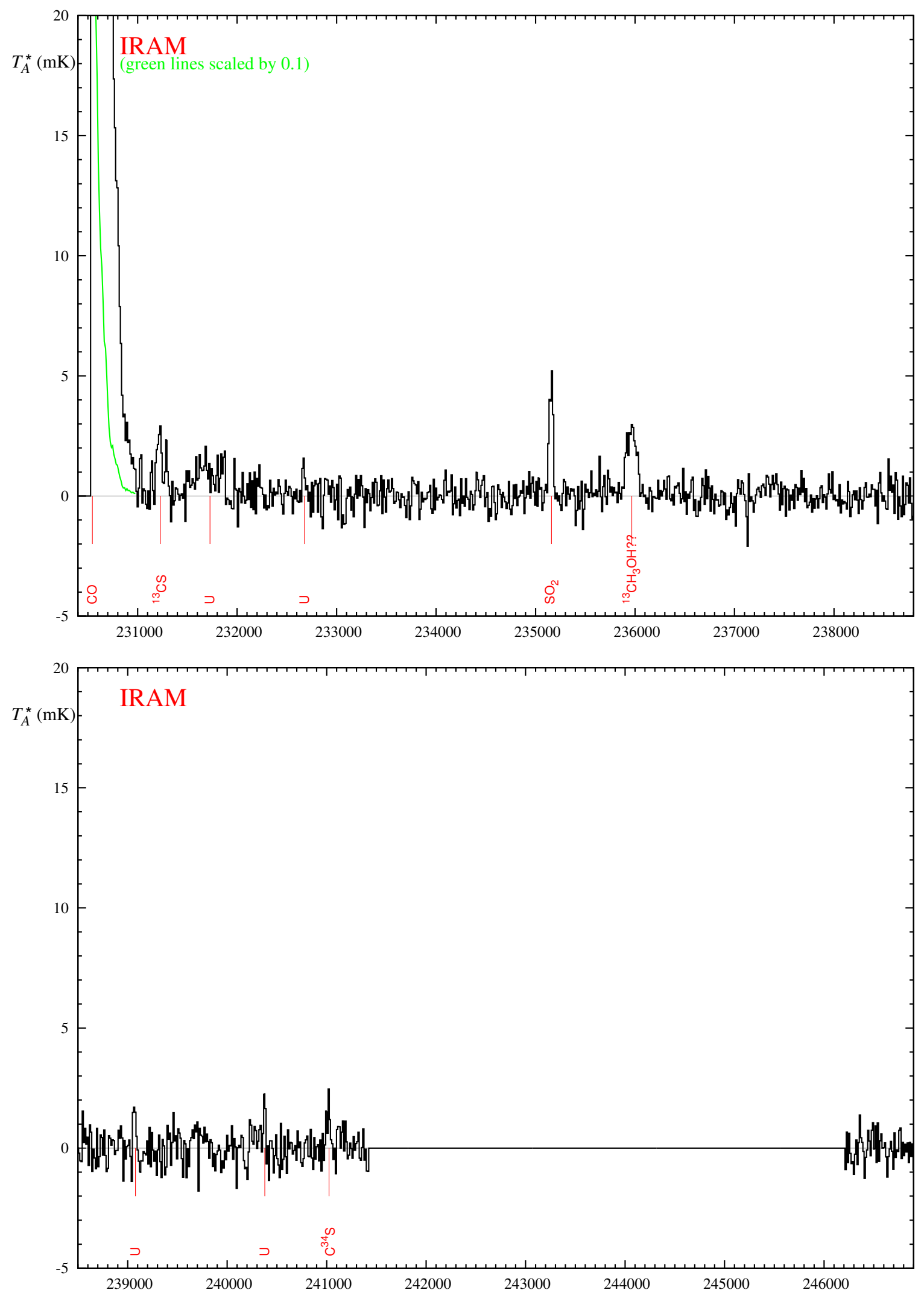

Fig. B.1. continued. 

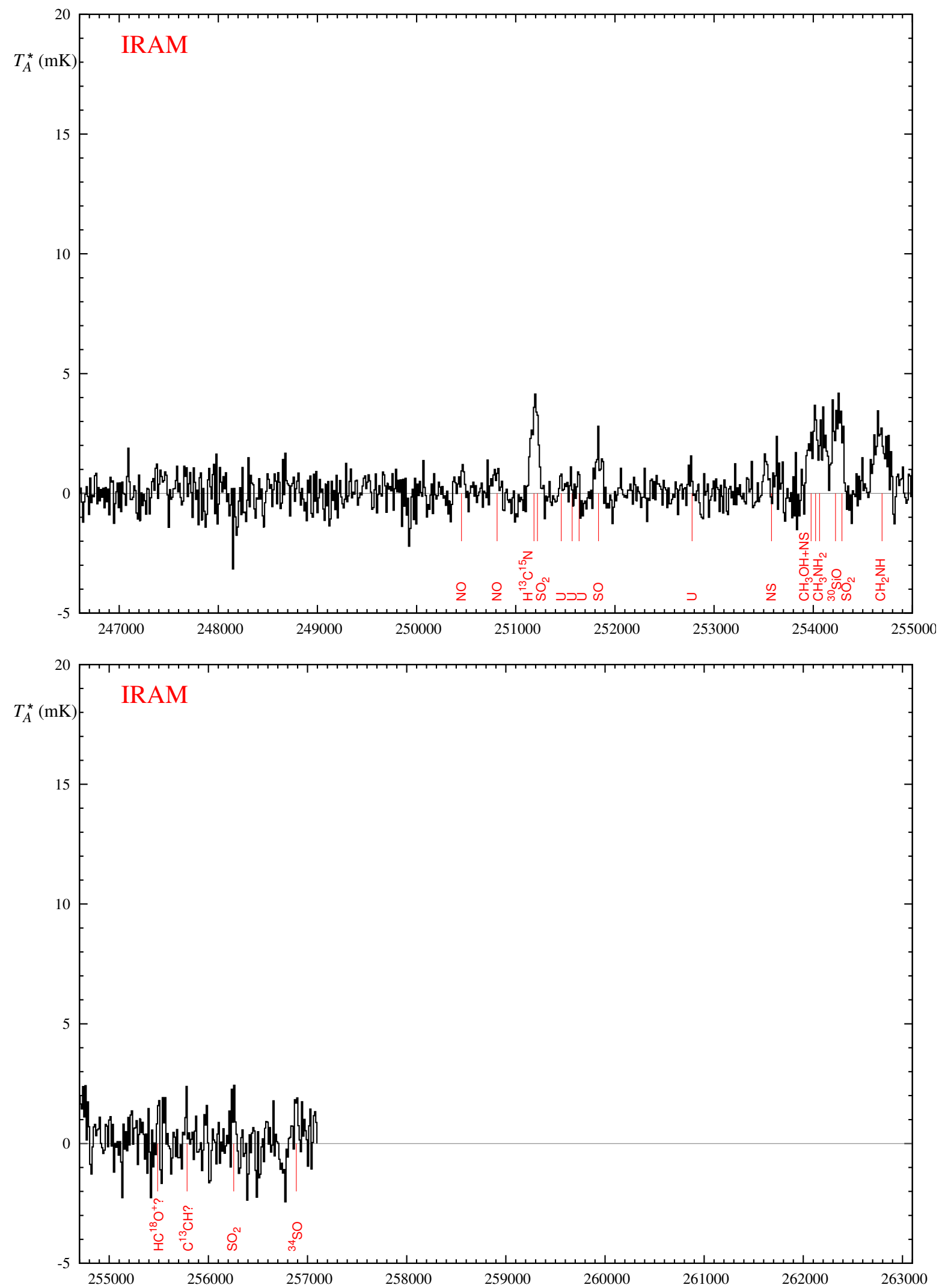

Fig. B.1. continued. 
T. Kamiński et al.: Molecules in CK Vul
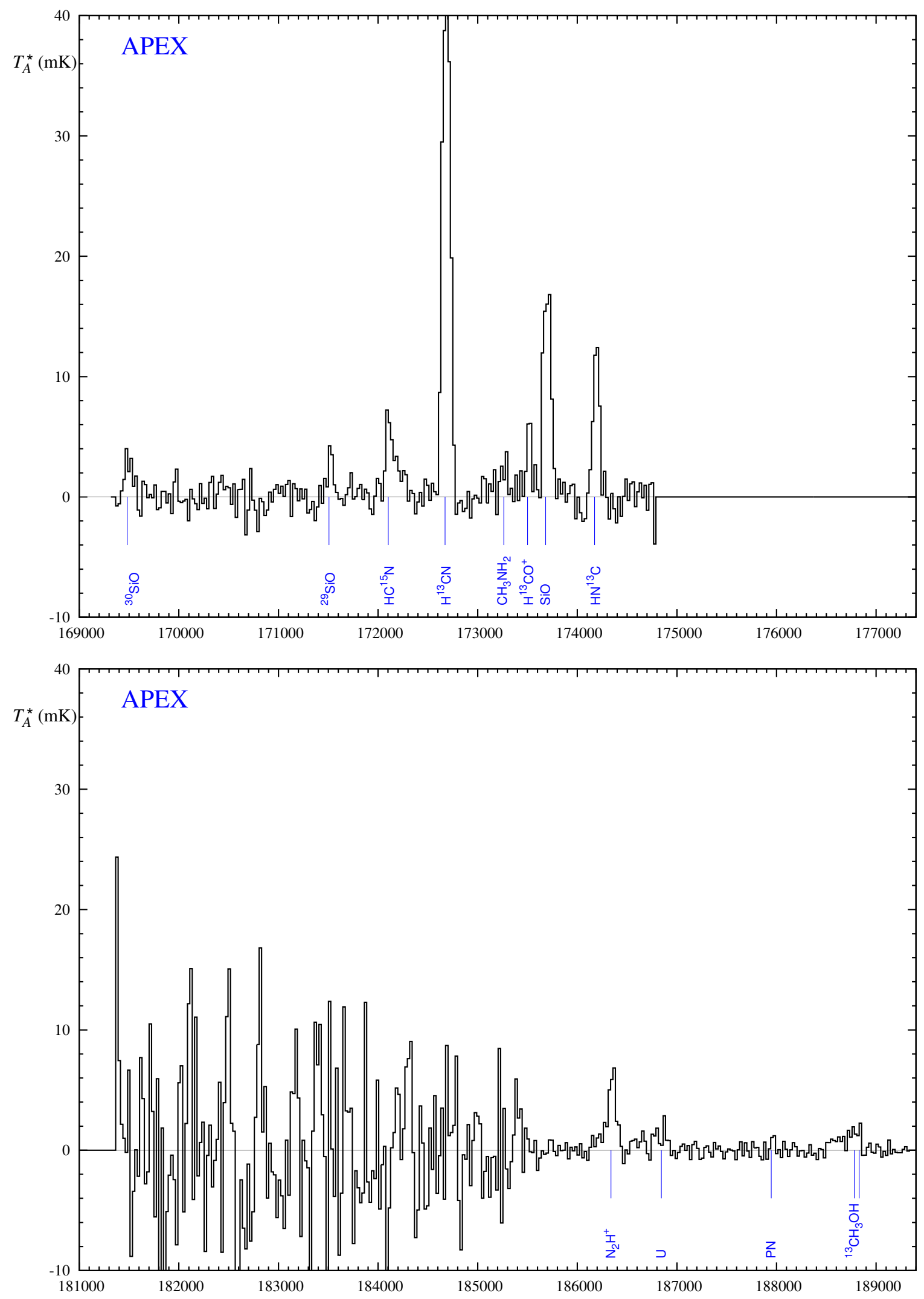

Fig. B.2. Same as Fig. B.1 but for APEX spectra. Magenta lines mark regions affected by telluric features or instrumental artifacts. 
A\&A 607, A78 (2017)
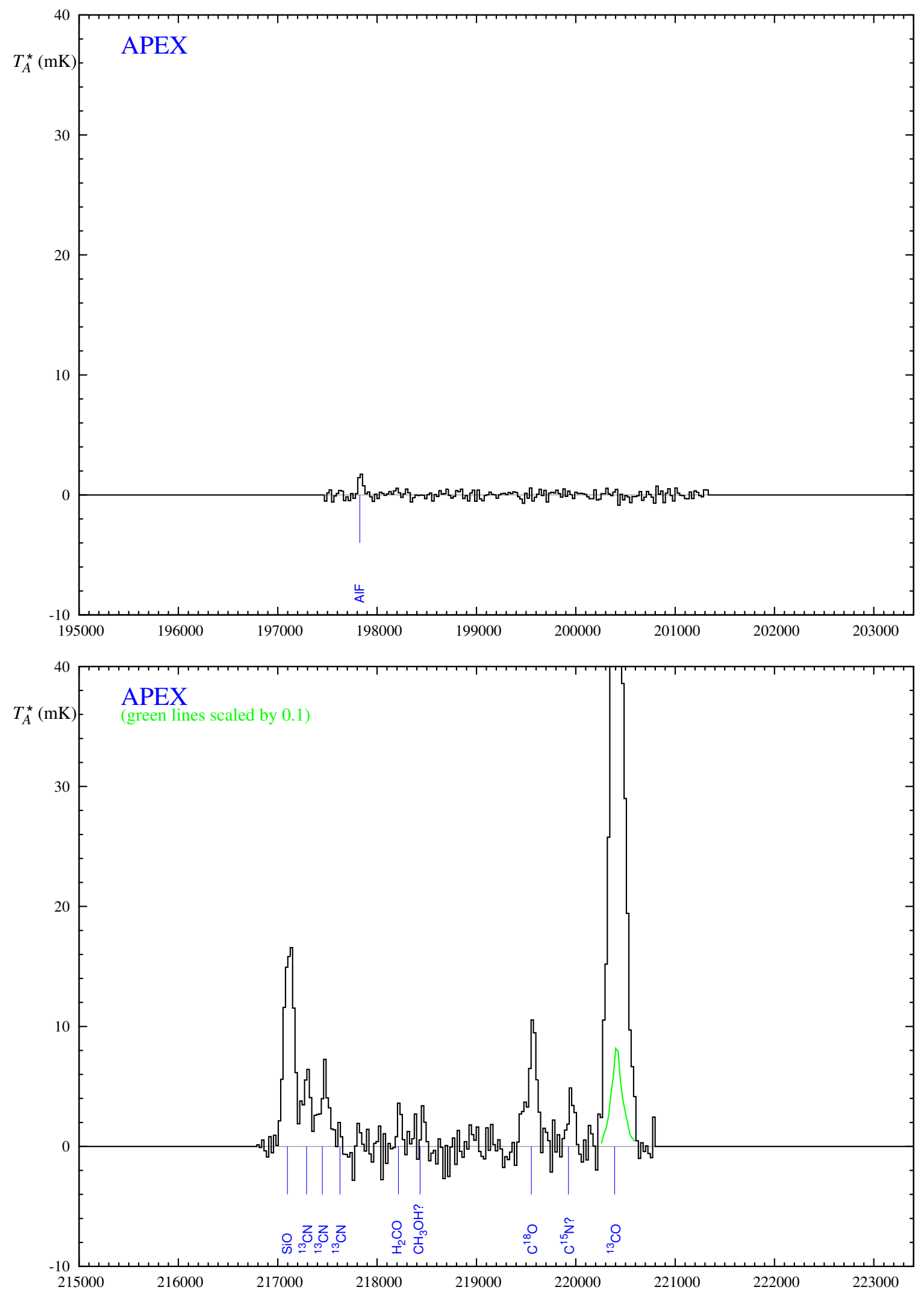

Fig. B.2. continued. 
T. Kamiński et al.: Molecules in CK Vul
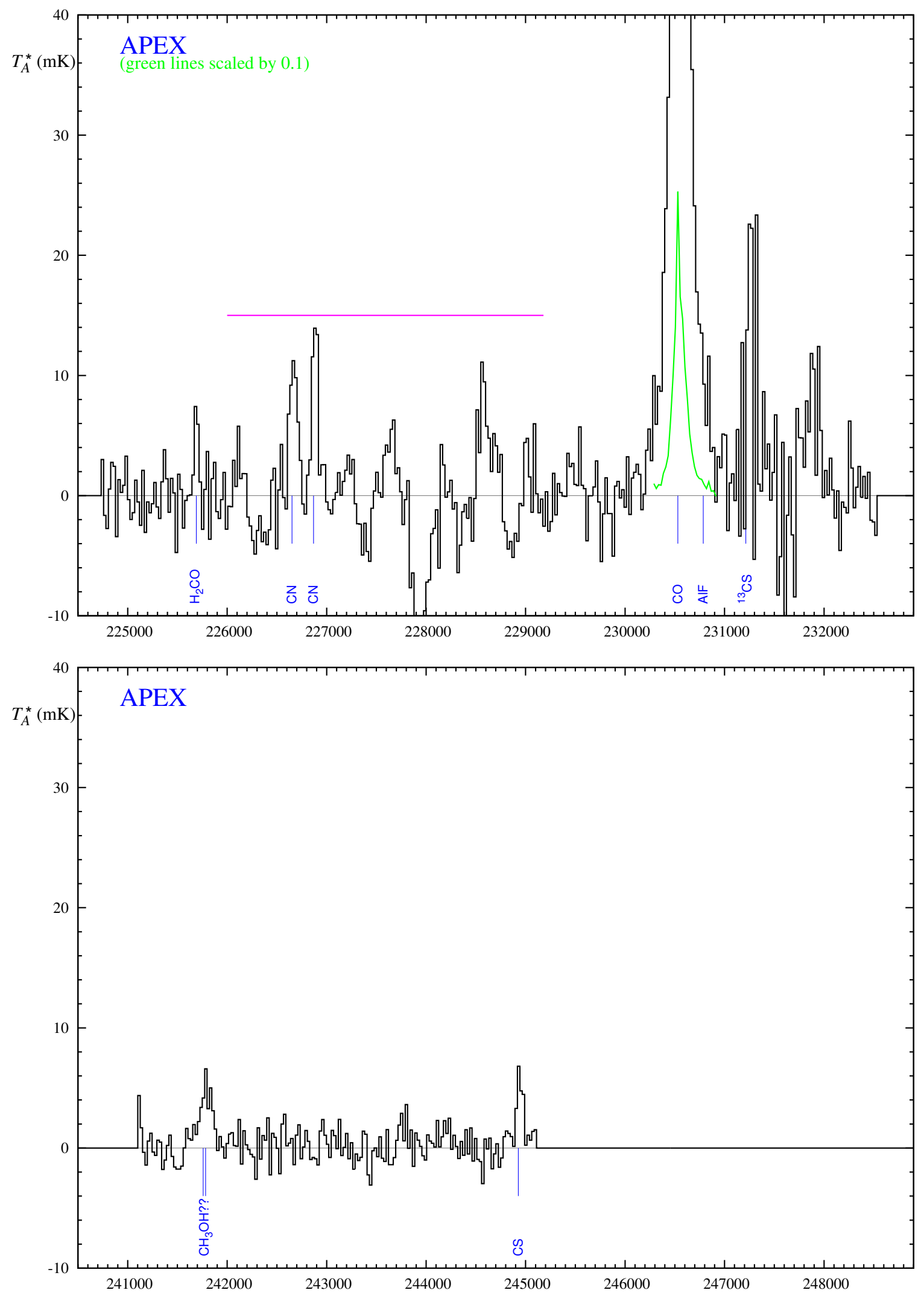

Fig. B.2. continued. 

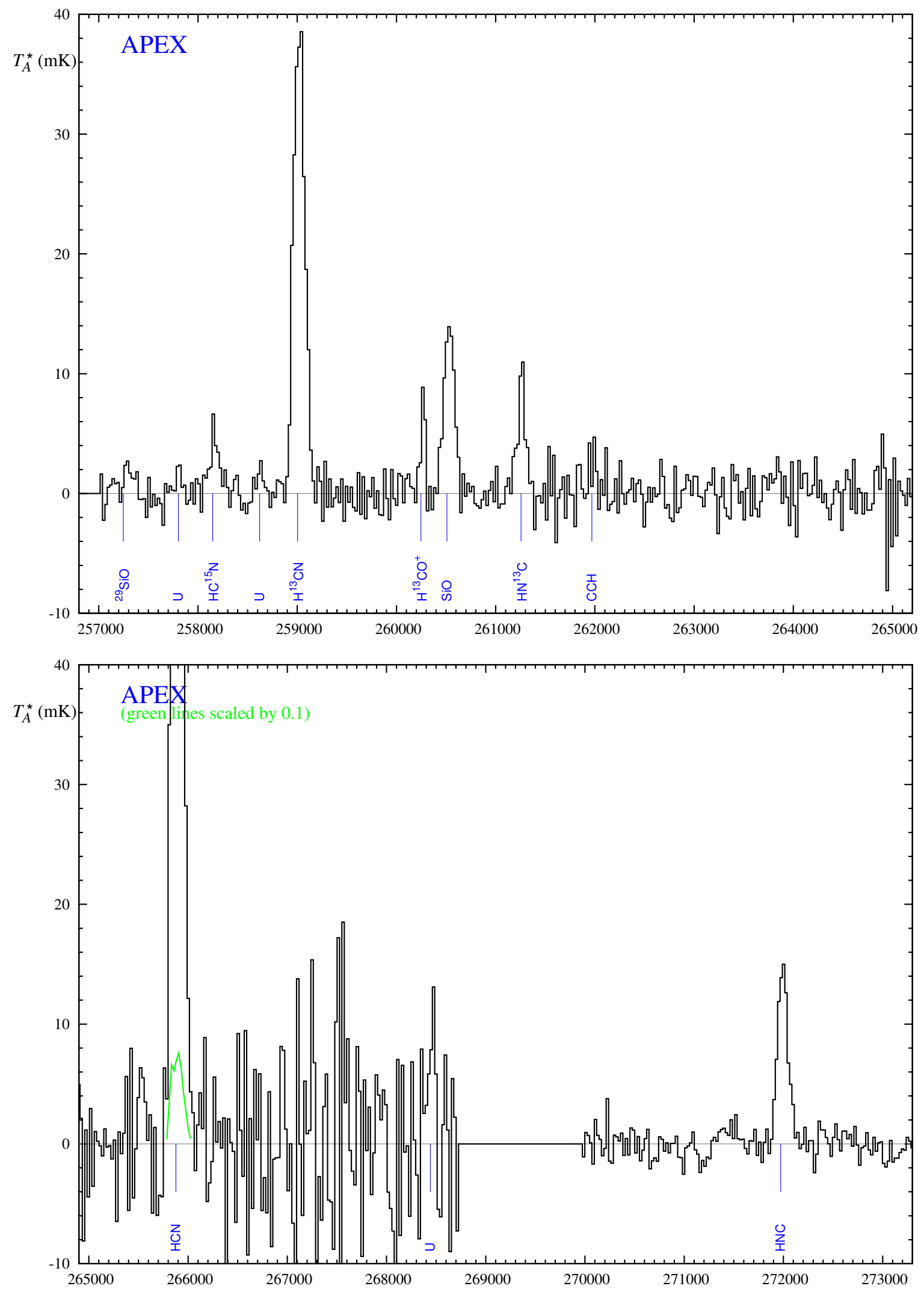

Fig. B.2. continued. 
T. Kamiński et al.: Molecules in CK Vul
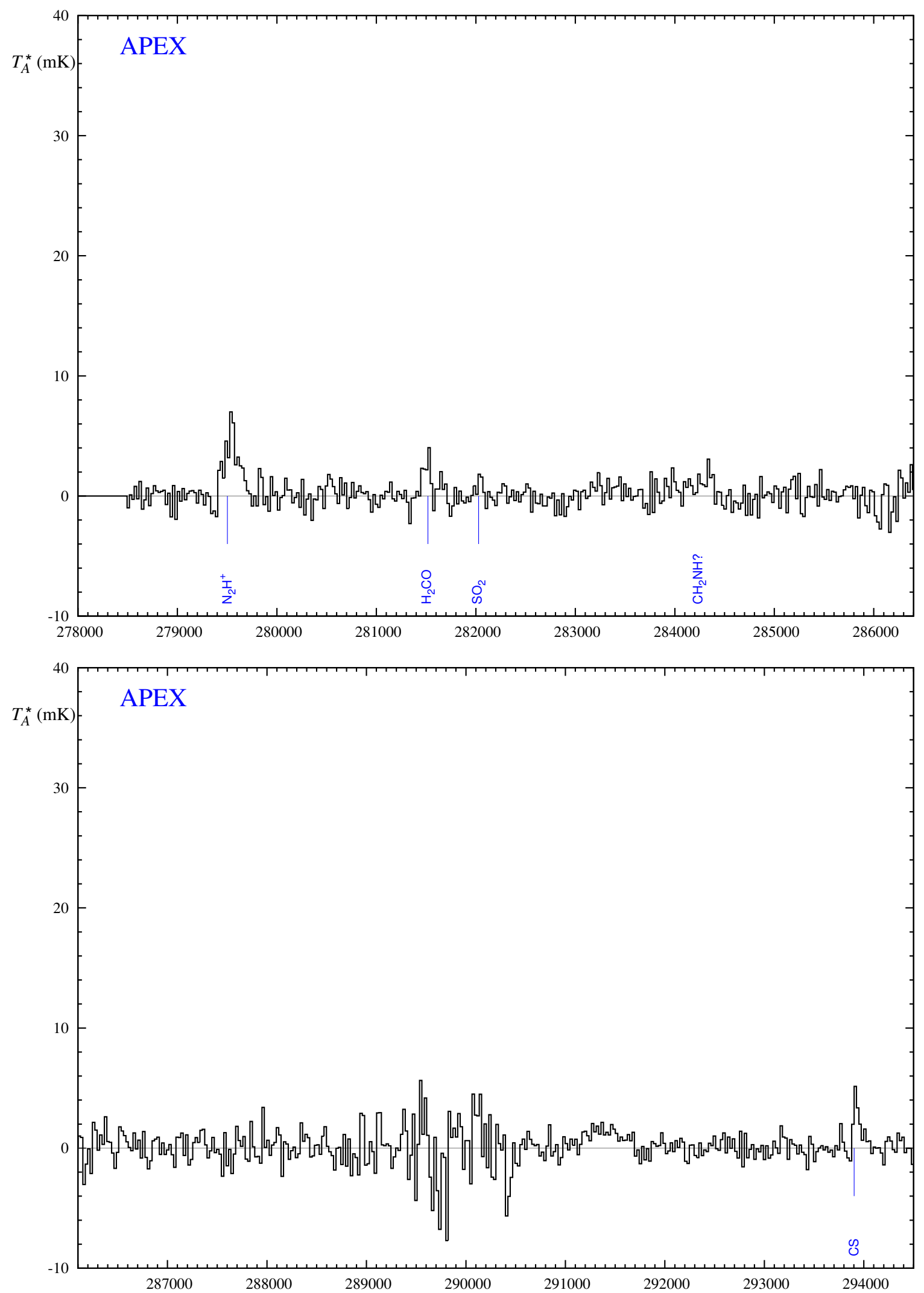

Fig. B.2. continued. 

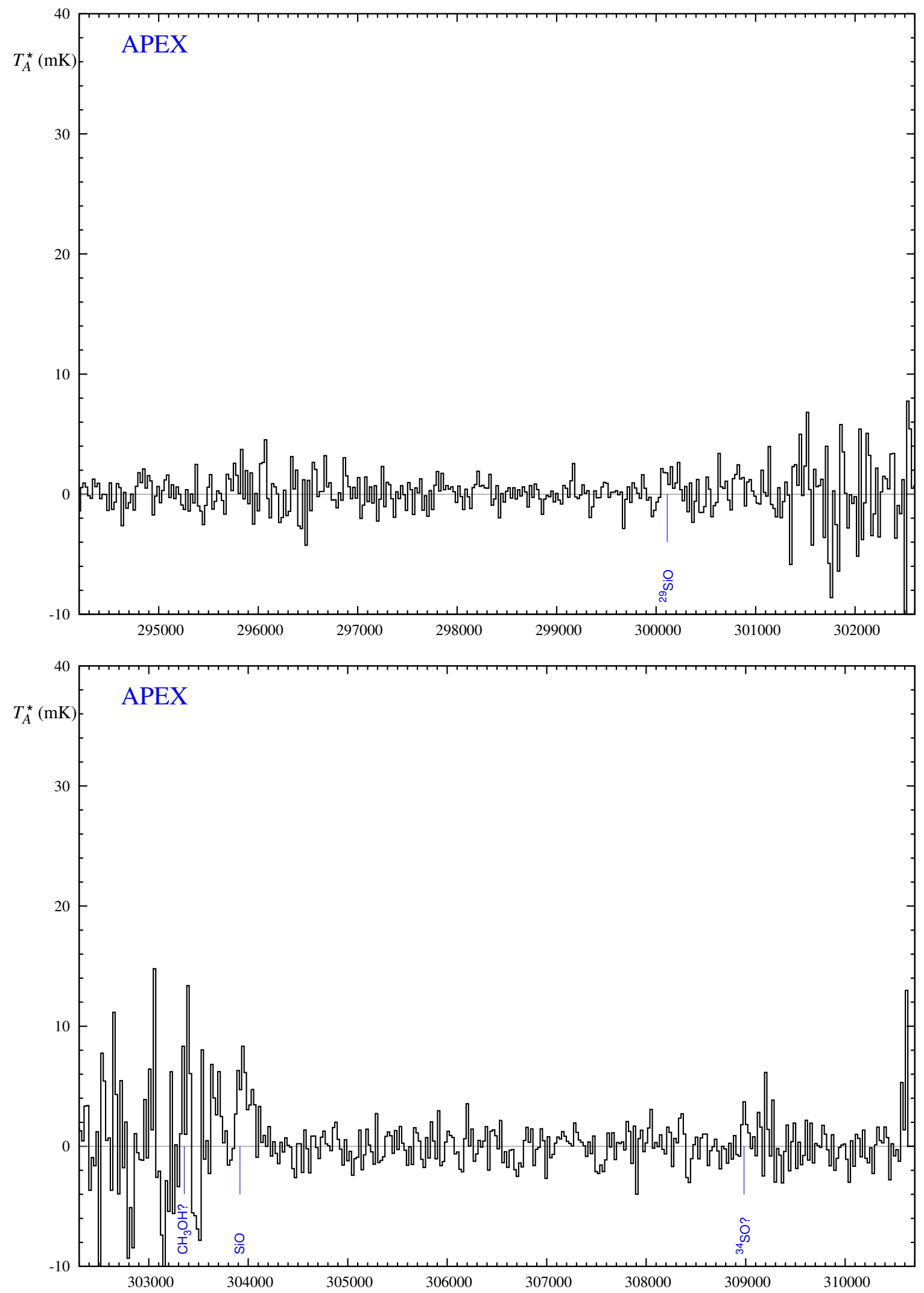

Fig. B.2. continued. 
T. Kamiński et al.: Molecules in CK Vul
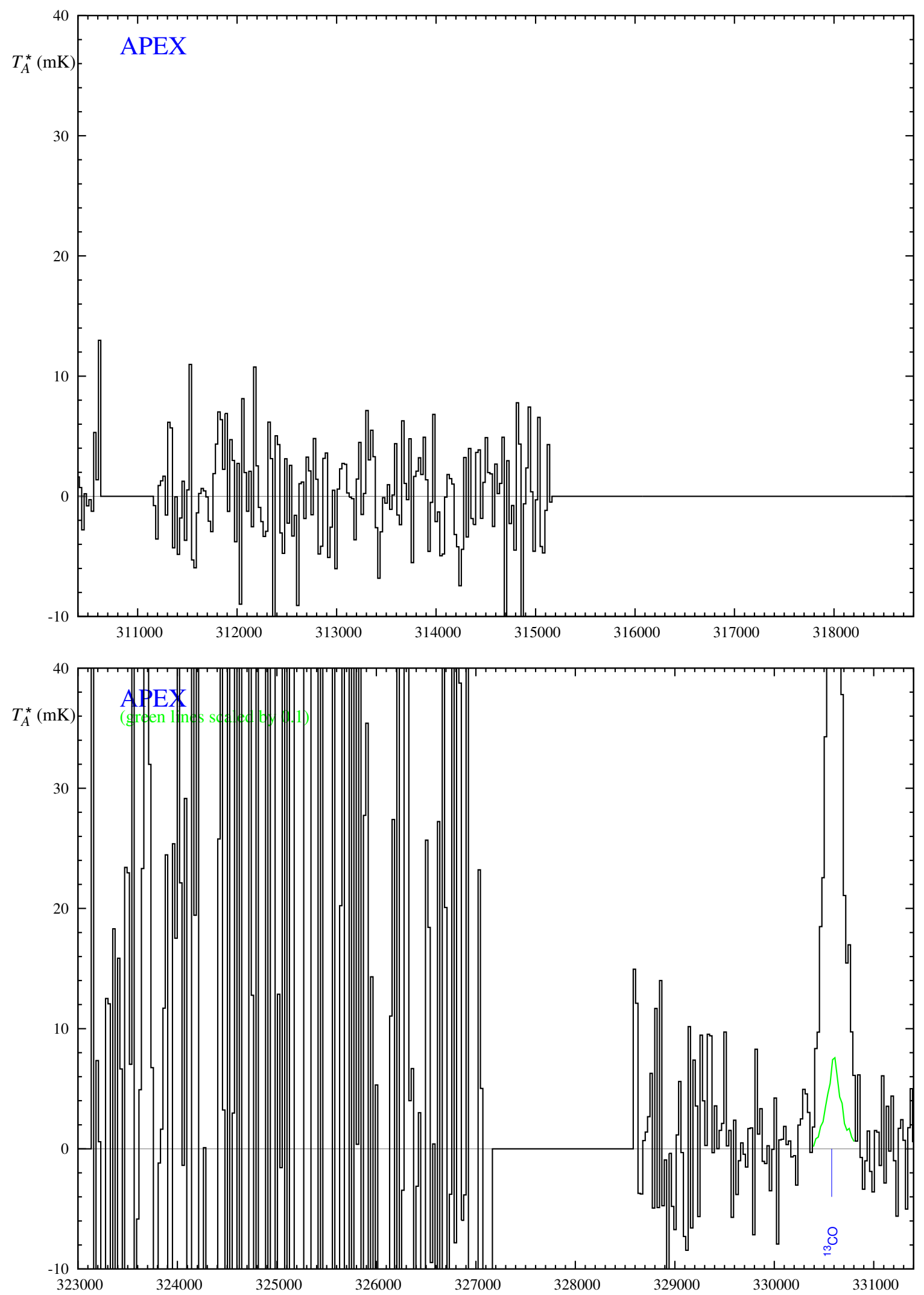

Fig. B.2. continued. 
A\&A 607, A78 (2017)
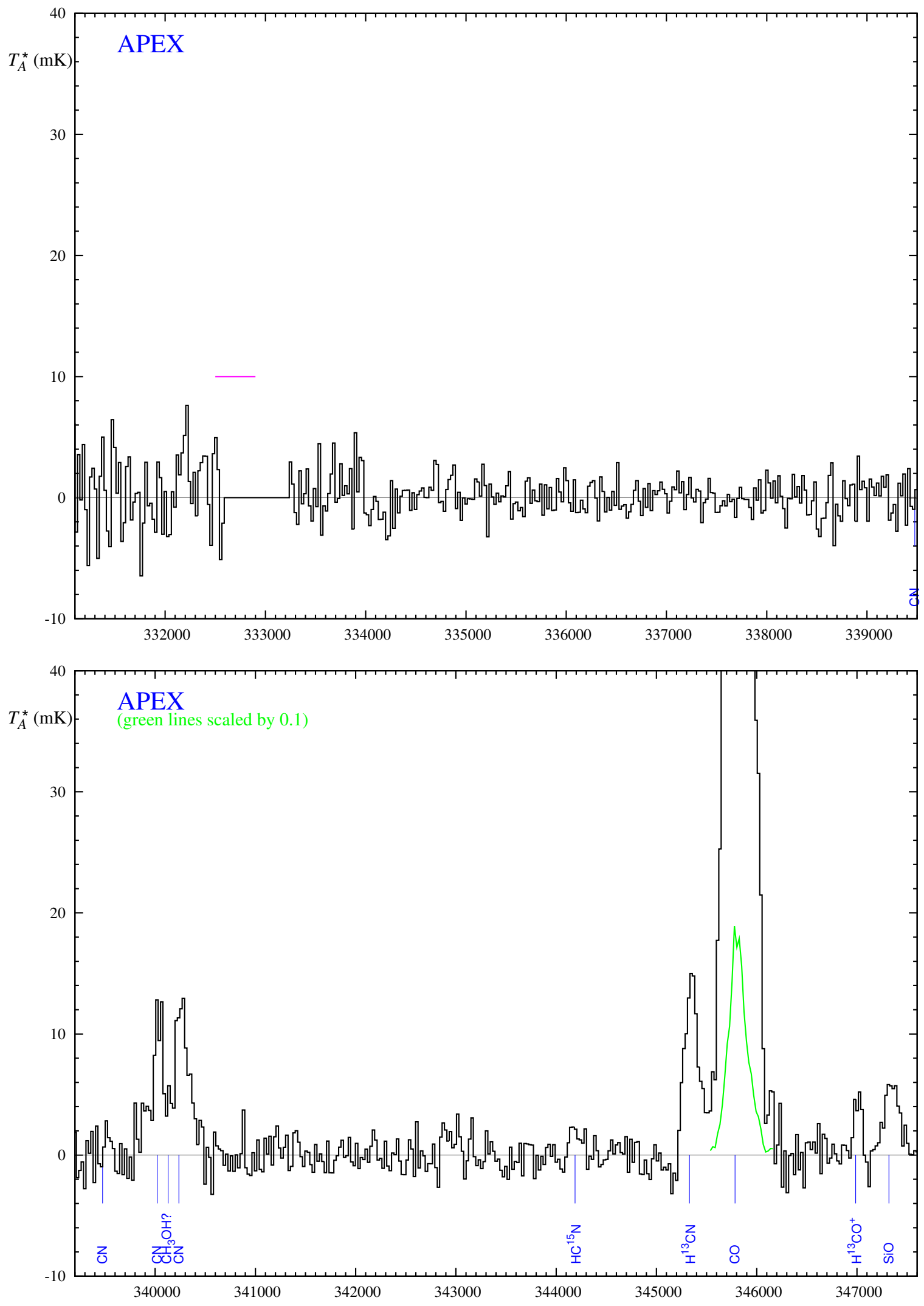

Fig. B.2. continued.

A78, page 34 of 66 
T. Kamiński et al.: Molecules in CK Vul
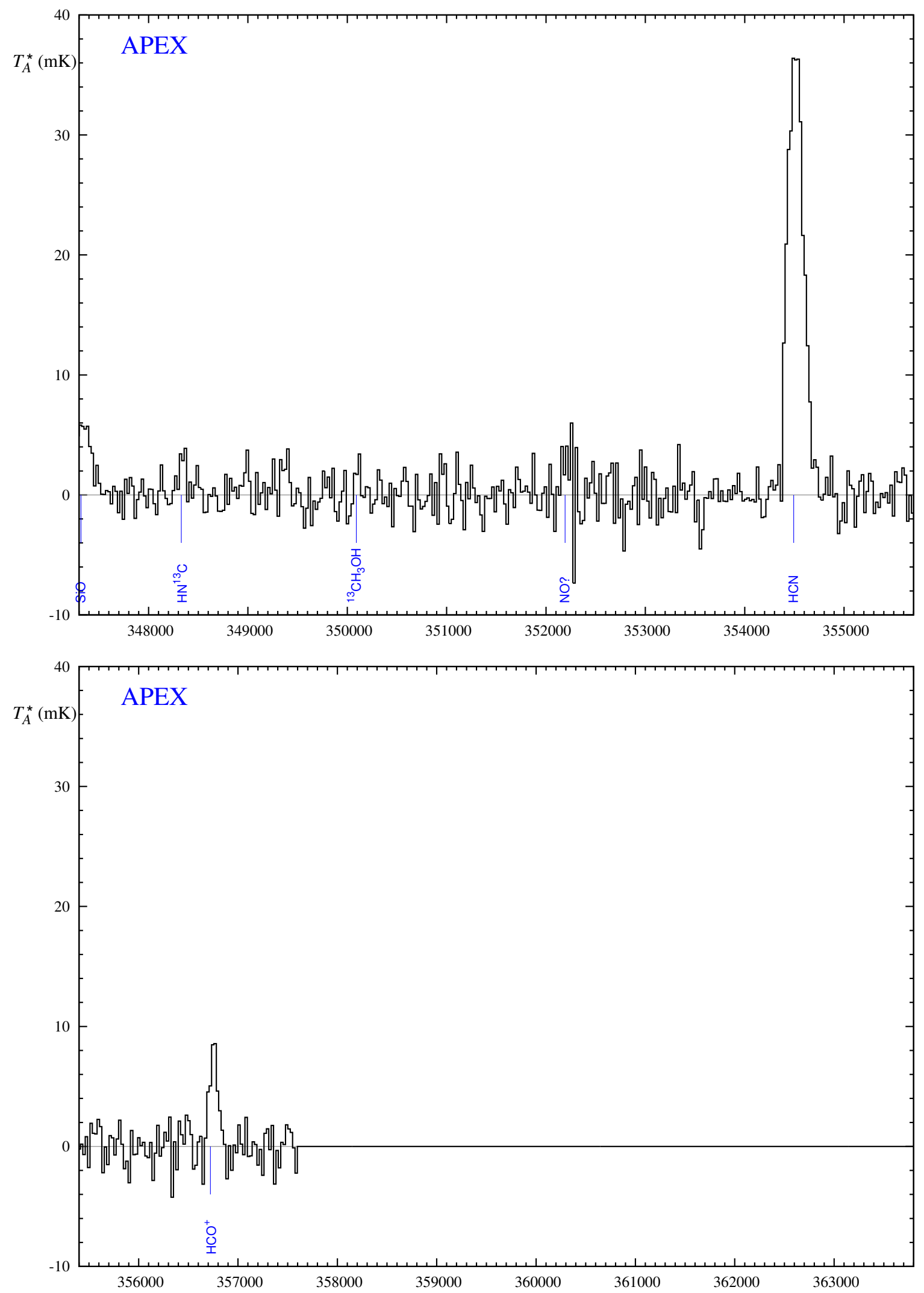

Fig. B.2. continued. 

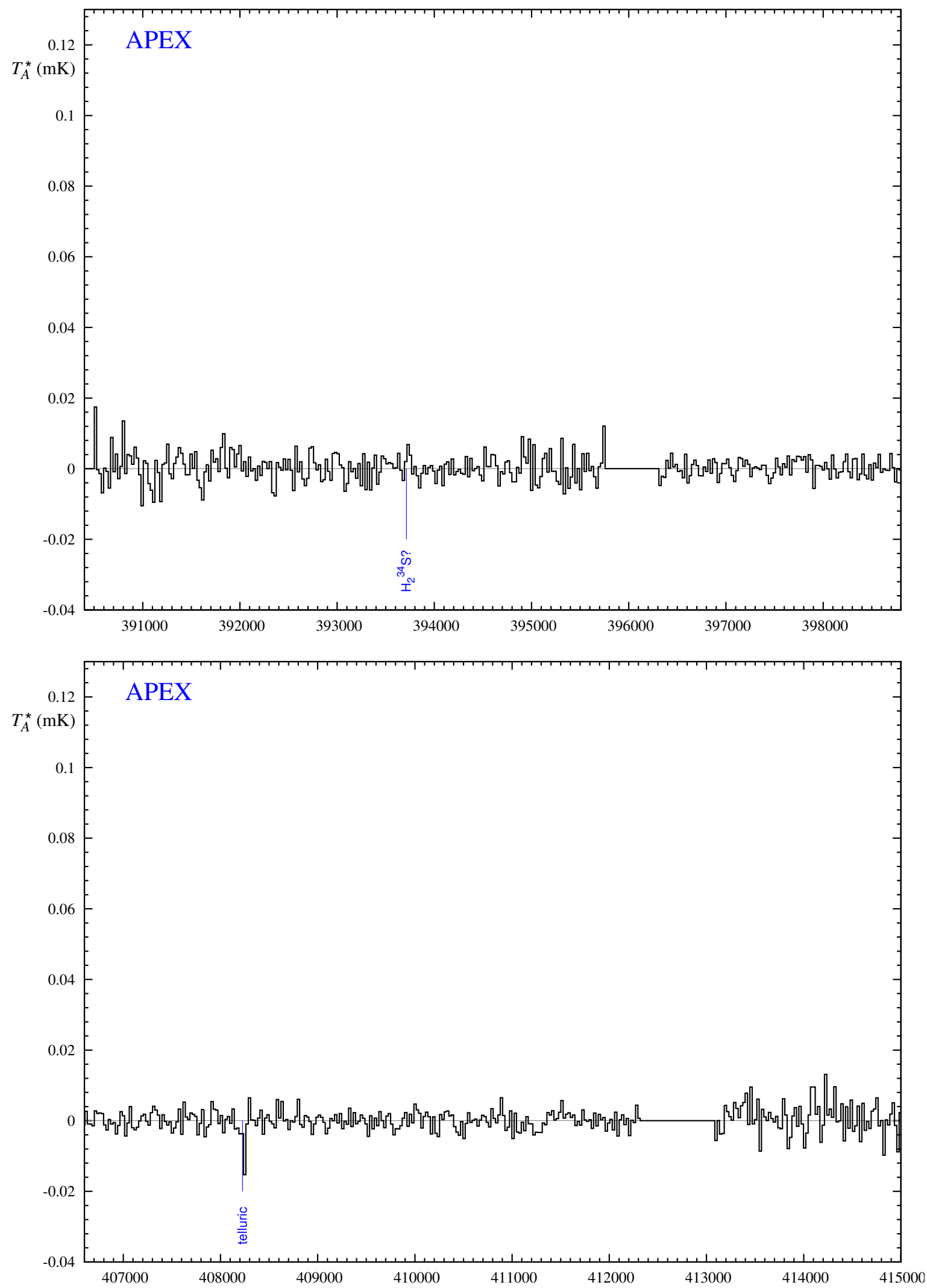

Fig. B.2. continued. 
T. Kamiński et al.: Molecules in CK Vul
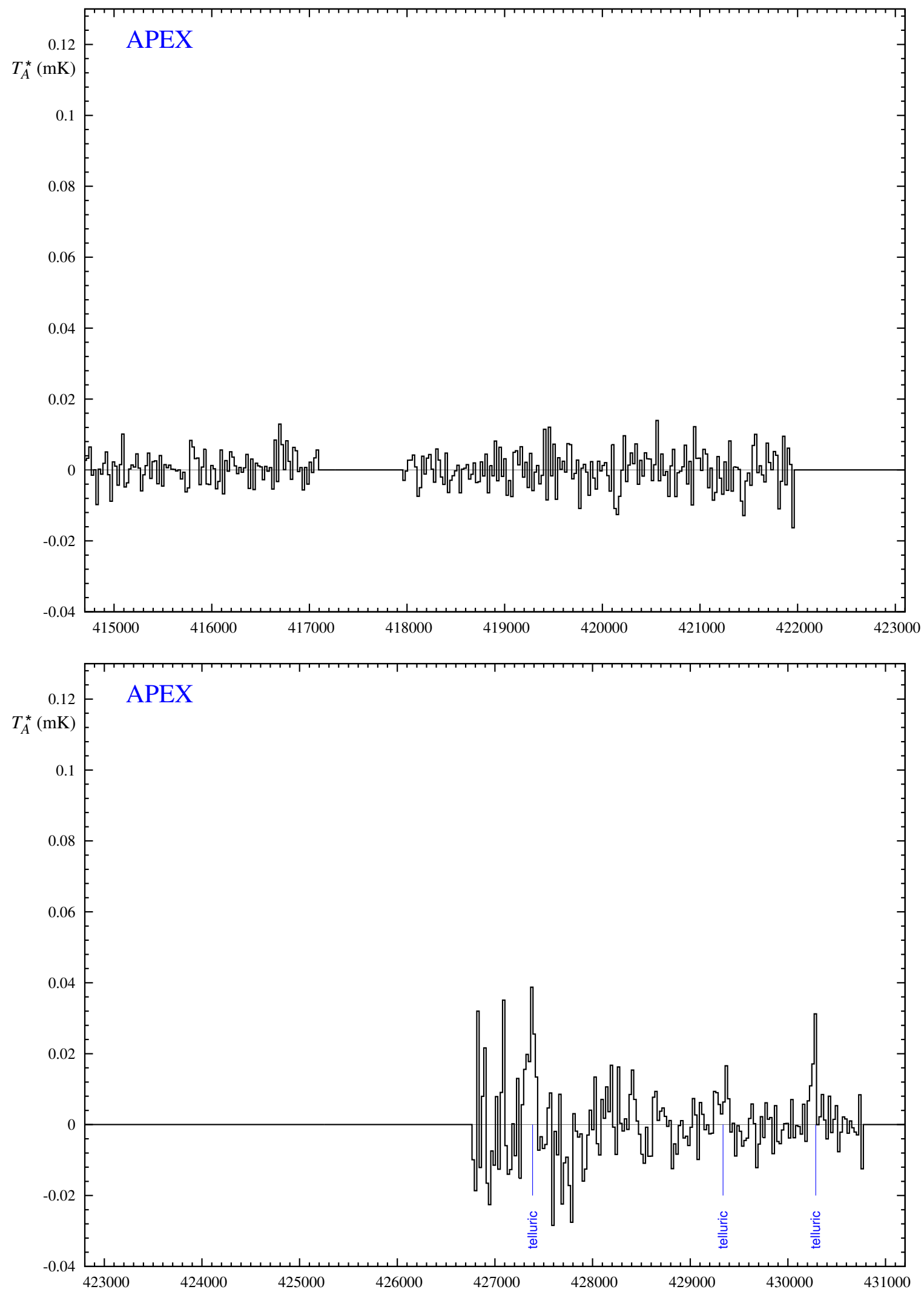

Fig. B.2. continued.

A78, page 37 of 66 
A\&A 607, A78 (2017)
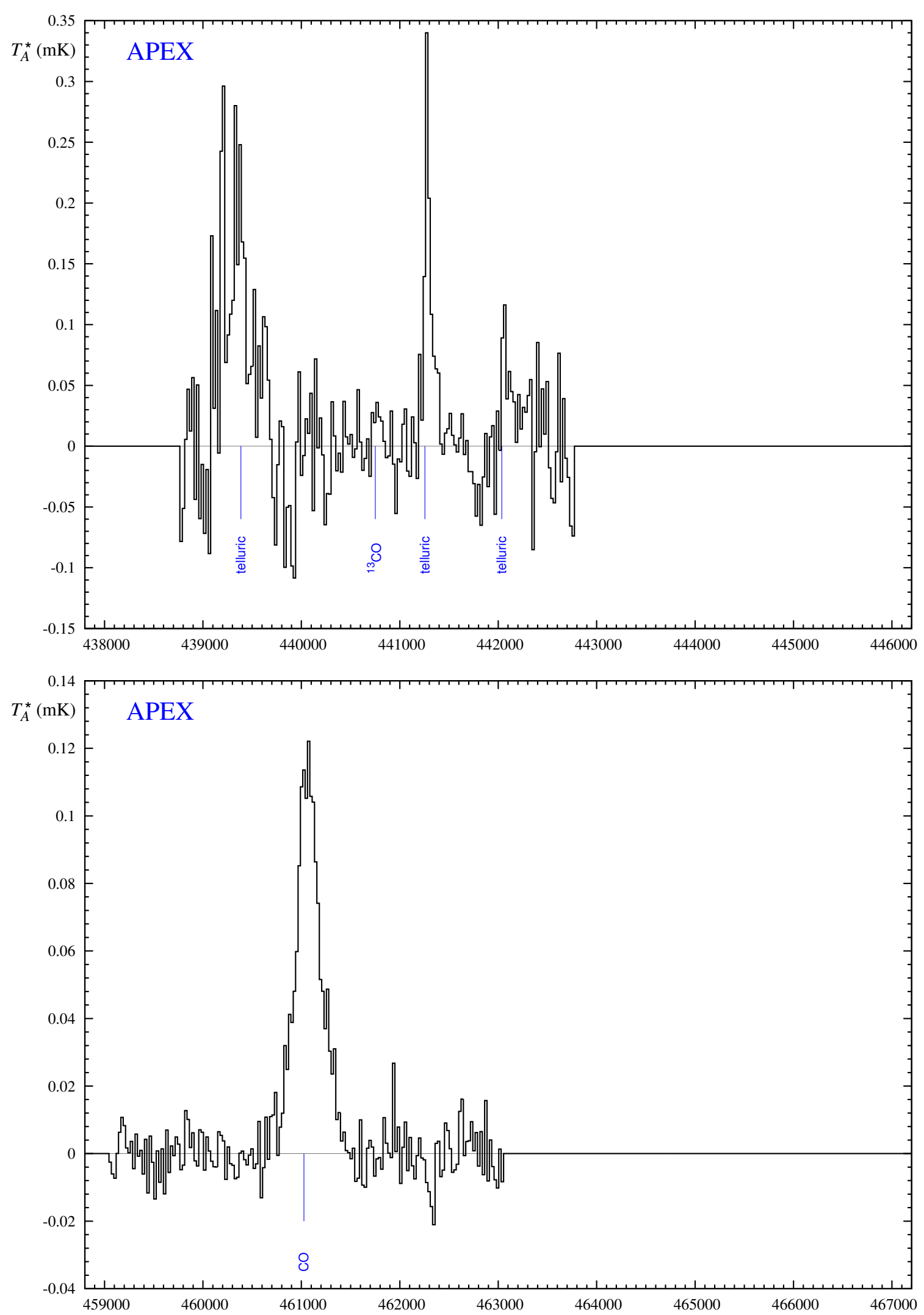

Fig. B.2. continued. 
T. Kamiński et al.: Molecules in CK Vul
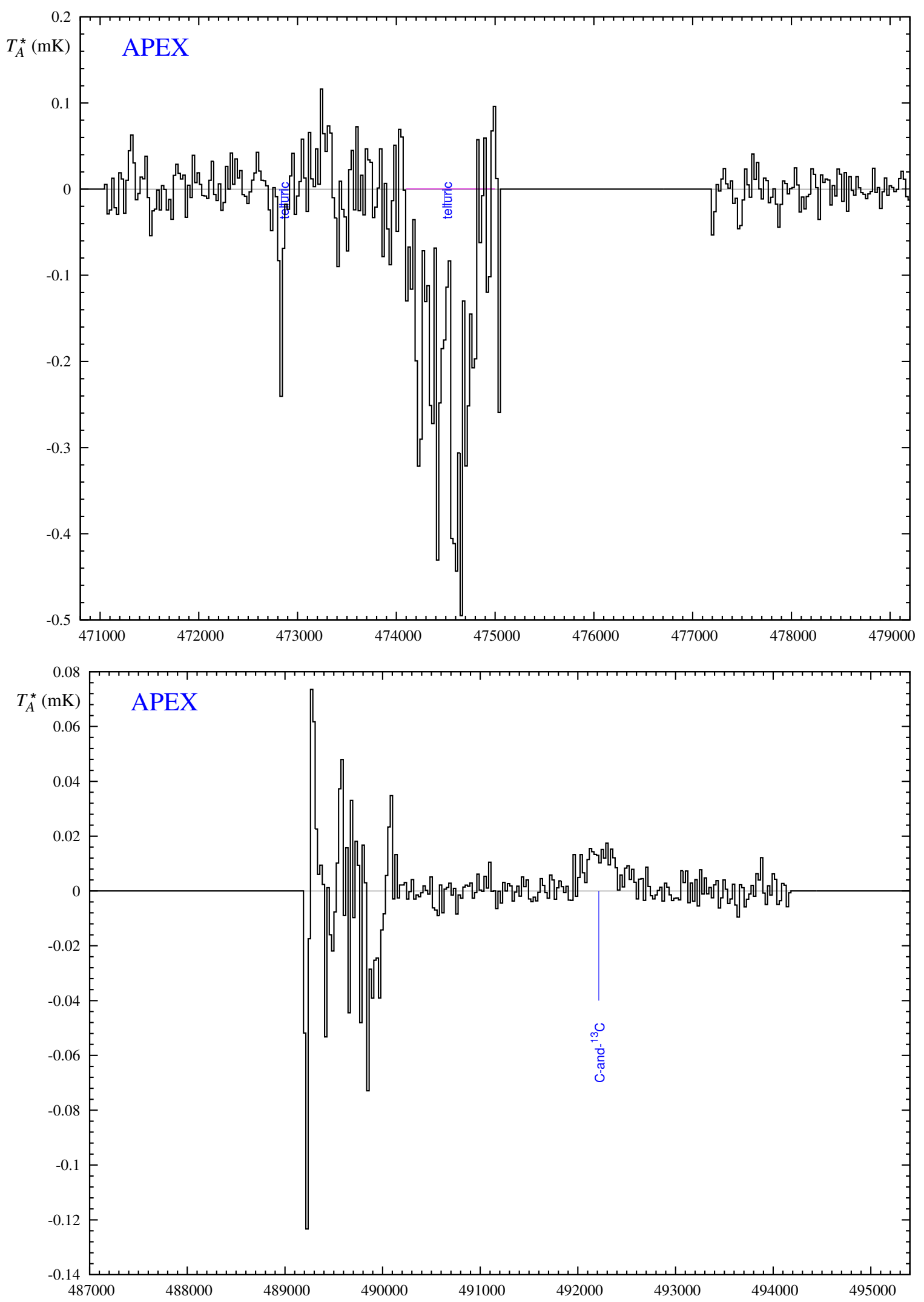

Fig. B.2. continued. 
A\&A 607, A78 (2017)
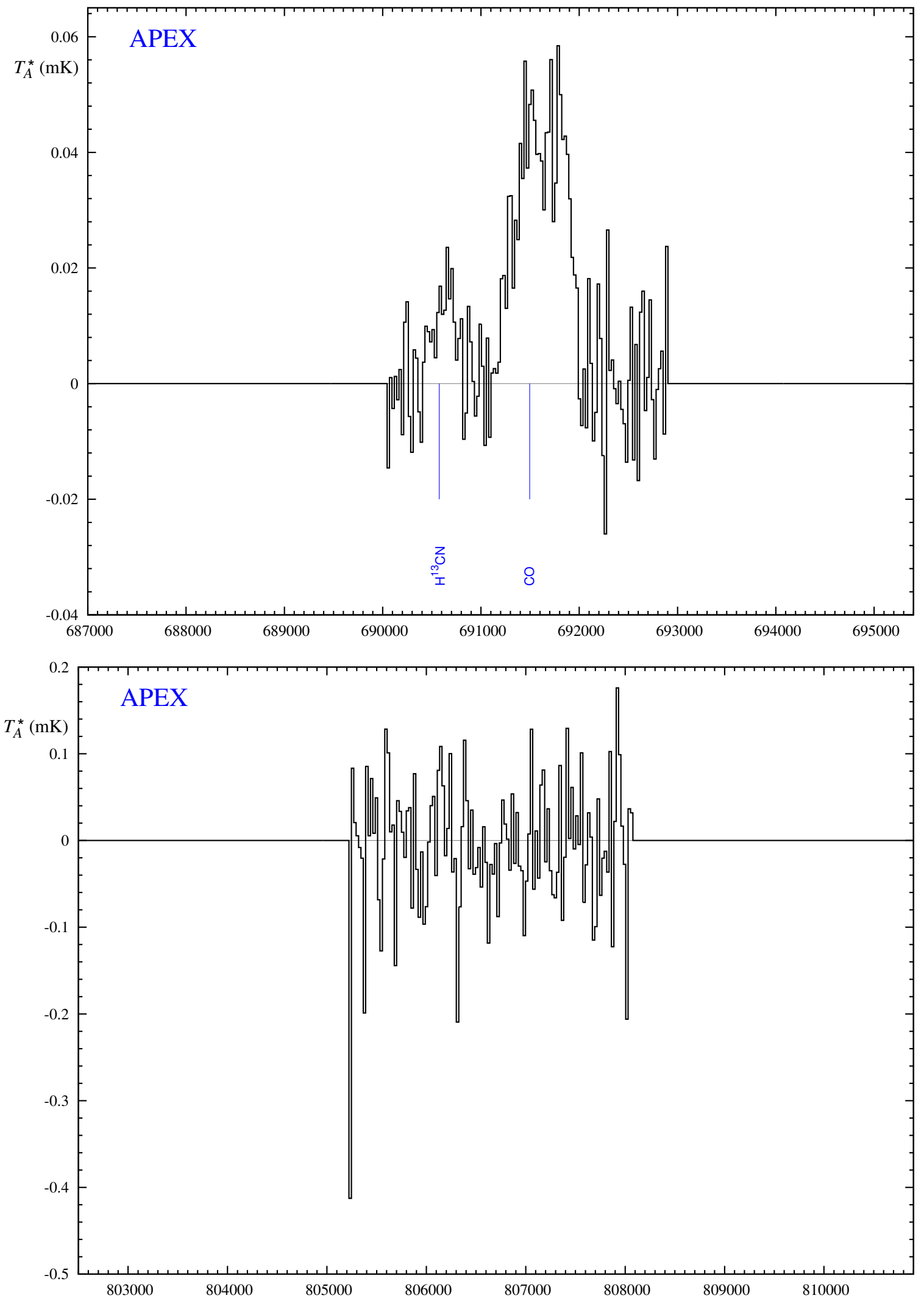

Fig. B.2. continued. 
T. Kamiński et al.: Molecules in CK Vul

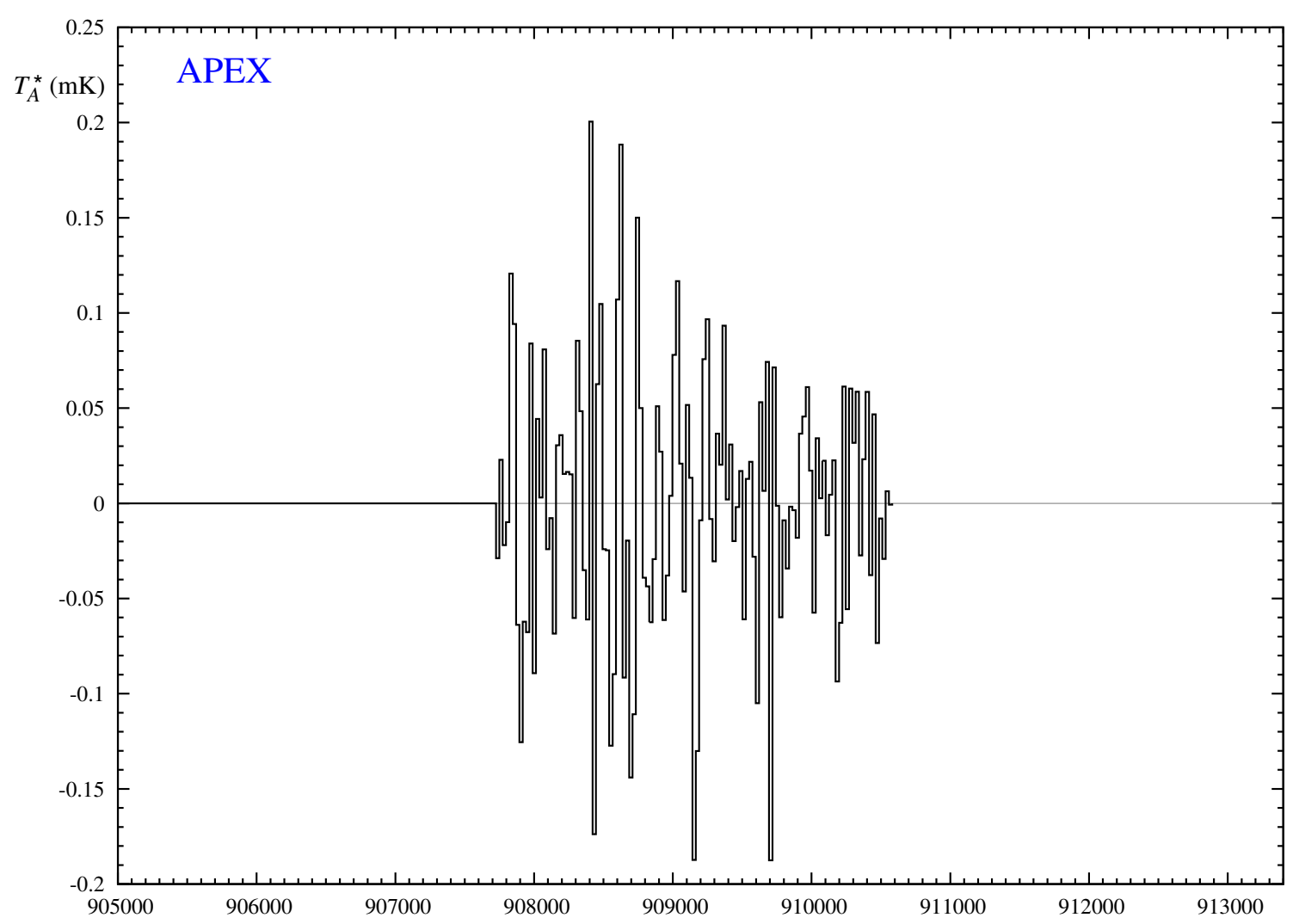

Fig. B.2. continued. 


\section{Appendix C: A list of identified transitions}

Table C.1. Identified transitions in IRAM spectra.

\begin{tabular}{|c|c|c|}
\hline Molecule & Transition & Rest frequency (MHz) \\
\hline $\mathrm{U}$ & $\mathrm{U}$ & 75770.00 \\
\hline${ }^{13} \mathrm{CH}_{3} \mathrm{NH}_{2}$ & $\mathrm{U}$ & 75838.45 \\
\hline OSB-CS & $\mathrm{U}$ & 76872.43 \\
\hline $\mathrm{CH}_{3} \mathrm{NH}_{2}$ & $(1,1,2-1,0,3)$ & 79008.42 \\
\hline $\mathrm{H}^{13} \mathrm{CCCN}$ & $(9-8)$ & 79350.46 \\
\hline $\mathrm{Si}^{18} \mathrm{O}$ & $(2-1)$ & 80704.94 \\
\hline $\mathrm{U}$ & $\mathrm{U}$ & 81168.86 \\
\hline $\mathrm{HC}^{13} \mathrm{CCN}$ & $(9-8)$ & 81534.11 \\
\hline $\mathrm{HCC}^{13} \mathrm{CN}$ & $(9-8)$ & 81541.98 \\
\hline OSB- $\mathrm{N}_{2} \mathrm{H}^{+}$ & $\mathrm{U}$ & 81684.39 \\
\hline $\mathrm{HC}_{3} \mathrm{~N}$ & $(9-8)$ & 81881.47 \\
\hline $\mathrm{U}$ & $\mathrm{U}$ & 83541.41 \\
\hline $\mathrm{Si}^{17} \mathrm{O} ?$ & $(2-1)$ & 83588.65 \\
\hline $\mathrm{H}^{13} \mathrm{C}^{15} \mathrm{~N}$ & $(1-0)$ & 83727.58 \\
\hline $\mathrm{U}$ & U & 84102.78 \\
\hline $\mathrm{CH}_{3} \mathrm{NH}_{2}$ ? & $(4,0,0-3,-1,1)$ & 84215.03 \\
\hline${ }^{13} \mathrm{CCH}$ ? & $(1-0)$ & 84154.51 \\
\hline${ }^{30} \mathrm{SiO}$ & $(2-1)$ & 84746.17 \\
\hline $\mathrm{H}^{15} \mathrm{~N}^{13} \mathrm{C}$ ? & $(1-0)$ & 85258.92 \\
\hline $\mathrm{CH}_{3} \mathrm{NH}_{2}$ ? & $(5,1,6-5,0,7)$ & 85350.10 \\
\hline OSB-13CN & $\mathrm{U}$ & 85469.39 \\
\hline${ }^{29} \mathrm{SiO}$ & $(2-1)$ & 85759.19 \\
\hline $\mathrm{HC}^{15} \mathrm{~N}$ & $(1-0)$ & 86054.97 \\
\hline $\mathrm{H}^{13} \mathrm{CN}$ & $(1-0)$ & 86339.92 \\
\hline $\mathrm{H}^{13} \mathrm{CO}^{+}$ & $(1-0)$ & 86754.29 \\
\hline $\mathrm{SiO}$ & $(2-1)$ & 86846.98 \\
\hline $\mathrm{HN}^{13} \mathrm{C}$ & $(1-0)$ & 87090.83 \\
\hline $\mathrm{CCH}$ & $\left(1,1.5, F-0,0.5, F^{\prime}\right)$ & 87318.45 \\
\hline $\mathrm{CCH}$ & $\left(1,0.5, F-0,0.5, F^{\prime}\right)$ & 87408.95 \\
\hline SiN? & $\left(2,2.5, F-1,1.5, F^{\prime}\right)$ & 87562.12 \\
\hline $\mathrm{CH}_{3} \mathrm{NH}_{2}$ & $(2,-1,1-1,1,0)$ & 87795.01 \\
\hline $\mathrm{HNCO}$ & $(4,0,4-3,0,3)$ & 87925.24 \\
\hline $\mathrm{H}^{13} \mathrm{CCCN}$ & $(10-9)$ & 88166.83 \\
\hline $\mathrm{HCN}$ & $(1-0)$ & 88631.60 \\
\hline $\mathrm{H}^{15} \mathrm{NC}$ & $(1-0)$ & 88865.72 \\
\hline $\mathrm{CH}_{3} \mathrm{NH}_{2}$ & $(2,-1,1-2,0,0)$ & 89081.46 \\
\hline $\mathrm{HCO}^{+}$ & $(1-0)$ & 89188.52 \\
\hline${ }^{13} \mathrm{CH}_{3} \mathrm{CN}$ & (5-4) & 89331.28 \\
\hline $\mathrm{CH}_{3} \mathrm{NH}_{2}$ & $(1,1,0-1,0,1)$ & 89956.07 \\
\hline${ }^{15} \mathrm{NNH}^{+}$ & $(1-0)$ & 90263.84 \\
\hline $\mathrm{HC}^{13} \mathrm{CCN}$ & (10-9) & 90593.06 \\
\hline $\mathrm{HCC}^{13} \mathrm{CN}$ & $(10-9)$ & 90601.78 \\
\hline $\mathrm{HNC}$ & $(1,0,0-0,0,0)$ & 90663.57 \\
\hline $\mathrm{SiS}$ & $(5-4)$ & 90771.56 \\
\hline $\mathrm{HC}_{3} \mathrm{~N}$ & $(10-9)$ & 90979.02 \\
\hline $\mathrm{N}^{15} \mathrm{NH}^{+}$ & $(1-0)$ & 91205.70 \\
\hline $\mathrm{CH}_{3} \mathrm{NH}_{2}$ ?? & $(4,0,5-3,1,5)$ & 91848.43 \\
\hline $\mathrm{CH}_{3} \mathrm{CN}$ & $(5-4)$ & 91979.99 \\
\hline${ }^{13} \mathrm{CS}$ & $(2-1)$ & 92494.31 \\
\hline $\mathrm{CH}_{3}^{18} \mathrm{OH} ?$ & $\left(2, K_{a}, 2-1, K_{a}^{\prime}, 1\right)$ & 92725.47 \\
\hline $\mathrm{N}_{2} \mathrm{H}^{+}$ & $(1-0)$ & 93173.40 \\
\hline PN & $(2-1)$ & 93979.77 \\
\hline${ }^{13} \mathrm{CH}_{3} \mathrm{OH}$ & $(2,0,2-1,0,1)$ & 94407.13 \\
\hline${ }^{13} \mathrm{CH}_{3} \mathrm{OH}$ & $(2,1,1-1,1,0)$ & 94420.45 \\
\hline $\mathrm{CH}_{3} \mathrm{NH}_{2}$ ?? & $(4,0,2-3,-1,3)$ & 95145.81 \\
\hline $\mathrm{C}^{34} \mathrm{~S}$ & $(2-1)$ & 96412.95 \\
\hline
\end{tabular}

Notes. Quantum assignments to transitions follow the notation in JPL or CDMS. 
Table C.1. continued.

\begin{tabular}{|c|c|c|}
\hline Molecule & Transition & Rest frequency (MHz) \\
\hline $\mathrm{CH}_{3} \mathrm{OH}$ & $\left(2, K_{a}, K_{c}-1, K_{a}^{\prime}, K_{c}^{\prime}\right)$ & 96739.36 \\
\hline $\mathrm{CH}_{3} \mathrm{OH}$ & $(2,1,1-1,1,0)$ & 96755.51 \\
\hline $\mathrm{H}^{13} \mathrm{CCCN}$ & $(11-10)$ & 96983.00 \\
\hline $\mathrm{C}^{33} \mathrm{~S} ?$ & $(2-1)$ & 97172.06 \\
\hline${ }^{34} \mathrm{SO}$ & $(2,3-1,2)$ & 97715.32 \\
\hline $\mathrm{CS}$ & $(2-1)$ & 97980.95 \\
\hline $\mathrm{U}$ & $\mathrm{U}$ & 98347.65 \\
\hline AlF & $(3-2)$ & 98926.73 \\
\hline $\mathrm{CH}_{3} \mathrm{NH}_{2} ? ?$ & $(4,0,5-3,1,4)$ & 99127.25 \\
\hline $\mathrm{SO}$ & $(2,3-1,2)$ & 99299.87 \\
\hline $\mathrm{HC}^{13} \mathrm{CCN}$ & $(11-10)$ & 99651.85 \\
\hline $\mathrm{HCC}^{13} \mathrm{CN}$ & $(11-10)$ & 99661.47 \\
\hline $\mathrm{HC}_{3} \mathrm{~N}$ & $(11-10)$ & 100076.39 \\
\hline OSB-SiO & $\mathrm{U}$ & 100564.77 \\
\hline $\mathrm{H}_{2} \mathrm{CS}$ & $(3,1,3-2,1,2)$ & 101477.81 \\
\hline $\mathrm{U}$ & $\mathrm{U}$ & 102565.87 \\
\hline $\mathrm{H}_{2} \mathrm{CS}$ & $(3,0,3-2,0,2)$ & 103040.45 \\
\hline $\mathrm{SO}_{2}$ & $(3,1,3-2,0,2)$ & 104029.42 \\
\hline $\mathrm{H}_{2} \mathrm{CS}$ & $(3,1,2-2,1,1)$ & 104617.04 \\
\hline${ }^{13} \mathrm{C}^{18} \mathrm{O}$ & $(1-0)$ & 104711.40 \\
\hline $\mathrm{H}^{13} \mathrm{CCCN}$ & $(12-11)$ & 105799.11 \\
\hline $\mathrm{CH}_{2} \mathrm{NH}$ & $\left(4,0,4, F-3,1,3, F^{\prime}\right)$ & 105793.92 \\
\hline${ }^{14} \mathrm{CO} ?$ & $(1-0)$ & 105871.10 \\
\hline${ }^{13} \mathrm{CH}_{3} \mathrm{CN}$ & $(6-5)$ & 107196.57 \\
\hline OSB-H13CN? & $\mathrm{U}$ & 107164.67 \\
\hline OSB-SiO? & $\mathrm{U}$ & 107422.62 \\
\hline $\mathrm{U}$ & $\mathrm{U}$ & 108180.00 \\
\hline${ }^{13} \mathrm{CN}$ & $\left(1,0.5,1, F-0,0.5,1, F^{\prime}\right)$ & 108076.87 \\
\hline${ }^{13} \mathrm{CN}$ & $\left(1,0.5,0, F-0,0.5,1, F^{\prime}\right)$ & 108420.73 \\
\hline${ }^{13} \mathrm{CN}$ & $\left(1,0.5\right.$ or $1.5,1, F-0,0.5,0$ or $\left.1, F^{\prime}\right)$ & 108647.52 \\
\hline${ }^{13} \mathrm{CN}$ & $\left(1,1.5,2, F-0,0.5,1, F^{\prime}\right)$ & 108784.21 \\
\hline $\mathrm{SiS}$ & $(6-5)$ & 108924.30 \\
\hline $\mathrm{HC}_{3} \mathrm{~N}$ & $(12-11)$ & 109173.63 \\
\hline SO & $(3,2-2,1)$ & 109252.22 \\
\hline $\mathrm{C}^{15} \mathrm{~N}$ & $\left(1,0.5, F-0,0.5, F^{\prime}\right)$ & 109705.57 \\
\hline $\mathrm{C}^{18} \mathrm{O}$ & $(1-0)$ & 109782.17 \\
\hline HNCO & $(5,0,5-4,0,4)$ & 109904.92 \\
\hline $\mathrm{C}^{15} \mathrm{~N}$ & $\left(1,1.5, F-0,0.5, F^{\prime}\right)$ & 110021.71 \\
\hline${ }^{13} \mathrm{CO}$ & $(1-0)$ & 110201.35 \\
\hline $\mathrm{CH}_{3} \mathrm{CN}$ & $(6-5)$ & 110383.50 \\
\hline $\mathrm{CH}_{3}^{18} \mathrm{OH} ?$ & $(3,1,3-4,0,4)$ & 111209.73 \\
\hline $\mathrm{C}^{17} \mathrm{O}$ & $(1-0)$ & 112358.78 \\
\hline $\mathrm{CN}$ & $\left(1,0.5, F-0,0.5, F^{\prime}\right)$ & 113168.78 \\
\hline $\mathrm{CN}$ & $\left(1,1.5, F-0,0.5, F^{\prime}\right)$ & 113494.86 \\
\hline $\mathrm{H}^{13} \mathrm{CCCN}$ & $(13-12)$ & 114615.00 \\
\hline NS & $\Omega=0.5\left(2.5, F-1.5, F^{\prime}\right) l=e$ & 115160.07 \\
\hline $\mathrm{CO}$ & $(1-0)$ & 115271.20 \\
\hline gap & & $115490-126676$ \\
\hline $\mathrm{HCC}^{13} \mathrm{CN}$ & $(14-13)$ & 126839.59 \\
\hline $\mathrm{HC}^{13} \mathrm{CCN}$ & $(14-13)$ & 126827.35 \\
\hline${ }^{30} \mathrm{SiO}$ & $(3-2)$ & 127117.54 \\
\hline $\mathrm{HC}_{3} \mathrm{~N}$ & $(14-13)$ & 127367.67 \\
\hline $\mathrm{CH}_{2} \mathrm{NH}$ & $\left(2,0,2, F-1,0,1, F^{\prime}\right)$ & 127856.55 \\
\hline $\mathrm{U} ?$ & $\mathrm{U}$ & 127856.00 \\
\hline $\mathrm{U}$ & U & 128141.98 \\
\hline${ }^{29} \mathrm{SiO}$ & $(3-2)$ & 128637.04 \\
\hline $\mathrm{CH}_{3} \mathrm{CN} ? ?$ & $(7-6)$ & 128779.36 \\
\hline SO & $(3,3-2,2)$ & 129138.92 \\
\hline OSB-CS? & $\mathrm{U}$ & 129918.62 \\
\hline SO? & $(8,8-8,7)$ & 129953.66 \\
\hline
\end{tabular}


Table C.1. continued.

\begin{tabular}{|c|c|c|}
\hline Molecule & Transition & Rest frequency $(\mathrm{MHz})$ \\
\hline $\mathrm{SiO}$ & $(3-2)$ & 130268.68 \\
\hline SiN? & $\left(3,2.5, F-2,1.5, F^{\prime}\right)$ & 130710.83 \\
\hline SiN? & $\left(3,3.5, F-2,2.5, F^{\prime}\right)$ & 131215.24 \\
\hline $\mathrm{CH}_{3} \mathrm{NH}_{2}$ ? & $(3,1,0-2,-1,1)$ & 131685.75 \\
\hline $\mathrm{AlF}$ & $(4-3)$ & 131898.76 \\
\hline $\mathrm{CH}_{3} \mathrm{NH}_{2}$ & $(3,1,4-2,1,4)$ & 132201.25 \\
\hline $\mathrm{H}^{13} \mathrm{CCCN}$ & $(15-14)$ & 132246.36 \\
\hline $\mathrm{U}$ & $\mathrm{U}$ & 132526.88 \\
\hline${ }^{13} \mathrm{CH}_{3} \mathrm{OH} ?$ & $(5,1,4-4,-2,3)$ & 132960.07 \\
\hline $\mathrm{CH}_{3} \mathrm{NH}_{2}$ & $\left(3,0, \Gamma-2,0, \Gamma^{\prime}\right)$ & 132983.06 \\
\hline $\mathrm{CH}_{3} \mathrm{NH}_{2}$ & $\left(3,2, \Gamma-2,2, \Gamma^{\prime}\right)$ & 133022.24 \\
\hline $\mathrm{U}$ & $\mathrm{U}$ & 133144.76 \\
\hline $\mathrm{CH}_{2} \mathrm{NH}$ ? & $(2,1,1,3-1,1,0,2)$ & 133272.13 \\
\hline $\mathrm{CH}_{3} \mathrm{NH}_{2}$ & $(3,1,6-2,1,6)$ & 133421.06 \\
\hline $\mathrm{CH}_{3} \mathrm{NH}_{2}$ & $(3,1,5-2,1,5)$ & 133810.68 \\
\hline $\mathrm{SO}_{2}$ & $(8,2,6-8,1,7)$ & 134004.86 \\
\hline $\mathrm{CH}_{3} \mathrm{NH}_{2}$ & $(3,-1,1$ or $3-2,1,0$ or 2$)$ & 134327.05 \\
\hline $\mathrm{CH}_{3} \mathrm{NH}_{2} ? ?$ & $(5,0,5-4,1,5)$ & 134631.73 \\
\hline $\mathrm{OSB}-\mathrm{CH}_{3} \mathrm{OH}$ & $\mathrm{U}$ & 135277.80 \\
\hline $\mathrm{H}_{2} \mathrm{CS}$ & $(4,1,4-3,1,3)$ & 135298.26 \\
\hline $\mathrm{SO}_{2}$ & $(5,1,5-4,0,4)$ & 135696.02 \\
\hline $\mathrm{HC}_{3} \mathrm{~N}$ & $(15-14)$ & 136464.41 \\
\hline $\mathrm{H}_{2} \mathrm{CS}$ & $(4,2,3-3,2,2)$ & 137382.12 \\
\hline $\mathrm{H}_{2}^{13} \mathrm{CO}$ & $(2,1,2-1,1,1)$ & 137449.95 \\
\hline $\mathrm{CH}_{3}^{2} \mathrm{NH}_{2}$ ?? & $(5,0,3-4,1,2)$ & 137583.91 \\
\hline SO & $(3,4-2,3)$ & 138178.60 \\
\hline${ }^{13} \mathrm{CS}$ & $(3-2)$ & 138739.34 \\
\hline $\mathrm{CH}_{3}^{18} \mathrm{OH} ?$ & $\left(3, K_{a}, 3-2, K_{a}^{\prime}, 2\right)$ & 139080.31 \\
\hline $\mathrm{SO}_{2}^{3}$ & $(6,2,4-6,1,5)$ & 140306.17 \\
\hline $\mathrm{H}_{2} \mathrm{CO}$ & $(2,1,2-1,1,1)$ & 140839.50 \\
\hline PN & $(3-2)$ & 140967.69 \\
\hline $\mathrm{H}^{13} \mathrm{CCCN}$ & $(16-15)$ & 141061.78 \\
\hline${ }^{13} \mathrm{CH}_{3} \mathrm{OH}$ & $\left(3, K_{a}, 3-2, K_{a}, 2\right)$ & 141602.53 \\
\hline${ }^{13} \mathrm{CH}_{3} \mathrm{OH}$ & $\left(3, K_{a}, K_{c}-2, K_{a}, K_{c}\right)$ & 141623.55 \\
\hline $\mathrm{H}_{2}^{13} \mathrm{CO}$ & $(2,0,2-1,0,1)$ & 141983.74 \\
\hline $\mathrm{OSB}-\mathrm{H}_{2} \mathrm{CO}$ & $\mathrm{U}$ & 141983.74 \\
\hline${ }^{13} \mathrm{CH}_{3} \mathrm{CN}$ & $(8-7)$ & 142925.60 \\
\hline $\mathrm{U}$ & $\mathrm{U}$ & 143262.39 \\
\hline$C^{34} S$ & $(3-2)$ & 144617.10 \\
\hline $\mathrm{CH}_{3} \mathrm{OH}$ & $\left(3, K_{a}, 3-2, K_{a}, 2\right)$ & 145103.15 \\
\hline $\mathrm{CH}_{3} \mathrm{OH}$ & $\left(3, K_{a}, K_{c}-2, K_{a}, K_{c}\right)$ & 145124.41 \\
\hline $\mathrm{SiS}$ & $(8-7)$ & 145227.05 \\
\hline $\mathrm{H}_{2} \mathrm{CO}$ & $(2,0,2-1,0,1)$ & 145602.95 \\
\hline $\mathrm{CH}_{3} \mathrm{OH}$ ? & $(9,0,9-8,1,1)$ & 146618.70 \\
\hline $\mathrm{H}_{2}^{13} \mathrm{CO}$ & $(2,1,1-1,1,0)$ & 146635.67 \\
\hline $\mathrm{U}^{2}$ & $\mathrm{U}$ & 146828.37 \\
\hline $\mathrm{CS}$ & $(3-2)$ & 146969.03 \\
\hline $\mathrm{CH}_{3} \mathrm{CN}$ & $(8-7)$ & 147174.59 \\
\hline $\mathrm{U}$ & $\mathrm{U}$ & 147270.00 \\
\hline U & $\mathrm{U}$ & 150000.00 \\
\hline NO & $\Omega=0.5\left(2, F-1, F^{\prime}\right)$ & 150176.48 \\
\hline $\mathrm{H}_{2} \mathrm{CO}$ & $(2,1,1-1,1,0)$ & 150498.33 \\
\hline U & $\mathrm{U}$ & 151158.24 \\
\hline $\mathrm{SO}_{2}$ & $(2,2,0-2,1,1)$ & 151378.63 \\
\hline $\mathrm{U}$ & $\mathrm{U}$ & 152779.52 \\
\hline $\mathrm{HNCO}$ & $(7,0,7-6,0,6)$ & 153865.09 \\
\hline $\mathrm{U}$ & U & 154493.70 \\
\hline $\mathrm{HC}_{3} \mathrm{~N}$ & $(17-16)$ & 154657.28 \\
\hline${ }^{34} \mathrm{SO}$ & $(4,3-3,2)$ & 155506.80 \\
\hline $\mathrm{U}$ & $\mathrm{U}$ & 155810.60 \\
\hline
\end{tabular}


T. Kamiński et al.: Molecules in CK Vul

Table C.1. continued.

\begin{tabular}{|c|c|c|}
\hline Molecule & Transition & Rest frequency $(\mathrm{MHz})$ \\
\hline${ }^{13} \mathrm{CH}_{3} \mathrm{OH}$ & $(4,0,4-4,-1,4)$ & 156356.39 \\
\hline${ }^{13} \mathrm{CH}_{3} \mathrm{OH}$ & $\left(K, 0, K_{c}-K^{\prime},-1, K_{c}^{\prime}\right) K_{c}=K$ & 156373.66 \\
\hline $\mathrm{CH}_{3} \mathrm{OH}$ & $\left(K, 0, K_{c}-K^{\prime},-1, K_{c}\right) K_{c}=K$ & 157270.85 \\
\hline $\mathrm{SO}_{2}$ & $(3,2,2-3,1,3)$ & 158199.74 \\
\hline SO & $(4,3-3,2)$ & 158971.81 \\
\hline $\mathrm{U}$ & U & 159802.16 \\
\hline $\mathrm{U}$ & $\mathrm{U}$ & 160001.87 \\
\hline $\mathrm{SO}_{2}$ & $(10,0,10-9,1,9)$ & 160827.88 \\
\hline NS & $\Omega=0.5\left(3.5, F-2.5, F^{\prime}\right) l=e$ & 161300.59 \\
\hline $\mathrm{OSB}-\mathrm{HC}^{15} \mathrm{~N}$ & U & 161370.00 \\
\hline $\mathrm{Si}^{18} \mathrm{O}$ & $(4-3)$ & 161404.88 \\
\hline NS & $\Omega=0.5\left(3.5, F-2.5, F^{\prime}\right) l=f$ & 161697.91 \\
\hline $\mathrm{OSB}^{-29} \mathrm{SiO}$ & U & 161990.65 \\
\hline gap & & $162810-162980$ \\
\hline $\mathrm{SiS}$ & $(9-8)$ & 163376.78 \\
\hline AlF & $(5-4)$ & 164867.70 \\
\hline $\mathrm{SO}_{2}$ & $(5,2,4-5,1,5)$ & 165144.65 \\
\hline $\mathrm{SO}_{2}$ & $(7,1,7-6,0,6)$ & 165225.45 \\
\hline $\mathrm{U}$ & $\mathrm{U}$ & 165970.00 \\
\hline $\mathrm{CH}_{3} \mathrm{CN}$ & $(9,0-8,0)$ & 165569.08 \\
\hline $\mathrm{CH}_{2} \mathrm{NH}$ & $\left(1,1,0, F-1,0,1, F^{\prime}\right)$ & 166851.87 \\
\hline $\mathrm{H}^{13} \mathrm{C}^{15} \mathrm{~N}$ & $(2-1)$ & 167453.28 \\
\hline $\mathrm{CH}_{3} \mathrm{NH}_{2}$ & $(2,1,4-1,0,5)$ & 167598.40 \\
\hline $\mathrm{H}_{2}^{34} \mathrm{~S} ?$ & $(1,1,0-1,0,1)$ & 167910.52 \\
\hline${ }^{13} \mathrm{CCH}$ & $(2-1)$ & 168305.82 \\
\hline $\mathrm{H}_{2} \mathrm{~S}$ & $(1,1,0-1,0,1)$ & 168762.76 \\
\hline $\mathrm{H}_{2} \mathrm{CS}$ & $(5,1,5-4,1,4)$ & 169114.08 \\
\hline $\mathrm{CH}_{3} \mathrm{NH}_{2}$ & $(2,1,2-1,0,3)$ & 169447.51 \\
\hline${ }^{30} \mathrm{SiO}$ & $(4-3)$ & 169486.87 \\
\hline $\mathrm{CH}_{3} \mathrm{OH}$ ? & $(3,2,1-2,1,1)$ & 170060.58 \\
\hline $\mathrm{HC}^{18} \mathrm{O}^{+}$ & $(2-1)$ & 170322.63 \\
\hline $\mathrm{H}^{15} \mathrm{~N}^{13} \mathrm{C}$ & $(2-1)$ & 170515.68 \\
\hline $\mathrm{C}^{13} \mathrm{CH}$ & $(2-1)$ & 170520.94 \\
\hline $\mathrm{U}$ & $\mathrm{U}$ & 171070.00 \\
\hline${ }^{29} \mathrm{SiO}$ & $(4-3)$ & 171512.80 \\
\hline $\mathrm{H}_{2} \mathrm{CS}$ & $(5,0,5-4,0,4)$ & 171688.12 \\
\hline $\mathrm{H}_{2} \mathrm{CS}$ ? & $(5,2,4-4,2,3)$ & 171720.51 \\
\hline $\mathrm{H}_{2} \mathrm{CS}$ ? & $(5,2,3-4,2,2)$ & 171780.17 \\
\hline $\mathrm{HC}^{15} \mathrm{~N}$ & $(2-1)$ & 172107.96 \\
\hline $\mathrm{CH}_{2} \mathrm{NH}$ & $\left(2,1,1, F-2,0,2, F^{\prime}\right)$ & 172267.18 \\
\hline $\mathrm{H}^{13} \mathrm{CN}$ & $(2-1)$ & 172677.85 \\
\hline $\mathrm{U}$ & $\mathrm{U}$ & 172990.48 \\
\hline $\mathrm{CH}_{3} \mathrm{NH}_{2}$ & $(2,1,5-1,0,5)$ & 173267.80 \\
\hline $\mathrm{H}^{13} \mathrm{CO}^{+}$ & $(2-1)$ & 173506.70 \\
\hline $\mathrm{SiO}$ & (4-3) & 173688.24 \\
\hline $\mathrm{HN}^{13} \mathrm{C}$ & $(2-1)$ & 174179.41 \\
\hline $\mathrm{H}_{2} \mathrm{CS}$ & $(5,1,4-4,1,3)$ & 174345.22 \\
\hline $\mathrm{SiN}$ & $\left(4,4.5, F-3,3.5, F^{\prime}\right)$ & 174360.89 \\
\hline $\mathrm{CCH}$ & $\left(2,2.5, F-1,1.5, F^{\prime}\right)$ & 174664.11 \\
\hline $\mathrm{CCH}$ & $\left(2,1.5, F-1,0.5, F^{\prime}\right)$ & 174725.12 \\
\hline $\mathrm{CCH}$ & $\left(2,1.5, F-1,1.5, F^{\prime}\right)$ & 174818.11 \\
\hline $\mathrm{SO}_{2}$ & $(7,2,6-7,1,7)$ & 175275.72 \\
\hline $\mathrm{HNCO}$ & $(8,0,8-7,0,7)$ & 175843.70 \\
\hline $\mathrm{U}$ & $\mathrm{U}$ & 176749.10 \\
\hline $\mathrm{HCN}$ & $(2-1)$ & 177261.11 \\
\hline $\mathrm{H}^{15} \mathrm{NC}$ & $(2-1)$ & 177729.09 \\
\hline $\mathrm{HCO}^{+}$ & $(2-1)$ & 178375.06 \\
\hline gap & & $178480-230660$ \\
\hline $\mathrm{CO}$ & $(2-1)$ & 230538.00 \\
\hline
\end{tabular}


A\&A 607, A78 (2017)

Table C.1. continued.

\begin{tabular}{|c|c|c|}
\hline Molecule & Transition & Rest frequency (MHz) \\
\hline${ }^{13} \mathrm{CS}$ & $(5-4)$ & 231220.69 \\
\hline $\mathrm{U}$ & $\mathrm{U}$ & 231720.00 \\
\hline $\mathrm{U}$ & $\mathrm{U}$ & 232670.00 \\
\hline $\mathrm{SO}_{2}$ & $(4,2,2-3,1,3)$ & 235151.72 \\
\hline${ }^{13} \mathrm{CH}_{3} \mathrm{OH} ? ?$ & $(5,0,5-4,0,4)$ & 235960.37 \\
\hline $\mathrm{U}$ & $\mathrm{U}$ & 239070.00 \\
\hline $\mathrm{U}$ & $\mathrm{U}$ & 240370.00 \\
\hline $\mathrm{C}^{34} \mathrm{~S}$ & $(5-4)$ & 241016.09 \\
\hline gap & & $241410-246210$ \\
\hline NO & $\Omega=0.5\left(3, F-2, F^{\prime}\right)$ & 250444.39 \\
\hline $\mathrm{NO}$ & $\Omega=0.5\left(3, F-2, F^{\prime}\right)$ & 250803.29 \\
\hline $\mathrm{H}^{13} \mathrm{C}^{15} \mathrm{~N}$ & $(3-2)$ & 251175.23 \\
\hline $\mathrm{SO}_{2}$ & $(8,3,5-8,2,6)$ & 251210.59 \\
\hline $\mathrm{U}$ & $\mathrm{U}$ & 251450.00 \\
\hline $\mathrm{U}$ & $\mathrm{U}$ & 251560.00 \\
\hline $\mathrm{U}$ & $\mathrm{U}$ & 251630.00 \\
\hline $\mathrm{SO}$ & $(6,5-5,4)$ & 251825.77 \\
\hline $\mathrm{U}$ & $\mathrm{U}$ & 252770.00 \\
\hline NS & $\Omega=0.5\left(5.5, F-4.5, F^{\prime}\right) l=e$ & 253570.94 \\
\hline NS & $\Omega=0.5\left(5.5, F-4.5, F^{\prime}\right) l=f$ & 253969.71 \\
\hline $\mathrm{CH}_{3} \mathrm{OH}$ & $(2,0,2-1,-1,1)$ & 254015.34 \\
\hline $\mathrm{CH}_{3} \mathrm{NH}_{2}$ & $(4,1,4-3,0,5)$ & 254055.85 \\
\hline${ }^{30} \mathrm{SiO}$ & $(6-5)$ & 254216.66 \\
\hline $\mathrm{SO}_{2}$ & $(6,3,3-6,2,4)$ & 254280.54 \\
\hline $\mathrm{CH}_{2} \mathrm{NH}$ & $\left(4,0,4, F-3,0,3, F^{\prime}\right)$ & 254685.26 \\
\hline $\mathrm{HC}^{18} \mathrm{O}^{+} ?$ & $(3-2)$ & 255479.39 \\
\hline $\mathrm{C}^{13} \mathrm{CH} ?$ & $(3-2)$ & 255776.41 \\
\hline $\mathrm{SO}_{2}$ & $(5,3,3-5,2,4)$ & 256246.95 \\
\hline${ }^{34} \mathrm{SO}$ & $(6,7-5,6)$ & 256877.81 \\
\hline
\end{tabular}


Table C.2. Same as Table C.1 but for APEX spectra.

\begin{tabular}{|c|c|c|}
\hline Molecule & Transition & Rest frequency (MHz) \\
\hline${ }^{30} \mathrm{SiO}$ & $(4-3)$ & 169486.87 \\
\hline${ }^{29} \mathrm{SiO}$ & $(4-3)$ & 171512.80 \\
\hline $\mathrm{HC}^{15} \mathrm{~N}$ & $(2-1)$ & 172107.96 \\
\hline $\mathrm{H}^{13} \mathrm{CN}$ & $(2-1)$ & 172677.85 \\
\hline $\mathrm{CH}_{3} \mathrm{NH}_{2}$ & $(2,1,5-1,0,5)$ & 173267.80 \\
\hline $\mathrm{H}^{13} \mathrm{CO}^{+}$ & $(2-1)$ & 173506.70 \\
\hline $\mathrm{SiO}$ & $(4-3)$ & 173688.24 \\
\hline $\mathrm{HN}^{13} \mathrm{C}$ & $(2-1)$ & 174179.41 \\
\hline gap & & $174770-181380$ \\
\hline $\mathrm{N}_{2} \mathrm{H}^{+}$ & $(2-1)$ & 186344.68 \\
\hline $\mathrm{U}$ & $\mathrm{U}$ & 186850.00 \\
\hline $\mathrm{PN}$ & $(4-3)$ & 187953.26 \\
\hline${ }^{13} \mathrm{CH}_{3} \mathrm{OH}$ & $\left(4, K_{a}, 4-3, K_{a}, 3\right)$ & 188788.03 \\
\hline${ }^{13} \mathrm{CH}_{3} \mathrm{OH}$ & $\left(4, K_{a}, 3-3, K_{a}, 2\right)$ & 188836.43 \\
\hline gap & & $189320-19.480$ \\
\hline AlF & $(6-5)$ & 197833.15 \\
\hline gap & & $201330-216820$ \\
\hline $\mathrm{SiO}$ & $(5-4)$ & 217104.92 \\
\hline${ }^{13} \mathrm{CN}$ & $\left(2,1.5\right.$ or $2.5,1$ or $2, F-1,0.5$ or $\left.1.5,1, F^{\prime}\right)$ & 217297.72 \\
\hline${ }^{13} \mathrm{CN}$ & $\left(2,2.5,2\right.$ or $3, F-1,1.5,1$ or $\left.2, F^{\prime}\right)$ & 217456.59 \\
\hline${ }^{13} \mathrm{CN}$ & $\left(2,1.5,1, F-1,0.5,1, F^{\prime}\right)$ & 217633.04 \\
\hline $\mathrm{H}_{2} \mathrm{CO}$ & $(3,0,3-2,0,2)$ & 218222.19 \\
\hline $\mathrm{CH}_{3} \mathrm{OH} ?$ & $(4,2,2-3,1,2)$ & 218440.05 \\
\hline $\mathrm{C}^{18} \mathrm{O}$ & $(2-1)$ & 219560.35 \\
\hline $\mathrm{C}^{15} \mathrm{~N} ?$ & $\left(2,2.5, F-1,1.5, F^{\prime}\right)$ & 219933.63 \\
\hline${ }^{13} \mathrm{CO}$ & $(2-1)$ & 220398.68 \\
\hline gap & & $220790-224750$ \\
\hline $\mathrm{H}_{2} \mathrm{CO}$ & $(3,1,2-2,1,1)$ & 225697.78 \\
\hline $\mathrm{CN}$ & $\left(2,1.5, F-1,0.5, F^{\prime}\right)$ & 226658.92 \\
\hline $\mathrm{CN}$ & $\left(2,2.5, F-1,1.5, F^{\prime}\right)$ & 226876.39 \\
\hline instr. & & $227260-229180$ \\
\hline $\mathrm{CO}$ & $(2-1)$ & 230538.00 \\
\hline $\mathrm{AlF}$ & $(7-6)$ & 230793.89 \\
\hline${ }^{13} \mathrm{CS}$ & $(5-4)$ & 231220.69 \\
\hline gap & & $232540-241110$ \\
\hline $\mathrm{CH}_{3} \mathrm{OH} ? ?$ & $(5,-1,5-4,-1,4)$ & 241767.22 \\
\hline $\mathrm{CH}_{3} \mathrm{OH} ? ?$ & $(5,0,5-4,0,4)$ & 241791.43 \\
\hline $\mathrm{CS}$ & $(5-4)$ & 244935.56 \\
\hline gap & & $245100-257000$ \\
\hline${ }^{29} \mathrm{SiO}$ & $(6-5)$ & 257255.21 \\
\hline $\mathrm{HC}^{15} \mathrm{~N}$ & $(3-2)$ & 258157.00 \\
\hline $\mathrm{U}$ & $\mathrm{U}$ & 257810.00 \\
\hline $\mathrm{U}$ & $\mathrm{U}$ & 258630.00 \\
\hline $\mathrm{H}^{13} \mathrm{CN}$ & $(3-2)$ & 259011.80 \\
\hline $\mathrm{H}^{13} \mathrm{CO}^{+}$ & $(3-2)$ & 260255.34 \\
\hline $\mathrm{SiO}$ & $(6-5)$ & 260518.01 \\
\hline $\mathrm{HN}^{13} \mathrm{C}$ & $(3-2)$ & 261263.51 \\
\hline $\mathrm{CCH}$ & $(3,3.5,3-2,2.5,3)$ & 261978.12 \\
\hline $\mathrm{HCN}$ & $(3-2)$ & 265886.43 \\
\hline $\mathrm{U}$ & $\mathrm{U}$ & 268450.00 \\
\hline gap & & $268730-270000$ \\
\hline $\mathrm{HNC}$ & $(3-2)$ & 271981.142 \\
\hline gap & & $273970-278489$ \\
\hline $\mathrm{N}_{2} \mathrm{H}^{+}$ & $(3-2)$ & 279511.75 \\
\hline $\mathrm{H}_{2} \mathrm{CO}$ & $(4,1,4-3,1,3)$ & 281526.93 \\
\hline $\mathrm{SO}_{2}$ & $(6,2,4-5,1,5)$ & 282036.57 \\
\hline $\mathrm{CH}_{2} \mathrm{NH}$ ? & $\left(2,1,2, F-1,0,1, F^{\prime}\right)$ & 284254.50 \\
\hline $\mathrm{CS}$ & $(6-5)$ & 293912.09 \\
\hline${ }^{29} \mathrm{SiO}$ & $(7-6)$ & 300120.48 \\
\hline
\end{tabular}


Table C.2. continued.

\begin{tabular}{|c|c|c|}
\hline Molecule & Transition & Rest frequency $(\mathrm{MHz})$ \\
\hline $\mathrm{CH}_{3} \mathrm{OH}$ ? & $(1,1,0-1,0,1)$ & 303366.89 \\
\hline $\mathrm{SiO}$ & $(7-6)$ & 303926.81 \\
\hline${ }^{34} \mathrm{SO} ?$ & $(2,2-1,2)$ & 308993.58 \\
\hline gap & & $310610-311160$ \\
\hline${ }^{13} \mathrm{CO}$ & $(3-2)$ & 330587.97 \\
\hline telluric & & $332500-332900$ \\
\hline $\mathrm{CN}$ & $\left(3,2.5, F-2,2.5, F^{\prime}\right)$ & 339487.80 \\
\hline $\mathrm{CN}$ & $\left(3,2.5, F-2,1.5, F^{\prime}\right)$ & 340031.29 \\
\hline $\mathrm{CH}_{3} \mathrm{OH} ?$ & $(2,2,0,+0-3,1,3,+0)$ & 340141.22 \\
\hline $\mathrm{CN}$ & $\left(3,3.5, F-2,2.5, F^{\prime}\right)$ & 340248.80 \\
\hline $\mathrm{HC}^{15} \mathrm{~N}$ & $(4-3)$ & 344200.11 \\
\hline $\mathrm{H}^{13} \mathrm{CN}$ & $(4-3)$ & 345339.77 \\
\hline $\mathrm{CO}$ & $(3-2)$ & 345795.99 \\
\hline $\mathrm{H}^{13} \mathrm{CO}^{+}$ & $(4-3)$ & 346998.34 \\
\hline $\mathrm{SiO}$ & $(8-7)$ & 347330.58 \\
\hline $\mathrm{HN}^{13} \mathrm{C}$ & $(4-3)$ & 348340.90 \\
\hline${ }^{13} \mathrm{CH}_{3} \mathrm{OH}$ & $(1,1,1-0,0,0)$ & 350103.12 \\
\hline NO? & $(4,1,3.5,4.5-3,1,2.5,3.5)$ & 352204.30 \\
\hline $\mathrm{HCN}$ & $(4-3)$ & 354505.48 \\
\hline $\mathrm{HCO}^{+}$ & $(4-3)$ & 356734.22 \\
\hline gap & & $356600-390520$ \\
\hline $\mathrm{H}_{2}^{34} \mathrm{~S} ?$ & $(2,1,1-2,0,2)$ & 393725.70 \\
\hline gap & & $395720-396300$ \\
\hline gap & & $400300-401100$ \\
\hline $\mathrm{CH}_{3} \mathrm{NH}_{2}$ ? & $(5,-3,1-5,2,0)$ & 402354.89 \\
\hline $\mathrm{U}$ & $\mathrm{U}$ & 402500.00 \\
\hline telluric & & 408240.00 \\
\hline gap & & $412300-413100$ \\
\hline gap & & $417080-417970$ \\
\hline gap & & $421960-426760$ \\
\hline telluric & & 427400.00 \\
\hline telluric & & 429350.00 \\
\hline telluric & & 430300.00 \\
\hline gap & & $430750-438780$ \\
\hline telluric & & 439400.00 \\
\hline telluric & & 441270.00 \\
\hline${ }^{13} \mathrm{CO}$ & $(4-3)$ & 440765.17 \\
\hline telluric & & 442050.00 \\
\hline gap & & $442750-459050$ \\
\hline $\mathrm{CO}$ & $(4-3)$ & 461040.77 \\
\hline gap & & $463050-471070$ \\
\hline telluric & & 472850.00 \\
\hline telluric & & 474500.00 \\
\hline telluric & & $474100-475000$ \\
\hline gap & & $475040-477200$ \\
\hline gap & & $481200-489200$ \\
\hline $\mathrm{C}$ and ${ }^{13} \mathrm{C}$ & $(1-0)$ & 492160.651 \\
\hline gap & & 494 180-690060 \\
\hline $\mathrm{H}^{13} \mathrm{CN}$ & $(8-7)$ & 690552.08 \\
\hline $\mathrm{CO}$ & $(6-5)$ & 691473.08 \\
\hline gap & & $692880-805230$ \\
\hline gap & & 808 060-907 730 \\
\hline end & & 906600 \\
\hline
\end{tabular}




\section{Appendix D: Results of LTE excitation analysis}

Table D.1. Results of CASSIS analysis of the main isotopologues.

\begin{tabular}{|c|c|c|c|c|c|c|}
\hline Species & $\begin{array}{c}N \\
\left(\mathrm{~cm}^{-2}\right)\end{array}$ & $\begin{array}{l}T_{\mathrm{ex}} \\
(\mathrm{K})\end{array}$ & $\begin{array}{c}3 \sigma \text { range in } \\
T_{\mathrm{ex}}(\mathrm{K})\end{array}$ & $\begin{array}{c}F W H M \\
\left(\mathrm{~km} \mathrm{~s}^{-1}\right)\end{array}$ & $\begin{array}{l}\text { Size } \\
\left({ }^{\prime \prime}\right)\end{array}$ & $\begin{array}{c}V_{\mathrm{LSR}} \\
\left(\mathrm{km} \mathrm{s}^{-1}\right)\end{array}$ \\
\hline $\mathrm{AlF}^{a}$ & $6.9 \mathrm{e} 15$ & 7.1 & $6.6-7.6$ & 76 & 1.1 & -10.5 \\
\hline $\mathrm{CN}$ & $3.8 \mathrm{e} 15$ & 5.7 & $5.3-6.1$ & 120 & 11.1 & -10.0 \\
\hline $\mathrm{CO}$ & $3.0 \mathrm{e} 17$ & 11.3 & $10.2-12.3$ & 206 & 9.6 & -18.0 \\
\hline $\mathrm{CS}^{a}$ & $2.7 \mathrm{e} 15$ & 5.1 & $4.4-5.7$ & 138 & 4.5 & -11.5 \\
\hline $\mathrm{NO}$ & $4.0 \mathrm{e} 15$ & 4.9 & $4.0-5.7$ & 105 & 4.1 & 5.0 \\
\hline NS & $4.7 \mathrm{e} 14$ & 6.0 & $5.5-6.4$ & 185 & 5.0 & -11.0 \\
\hline PN & $1.7 \mathrm{e} 15$ & 4.5 & $3.9-5.4$ & 135 & 1.1 & -17.0 \\
\hline SO & $2.3 \mathrm{e} 15$ & 9.8 & $3.2-12.5$ & 90 & 1.4 & -7.0 \\
\hline $\mathrm{SiO}$ & $8.1 \mathrm{e} 13$ & 11.8 & $9.5-13.7$ & 163 & 11.6 & -12.5 \\
\hline $\mathrm{SiN}$ & $2.5 \mathrm{e} 14$ & 5.1 & $3.9-6.8$ & 65 & 2.2 & -8.0 \\
\hline $\mathrm{SiS}$ & $7.9 \mathrm{e} 15$ & 9.2 & $6.6-12.0$ & 133 & 0.9 & -9.0 \\
\hline $\mathrm{CCH}$ & $6.4 \mathrm{e} 14$ & 3.5 & $3.5-3.9$ & 154 & 7.0 & -9.5 \\
\hline $\mathrm{H}_{2} \mathrm{~S}^{b}$ & $8.9 \mathrm{e} 15$ & 5.5 & $>5.1$ & 145 & 2.0 & 8.4 \\
\hline $\mathrm{HCN}$ & $2.8 \mathrm{e} 14$ & 8.4 & $7.5-9.3$ & 145 & 9.6 & -14.3 \\
\hline $\mathrm{HCO}^{+}$ & $5.3 \mathrm{e} 14$ & 3.7 & $3.6-3.9$ & 77 & 4.5 & -10.5 \\
\hline $\mathrm{HNC}^{a}$ & $5.0 \mathrm{e} 14$ & 3.9 & $3.3-5.0$ & 140 & 9.5 & -15.0 \\
\hline $\mathrm{N}_{2} \mathrm{H}^{+}$ & $1.5 \mathrm{e} 14$ & 6.3 & $5.6-6.8$ & 173 & 4.5 & -15.5 \\
\hline $\mathrm{SO}_{2}$ & $9.4 \mathrm{e} 14$ & 9.4 & $6.2-15.7$ & 70 & 1.9 & -11.1 \\
\hline $\mathrm{H}_{2} \mathrm{CO}^{c}$ & $1.8 \mathrm{e} 15$ & 3.0 & $2.9-3.0$ & 130 & 7.2 & -8.5 \\
\hline $\mathrm{HNCO}^{a}$ & $3.1 \mathrm{e} 13$ & 12.5 & $9.7-19.5$ & 75 & 4.5 & -6.0 \\
\hline $\mathrm{H}_{2} \mathrm{CS}^{b}$ & $1.8 \mathrm{e} 15$ & 9.0 & $6.6-12.9$ & 150 & 1.0 & -10.0 \\
\hline $\mathrm{CH}_{2} \mathrm{NH}^{e}$ & $9.5 \mathrm{e} 13$ & 10.4 & $7.0-21.0$ & 160 & 4.5 & -8.0 \\
\hline $\mathrm{HC}_{3} \mathrm{~N}$ & $1.8 \mathrm{e} 14$ & 8.6 & $6.5-10.8$ & 130 & 6.8 & -9.6 \\
\hline $\mathrm{CH}_{3} \mathrm{CN}^{a, d, e}$ & $2.4 \mathrm{e} 14$ & 6.7 & $6.4-6.9$ & 200 & 2.9 & -2.7 \\
\hline $\mathrm{CH}_{3} \mathrm{OH}^{d, e}$ & $1.0 \mathrm{e} 16$ & 3.3 & $3.1-3.7$ & 130 & 4.5 & -15.6 \\
\hline $\mathrm{CH}_{3} \mathrm{NH}_{2}{ }^{a, e}$ & $1.6 \mathrm{e} 16$ & 3.9 & $3.2-5.0$ & 183 & 3.4 & -7.0 \\
\hline
\end{tabular}

Notes. The species listed here were simulated simultaneously with their rare istotopic versions. Isotopic ratios are given separately in Table 2 . ${ }^{(a)}$ Species analyzed using spectroscopic data from JPL. CDMS was used for all other species. ${ }^{(b)}$ Ortho to para ratio assumed to be $1 .{ }^{(c)}$ Ortho to para ratio is $2.5 \pm 0.8(3 \sigma)$. VASTEL database was used in the simulations. ${ }^{(d)}$ The ratio of $A$ to $E$ type species was assumed to be $1 .{ }^{(e)}$ Non-LTE excitation possible. 


\section{Appendix E: CASSIS LTE simulation}
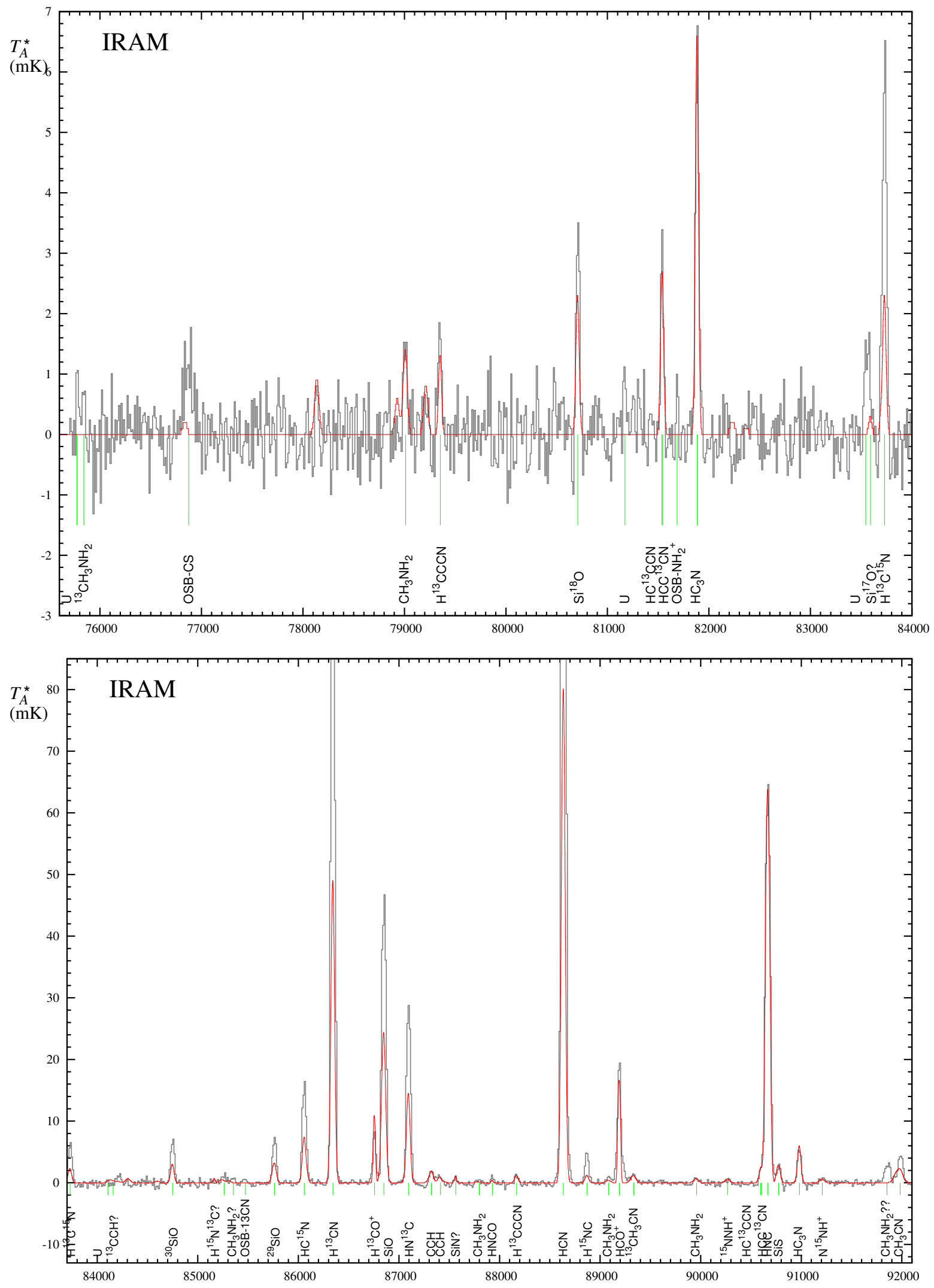

Fig. E.1. IRAM spectra (grey) and a CASSIS LTE simulation of the spectrum (red). Some parts of the specta with no detected lines were skipped. 
T. Kamiński et al.: Molecules in CK Vul
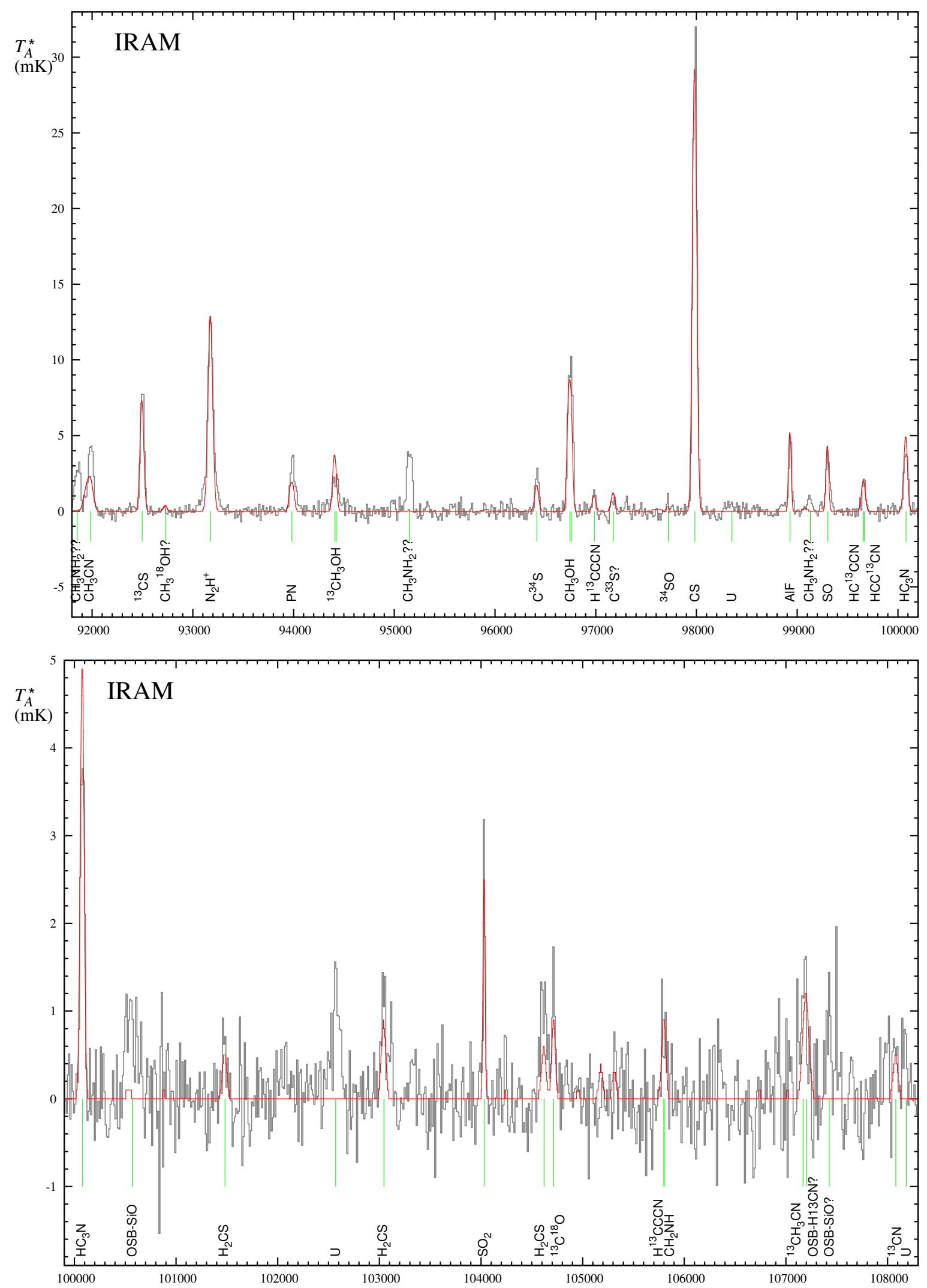

Fig. E.1. continued. 
A\&A 607, A78 (2017)
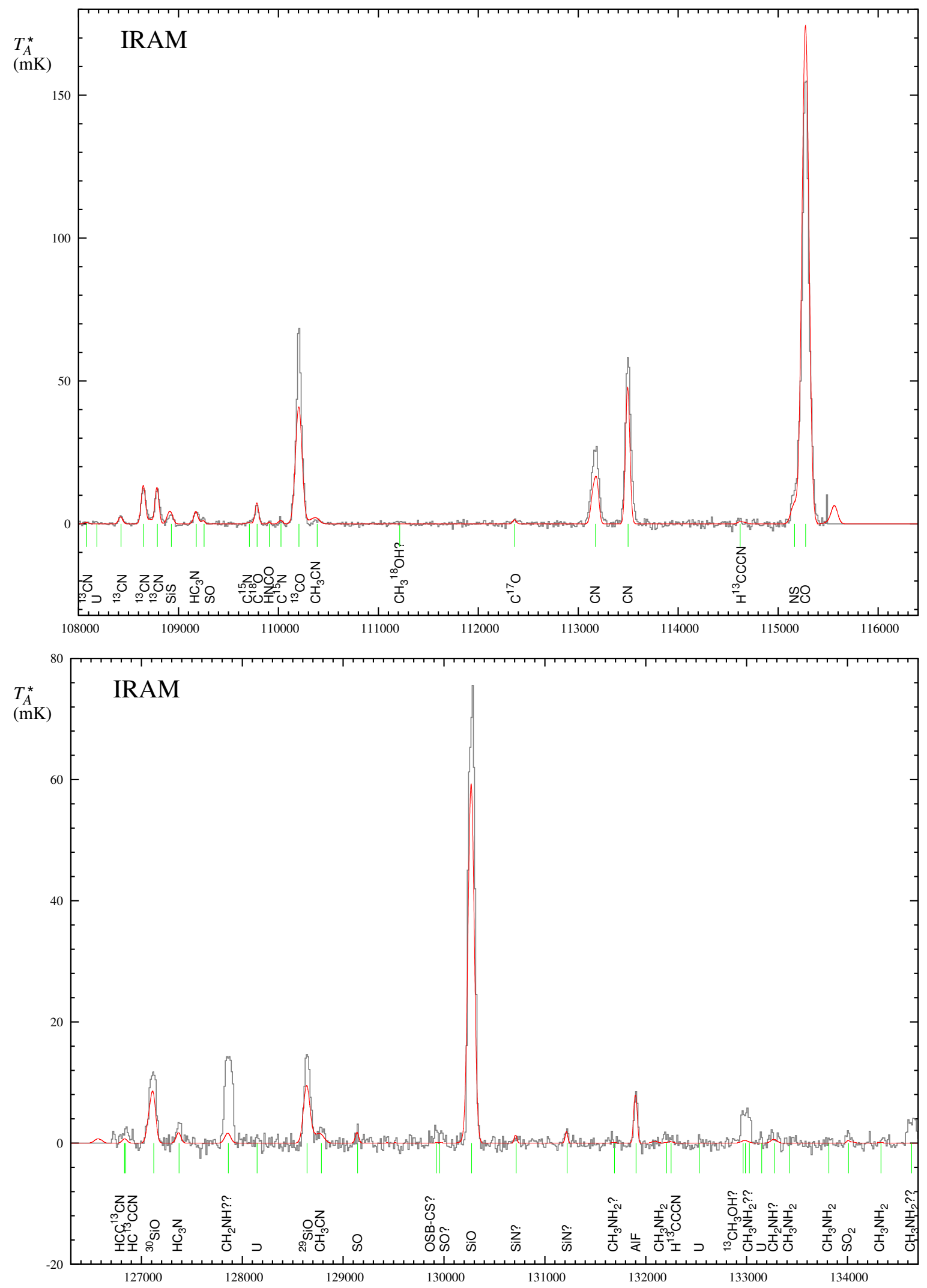

Fig. E.1. continued. 
T. Kamiński et al.: Molecules in CK Vul
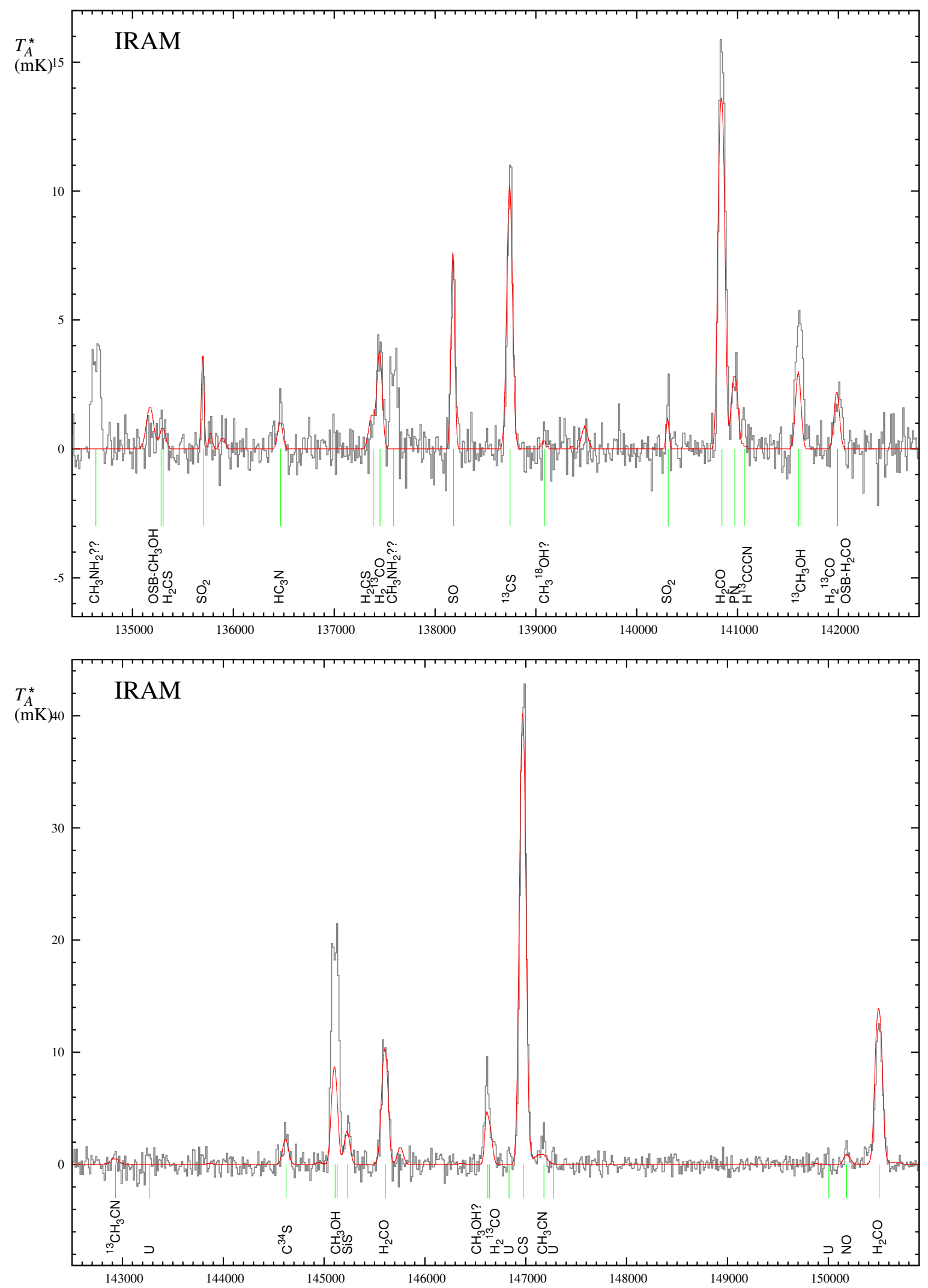

Fig. E.1. continued. 

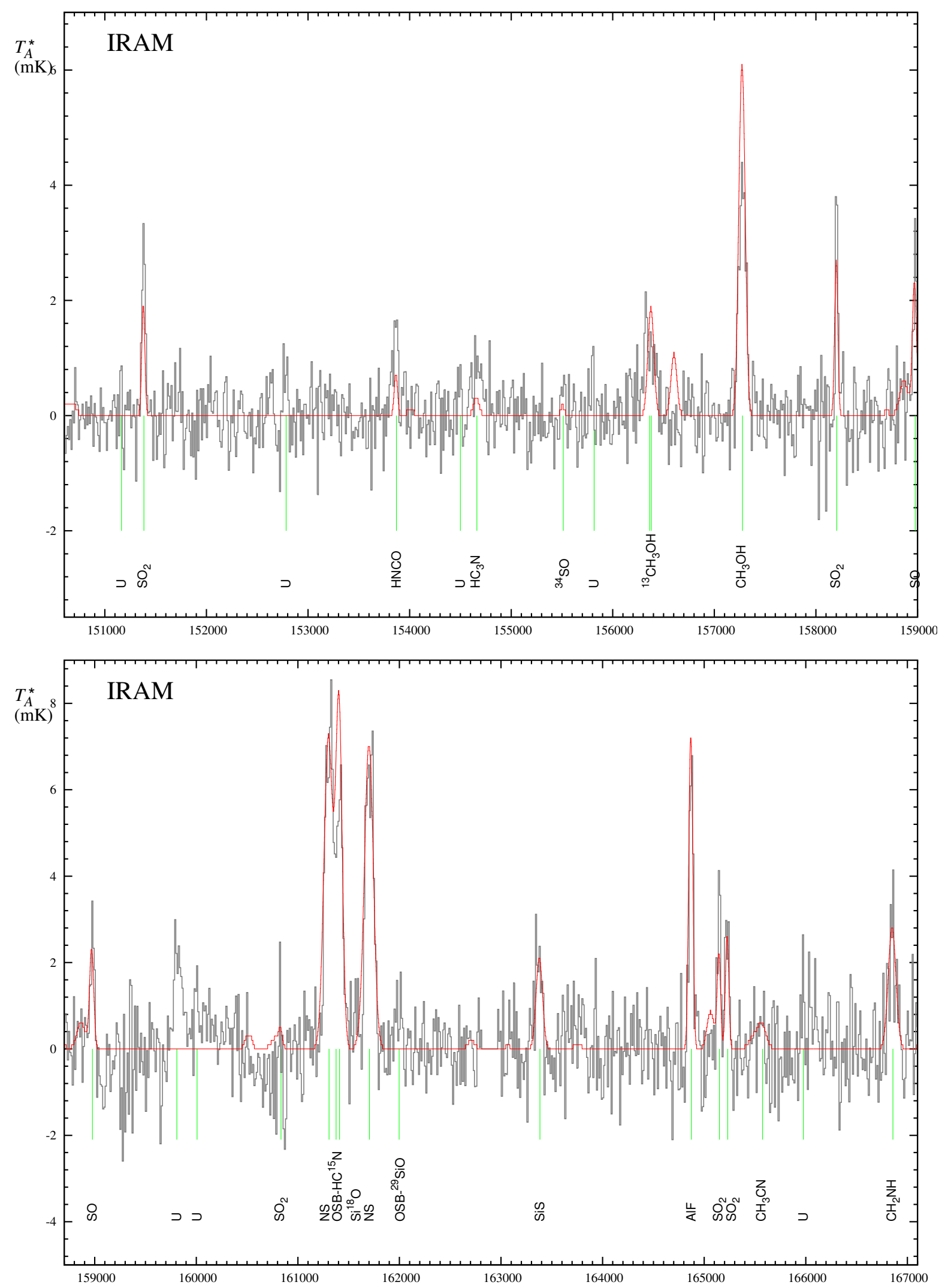

Fig. E.1. continued. 
T. Kamiński et al.: Molecules in CK Vul
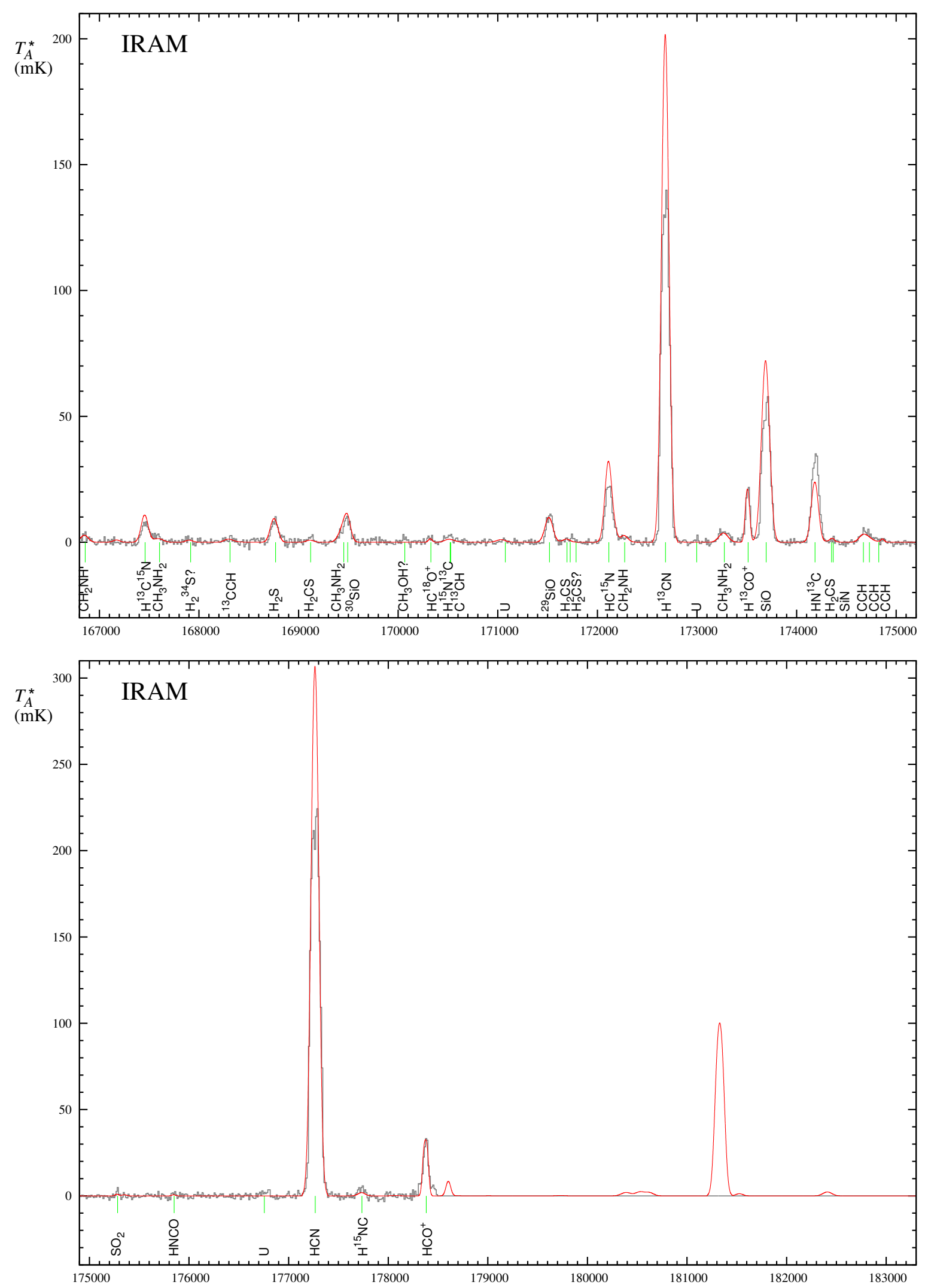

Fig. E.1. continued. 
A\&A 607, A78 (2017)
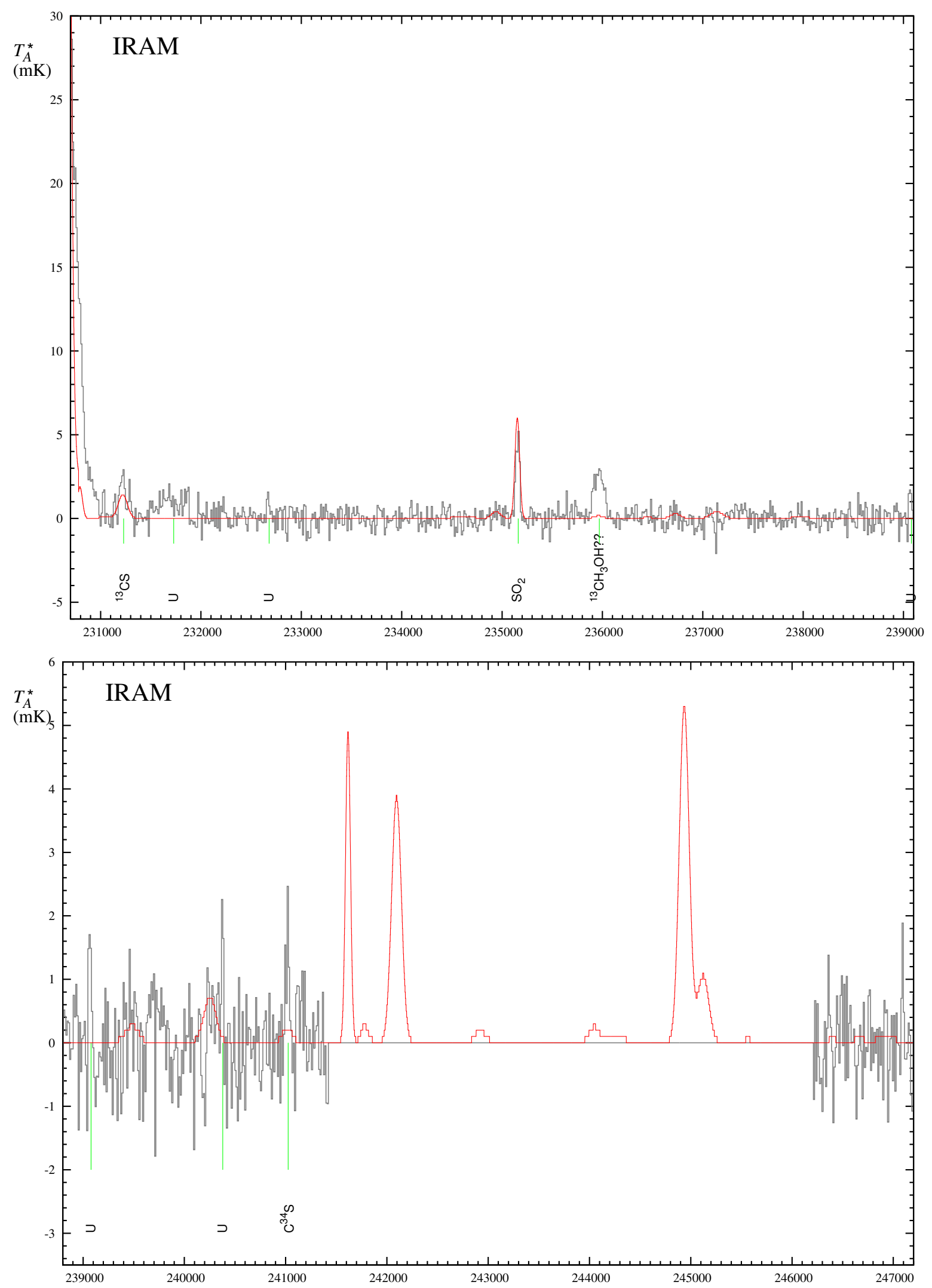

Fig. E.1. continued. 
T. Kamiński et al.: Molecules in CK Vul
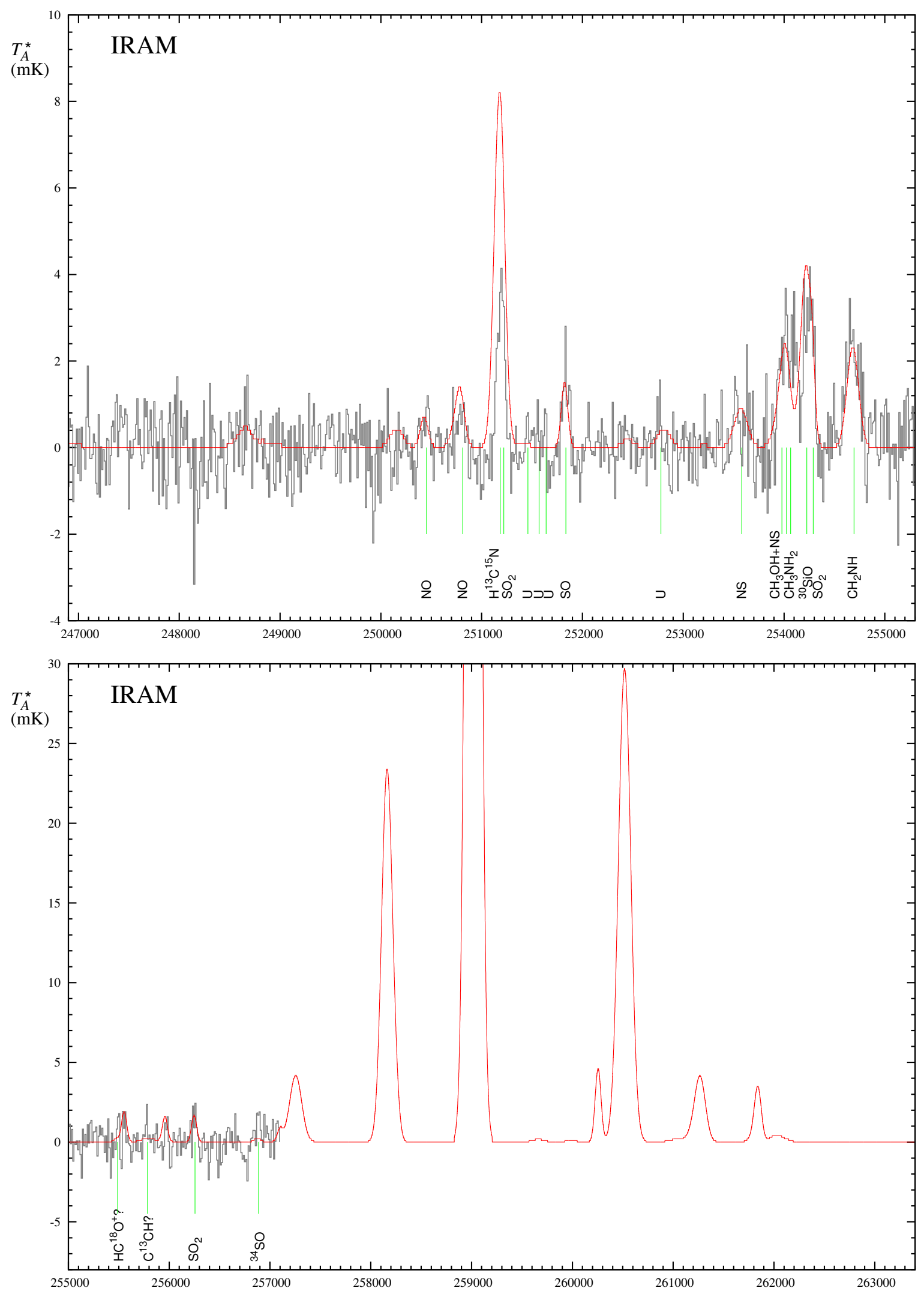

Fig. E.1. continued. 
A\&A 607, A78 (2017)
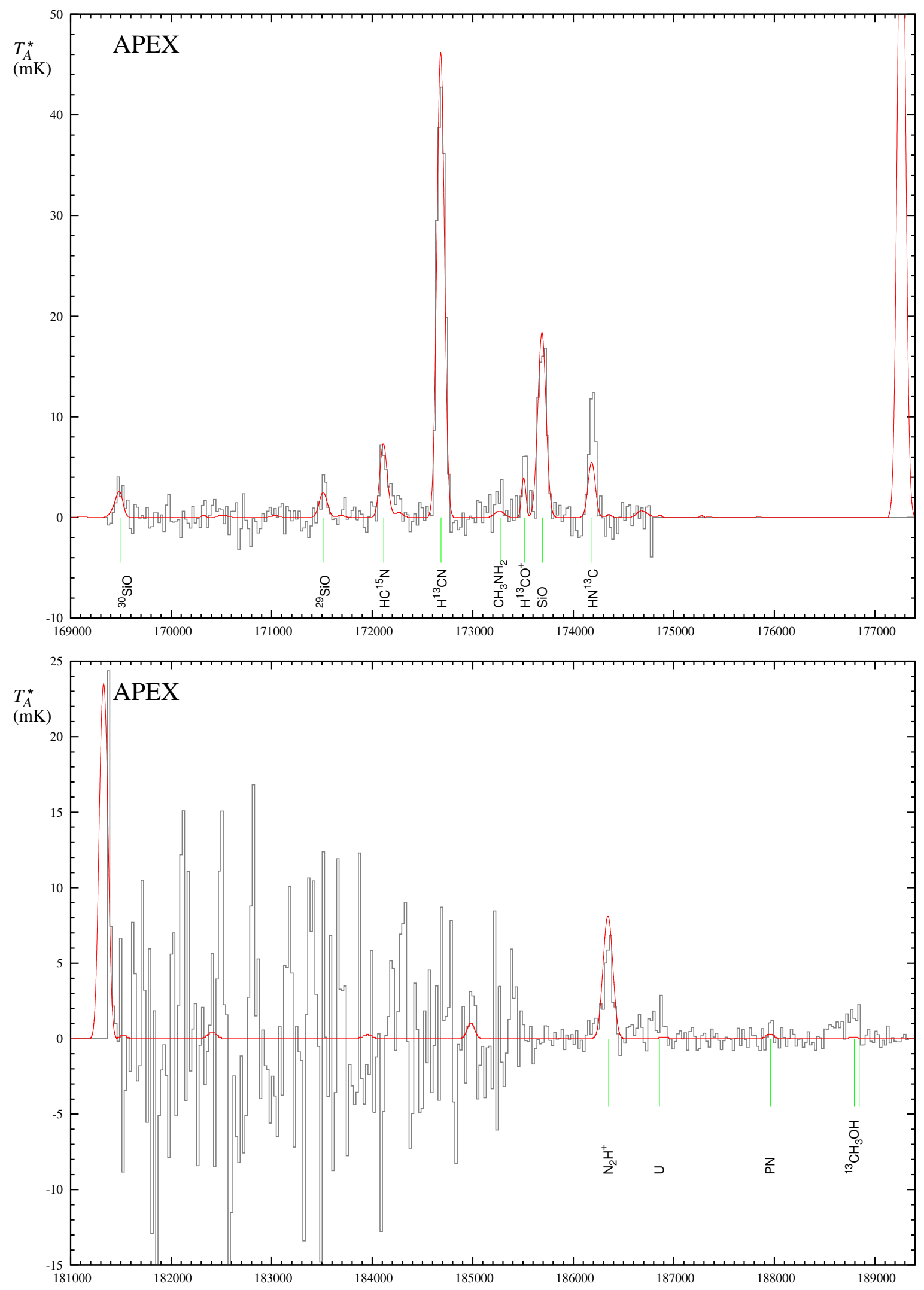

Fig. E.2. Same as Fig. E.1 but for APEX spectra. 
T. Kamiński et al.: Molecules in CK Vul
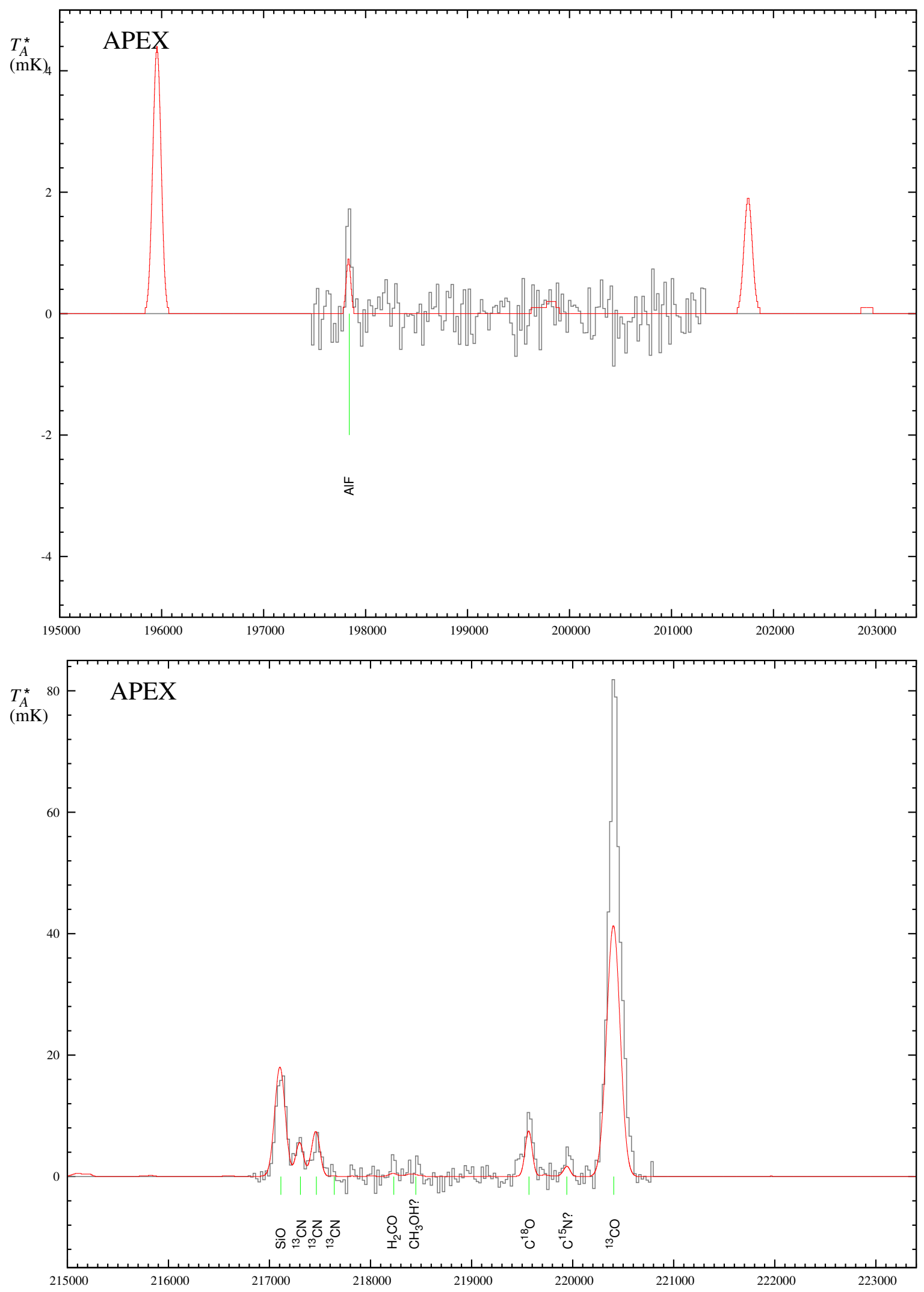

Fig. E.2. continued. 
A\&A 607, A78 (2017)
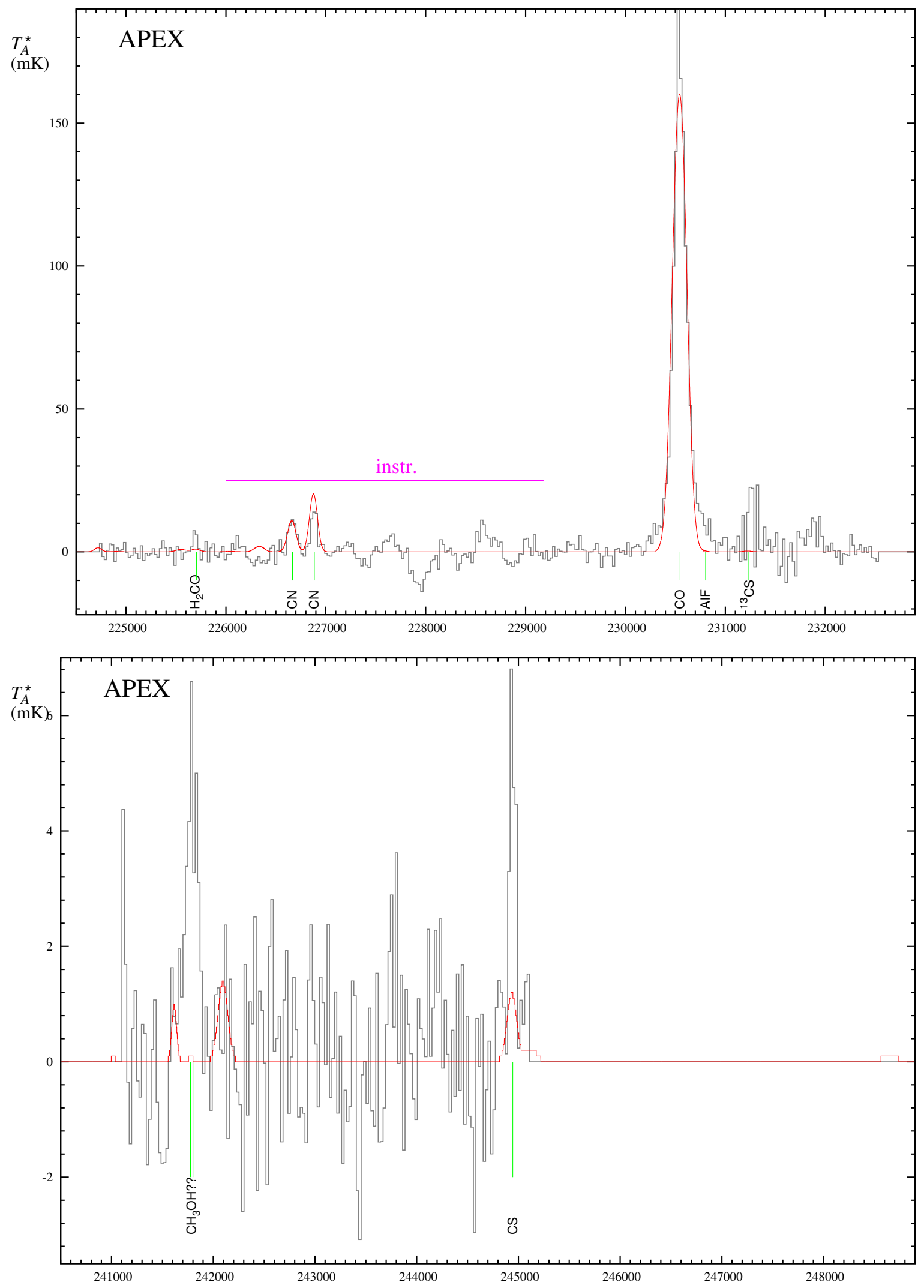

Fig. E.2. continued. 
T. Kamiński et al.: Molecules in CK Vul
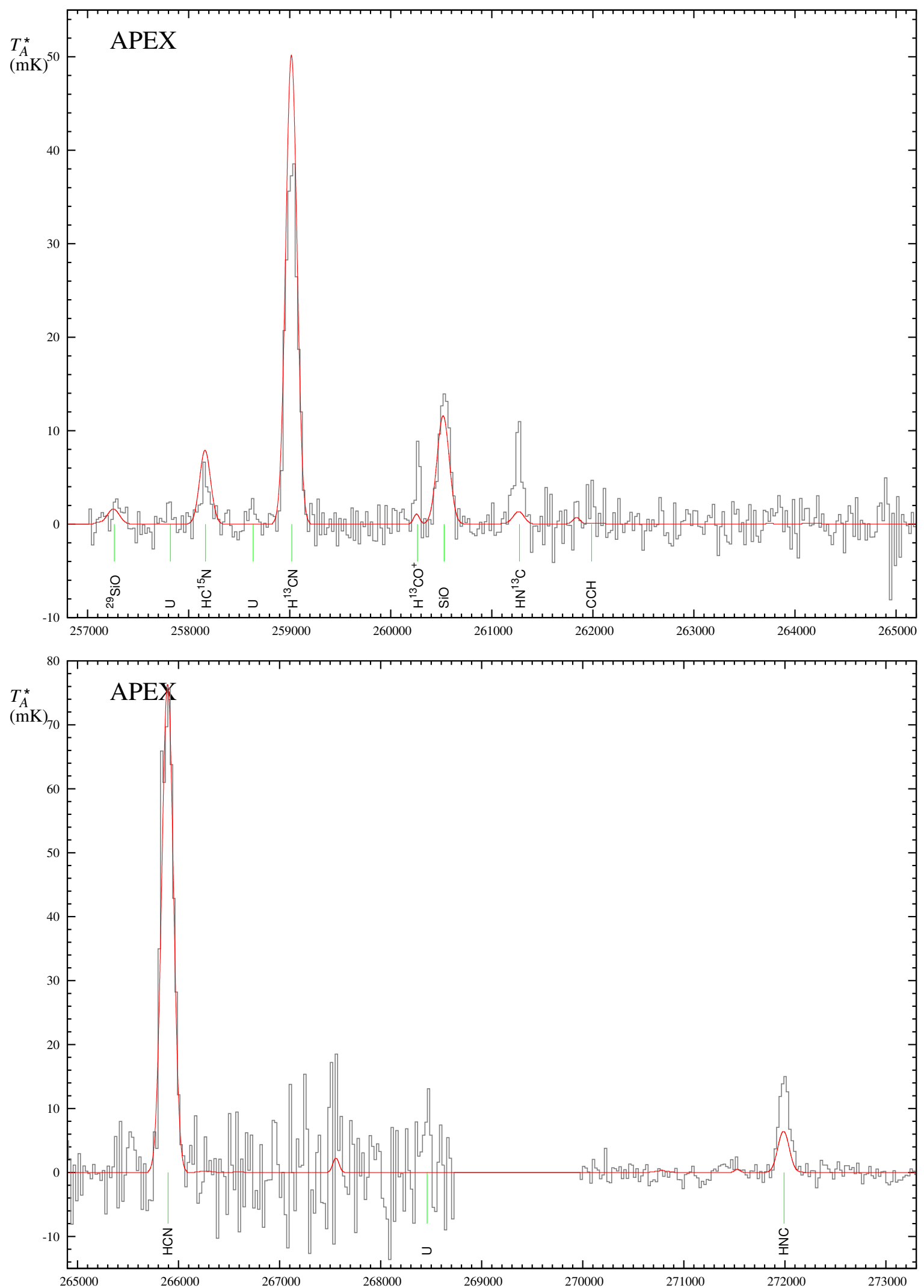

Fig. E.2. continued. 
A\&A 607, A78 (2017)
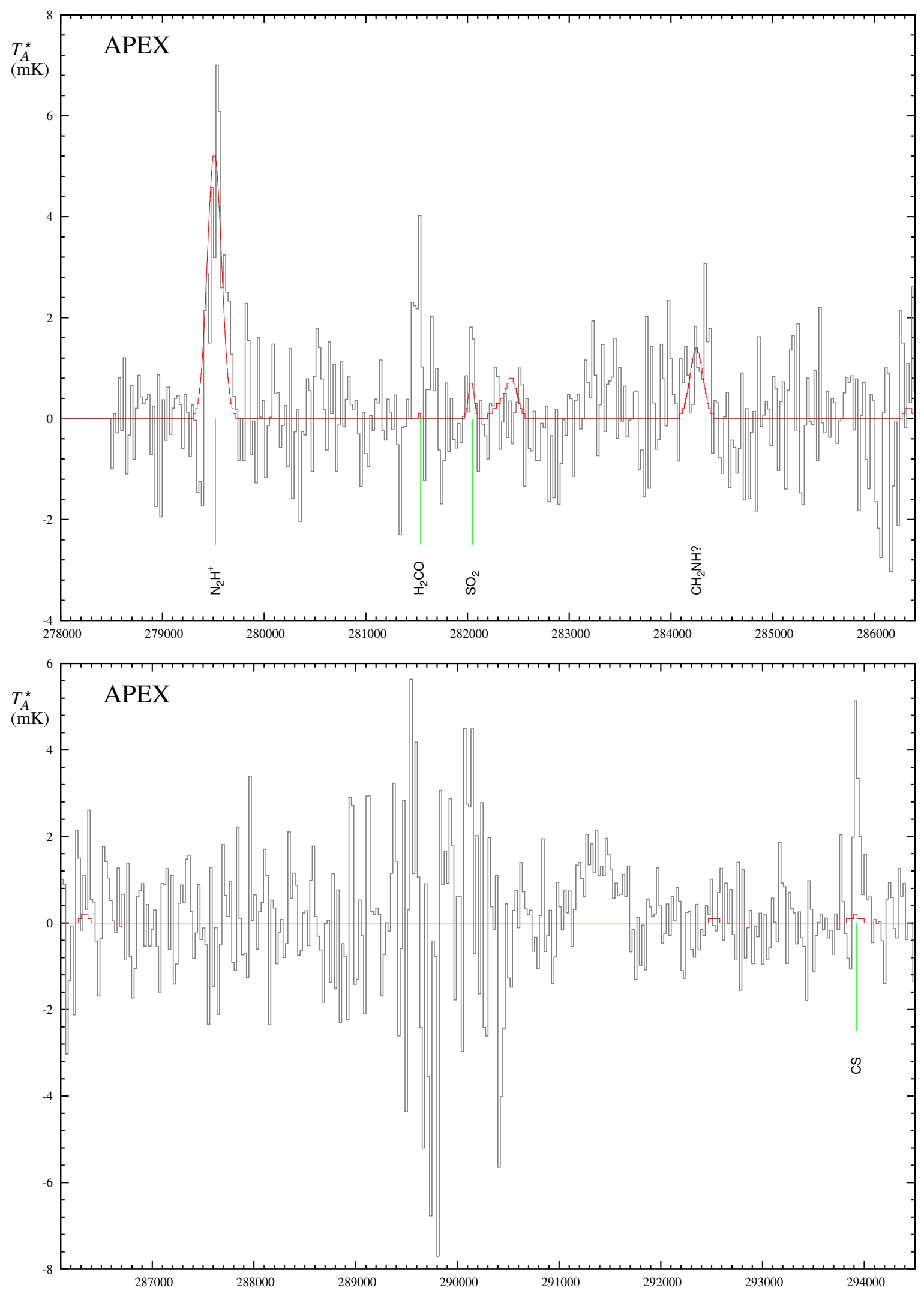

Fig. E.2. continued. 
T. Kamiński et al.: Molecules in CK Vul
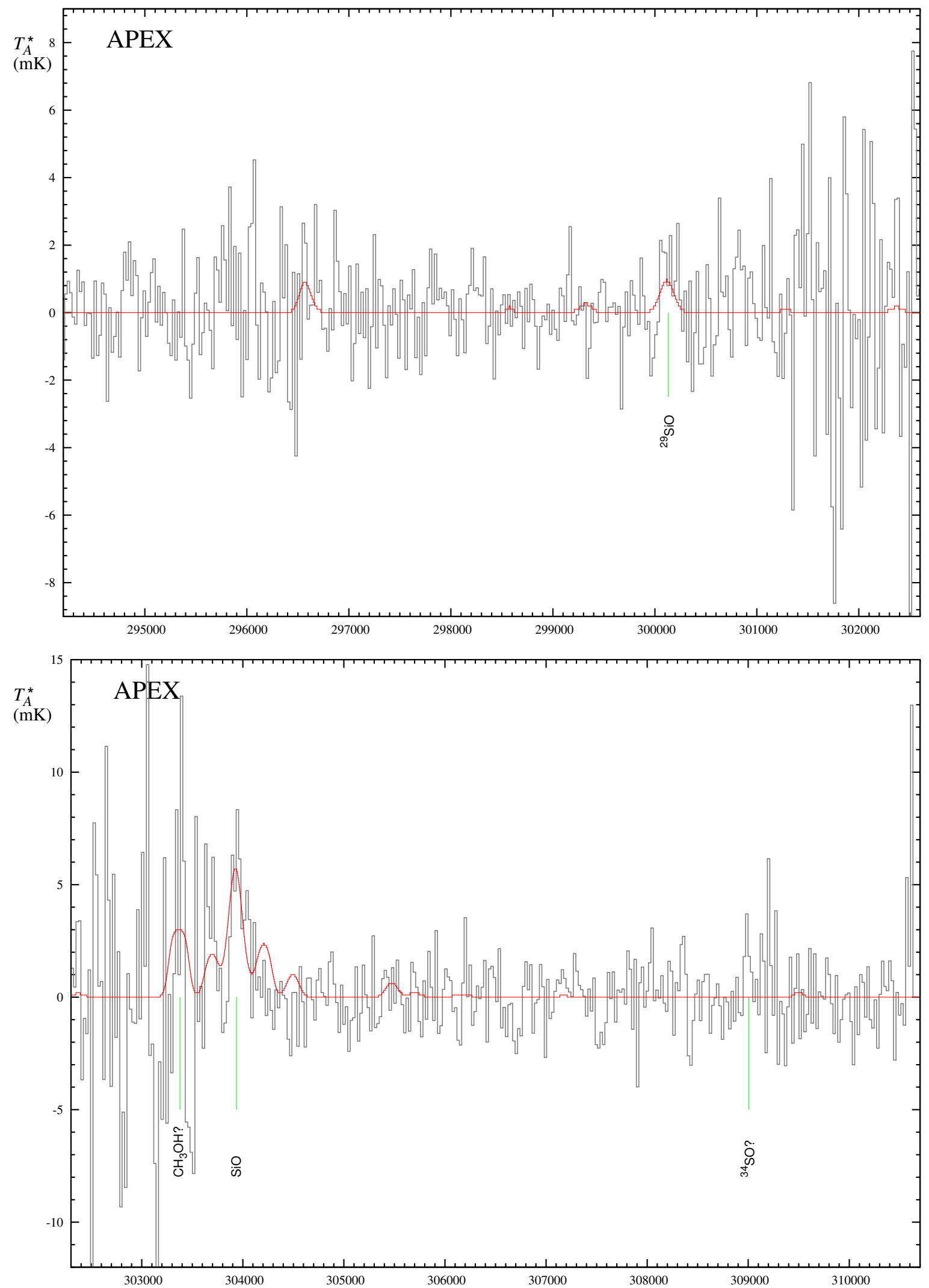

Fig. E.2. continued. 
A\&A 607, A78 (2017)
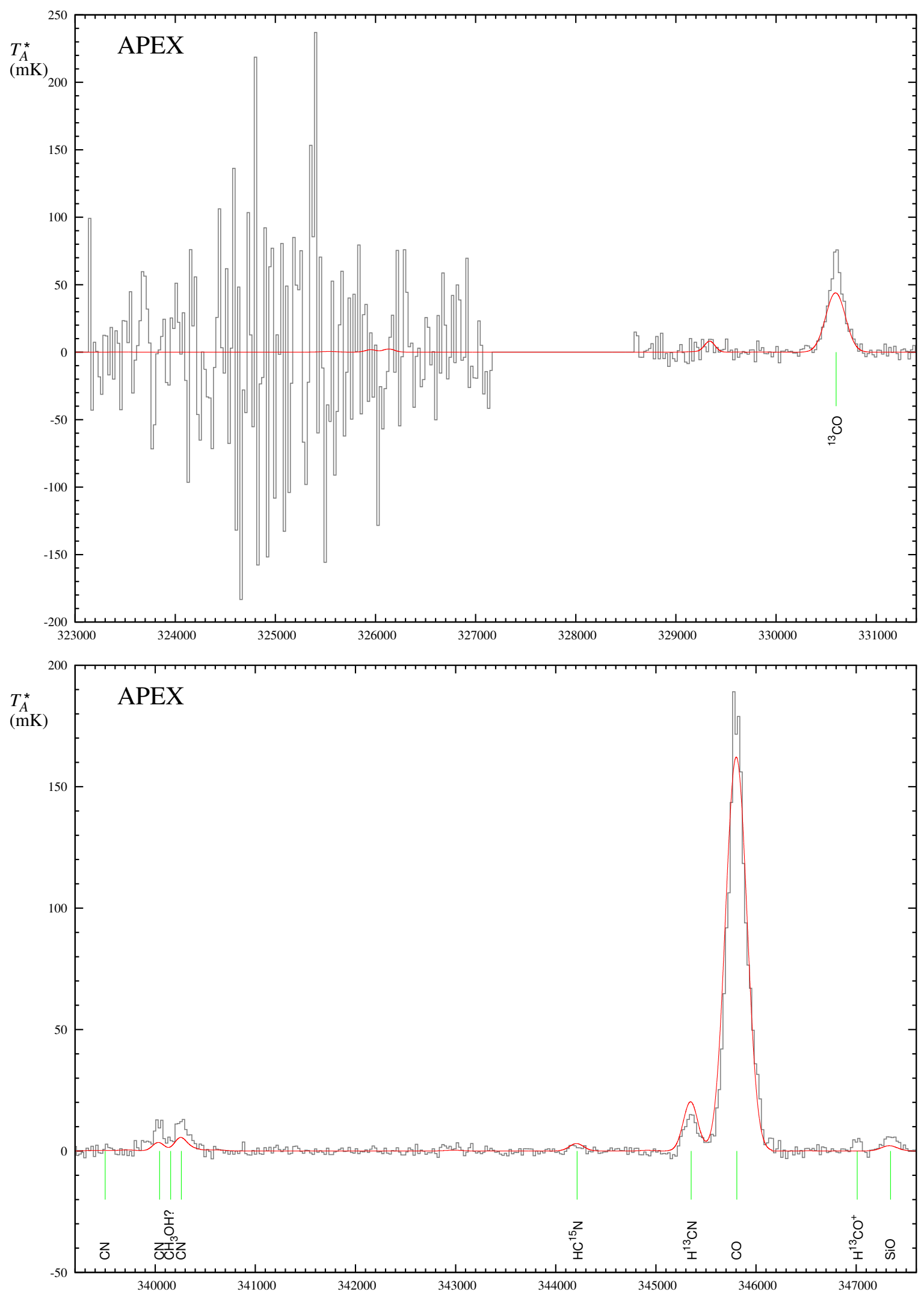

Fig. E.2. continued. 
T. Kamiński et al.: Molecules in CK Vul
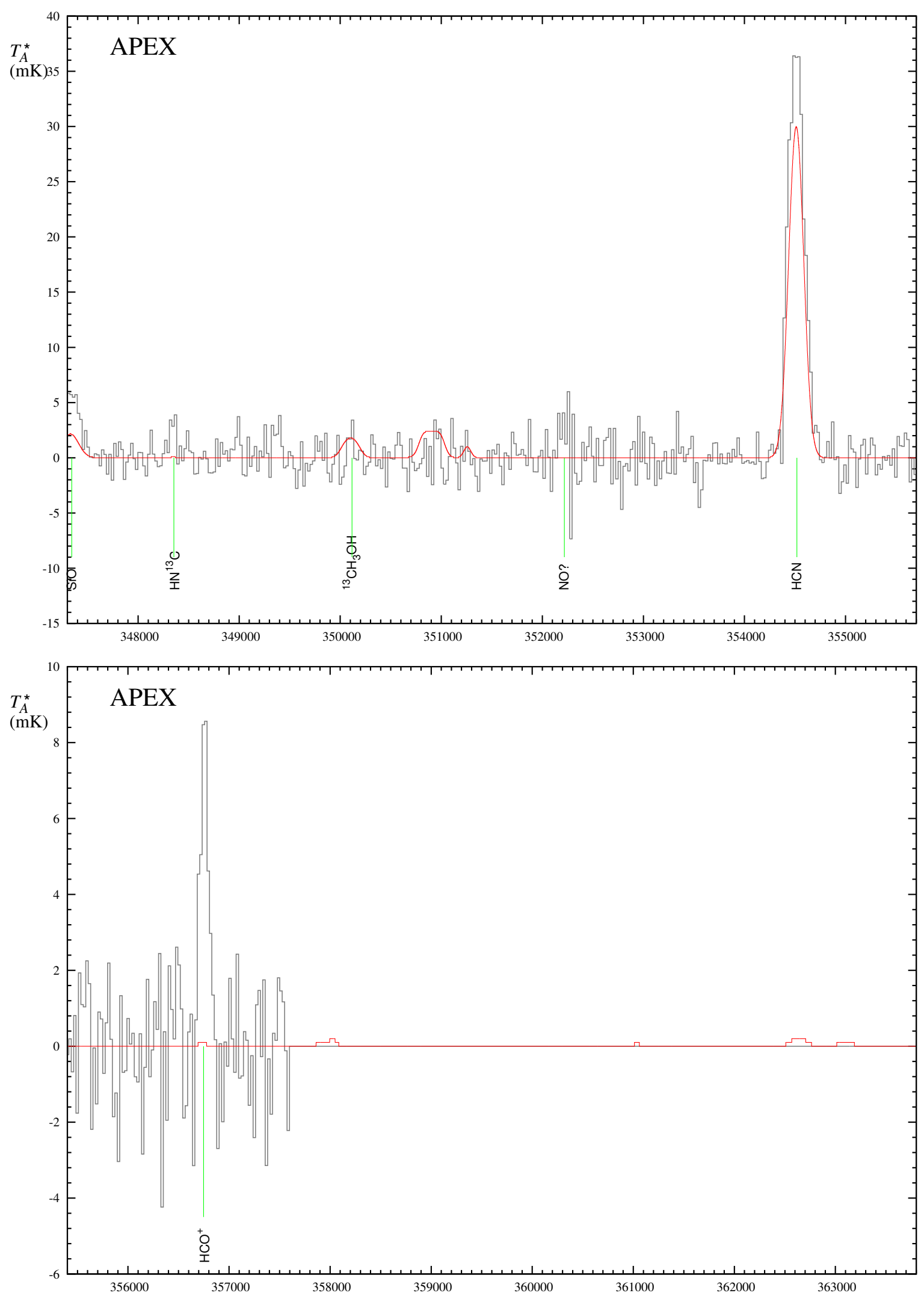

Fig. E.2. continued. 
A\&A 607, A78 (2017)
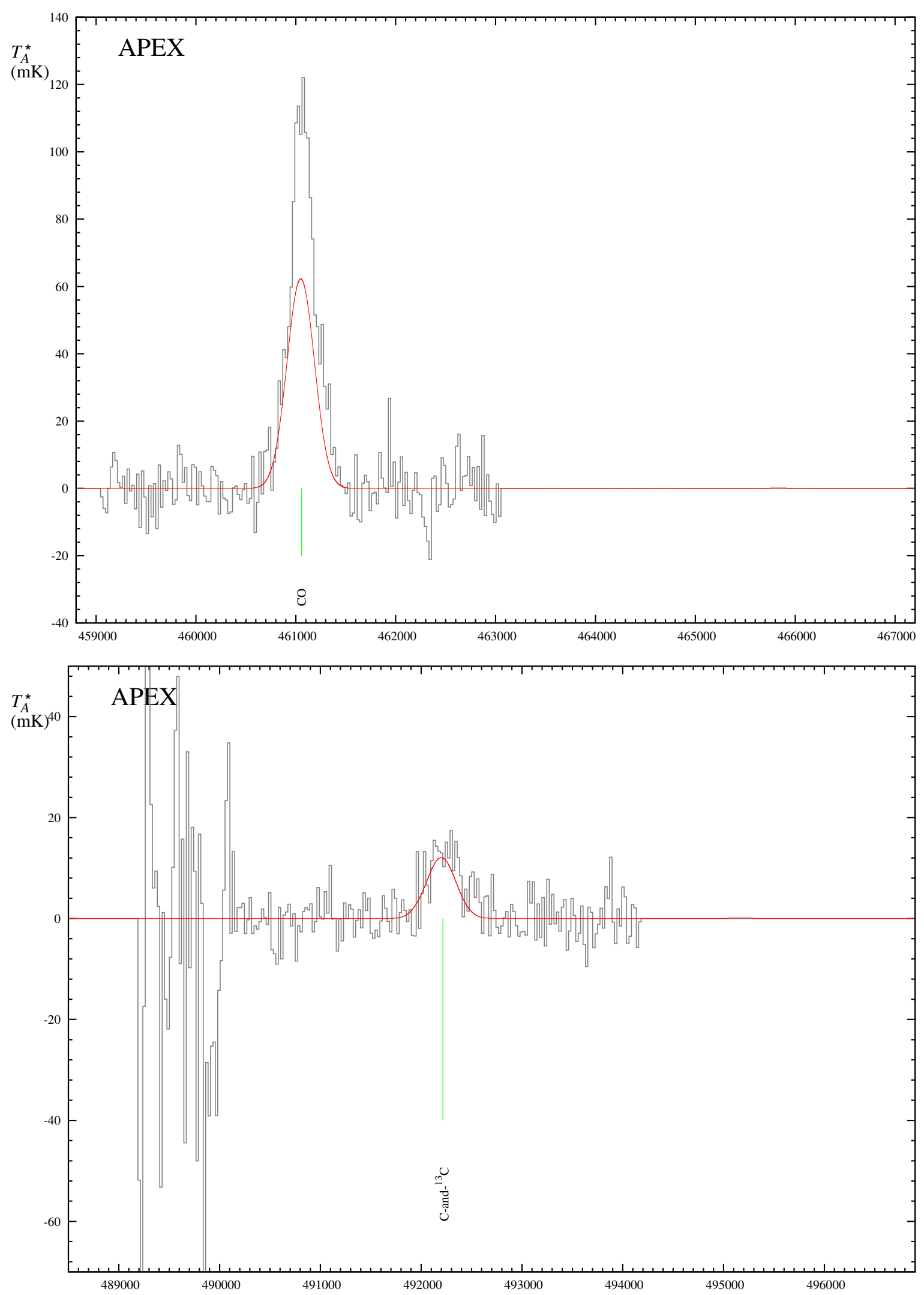

Fig. E.2. continued. 